\title{
Diretriz Brasileira de Cardio-oncologia - 2020
}

\section{Brazilian Cardio-oncology Guideline - 2020}

Realização: Sociedade Brasileira de Cardiologia (SBC)

Conselho de Normatizações e Diretrizes (2020-2021): Brivaldo Markman Filho, Antonio Carlos Sobral Sousa, Aurora Felice Castro Issa, Bruno Ramos Nascimento, Harry Correa Filho, Marcelo Luiz Campos Vieira

Coordenador de Normatizações e Diretrizes (2020-2021): Brivaldo Markman Filho

Autores da Diretriz: Ludhmila Abrahão Hajjar, ${ }^{1,2}{ }^{\oplus}$ Isabela Bispo Santos da Silva da Costa, ${ }^{\circledR}$ Marcelo Antônio Cartaxo Queiroga Lopes, ${ }^{3 \oplus}$ Paulo Marcelo Gehm Hoff, ${ }^{2,4}{ }^{\circledR}$ Maria Del Pilar Estevez Diz, ${ }^{2 \oplus}$ Silvia Moulin Ribeiro Fonseca, ${ }^{2,5}$ Cristina Salvadori Bittar, ${ }^{2,5}{ }^{\oplus}$ Marília Harumi Higuchi dos Santos Rehder, 2,5 Stephanie Itala Rizk, ${ }^{1,2}$. Dirceu Rodrigues Almeida, ${ }^{6}$ Gustavo dos Santos Fernandes, ${ }^{5}$ Luís Beck-da-Silva, ${ }^{7,8}$ Carlos Augusto Homem de Magalhães Campos, ${ }^{7}$ Marcelo Westerlund Montera, ${ }^{9}$ Sílvia Marinho Martins Alves, ${ }^{10}$ Júlia Tizue Fukushima, ${ }^{2 \oplus}$ Maria Verônica Câmara dos Santos, ${ }^{11,12}$ Carlos Eduardo Negrão, ${ }^{1}$ Thiago Liguori Feliciano da Silva, ${ }^{1}$ Silvia Moreira Ayub Ferreira, ${ }^{1 \oplus}$ Marcus Vinicius Bolivar Malachias, ${ }^{13}$ Maria da Consolação Vieira Moreira, ${ }^{14}$ Manuel Maria Ramos Valente Neto, ${ }^{2}$ Veronica Cristina Quiroga Fonseca, ${ }^{2}$ Maria Carolina Feres de Almeida Soeiro, ${ }^{1}$ Juliana Barbosa Sobral Alves, ${ }^{2}$ Carolina Maria Pinto Domingues Carvalho Silva, ${ }^{2}$ João Sbano, ${ }^{1 \oplus}$ Ricardo Pavanello, ${ }^{15}{ }^{\oplus}$ Ibraim Masciarelli F. Pinto, ${ }_{16}^{16}$ Antônio Felipe Simão, ${ }^{17}$ Marianna Deway Andrade Dracoulakis, ${ }^{18}$ Ana Oliveira Hoff, ${ }^{2}$ Bruna Morhy Borges Leal Assunção, ${ }^{2}$ Yana Novis, ${ }^{5}$ Laura Testa, ${ }^{2 \oplus}$ Aristóteles Comte de Alencar Filho, ${ }^{19}$ Cecília Beatriz Bittencourt Viana Cruz, ${ }^{1,2}$ Juliana Pereira, ${ }^{2}$ Diego Ribeiro Garcia, ${ }^{1}$ Cesar Higa Nomura, ${ }^{10}$ Carlos Eduardo Rochitte, ${ }^{1,20}$ Ariane Vieira Scarlatelli Macedo, ${ }^{21}$ Patricia Tavares Felipe Marcatti, ${ }^{22}$ Wilson Mathias Junior, ${ }^{1}$ [ Evanius Garcia Wiermann, ${ }^{23}$ Renata do Val, ${ }^{1}$ Helano Freitas, ${ }^{24}$ Anelisa Coutinho, ${ }^{25}$ Clarissa Maria de Cerqueira Mathias, ${ }^{26,27}$ Fernando Meton de Alencar Camara Vieira, ${ }^{28}$ André Deeke Sasse, ${ }^{29,30}$ Vanderson Rocha, ${ }^{2}$ José Antônio Franchini Ramires, ${ }^{10}$ Roberto Kalil Filho ${ }^{1,20}$

Instituto do Coração do Hospital das Clínicas da Faculdade de Medicina da Universidade de São Paulo, ${ }^{1}$ São Paulo, SP - Brasil Instituto do Câncer Hospital das Clínicas da Faculdade de Medicina da Universidade de São Paulo, ${ }^{2}$ São Paulo, SP - Brasil Hospital Alberto Urquiza Wanderley, João Pessoa, PB - Brasil Instituto D'or Pesquisa e Ensino, ${ }^{4}$ Rio de Janeiro, $R J$ - Brasil

Hospital Sírio Libanês, ${ }^{5}$ São Paulo, SP - Brasil

Universidade Federal de São Paulo (UNIFESP), ${ }^{6}$ São Paulo, SP - Brasil

Hospital de Clínicas de Porto Alegre, ${ }^{7}$ Porto Alegre, RS - Brasil

Universidade Federal do Rio Grande do Sul, ${ }^{8}$ Porto Alegre, RS - Brasil

Hospital Pró-Cardíaco, ${ }^{9}$ Rio de Janeiro, RJ - Brasil

Pronto Socorro Cardiológico de Pernambuco (PROCAPE), ${ }^{10}$ Recife, PE - Brasil

Sociedade Brasileira de Oncologia Pediátrica (SOBOPE), ${ }^{11}$ São Paulo, SP - Brasil

Departamento de Cardiopatias Congênitas e Cardiologia Pediátrica (DCC/CP) da Sociedade Brasileira de Cardiologia (SBC), ${ }^{12}$ Rio de Janeiro, RJ - Brasil Faculdade de Ciências Médicas de Minas Gerais, ${ }^{13}$ Belo Horizonte, MG - Brasil

Universidade Federal de Minas Gerais, ${ }^{14}$ Belo Horizonte, MG - Brasil

Hospital do Coração da Associação do Sanatório Sírio - HCor, ${ }^{15}$ São Paulo, SP - Brasil

Instituto Dante Pazzanese de Cardiologia, ${ }^{16}$ São Paulo, SP - Brasil

Instituto de Cardiologia de Santa Catarina, ${ }^{17}$ São José, SC - Brasil 
Hospital da Bahia, ${ }^{18}$ Salvador, BA - Brasil

Universidade Federal do Amazonas, ${ }^{19}$ Manaus, AM - Brasil

Hospital do Coração (HCOR), ${ }^{20}$ São Paulo, SP - Brasil

Santa Casa de Misericórdia de São Paulo, ${ }^{21}$ São Paulo, SP - Brasil

Rede Mater Dei de Saúde, ${ }^{22}$ Belo Horizonte, MG - Brasil

Centro de Oncologia do Paraná, ${ }^{23}$ Curitiba, $P R$ - Brasil

A.C. Camargo Cancer Center, ${ }^{24}$ São Paulo, SP - Brasil

Hospital Aliança, ${ }^{25}$ Salvador, BA - Brasil

NOB/Oncoclínicas, ${ }^{26}$ Salvador, BA - Brasil

Sociedade Brasileira de Oncologia Clínica, ${ }^{27}$ São Paulo, SP - Brasil

Grupo Americas Oncologia, ${ }^{28}$ Rio de Janeiro, RJ - Brasil

Grupo SOnhe, ${ }^{29}$ Campinas, SP - Brasil

Universidade Estadual de Campinas (Unicamp), 30 Campinas, SP - Brasil

Esta diretriz deverá ser citada como: Hajjar LA, Costa IBSS, Lopes MACQ, Hoff PMG, Diz MDPE, Fonseca SMR, et al. Diretriz Brasileira de Cardio-oncologia - 2020. Arq Bras Cardiol. 2020; 115(5):1006-1043

Nota: Estas diretrizes se prestam a informar e não a substituir o julgamento clínico do médico que, em última análise, deve determinar o tratamento apropriado para seus pacientes.

Correspondência: Sociedade Brasileira de Cardiologia - Av. Marechal Câmara, 360/330 - Centro - Rio de Janeiro - CEP: $20020-907$. E-mail: diretrizes@cardiol.br

DOI: https://doi.org/10.36660/abc.20201006 


\begin{tabular}{|c|c|}
\hline \multicolumn{2}{|r|}{ Diretriz Brasileira de Cardio-oncologia - 2020} \\
\hline \multicolumn{2}{|c|}{0 relatório abaixo lista as declarações de interesse conforme relatadas à SBC pelos especialistas durante o período de desenvolvimento desta diretriz, 2020.} \\
\hline Especialista & Tipo de relacionamento com a indústria \\
\hline Ana Oliveira Hoff & $\begin{array}{l}\text { DECLARAÇÃO FINANCEIRA } \\
\text { A- PAGAMENTO DE QUALQUER ESPÉCIE E DESDE QUE ECONOMICAMENTE APRECIÁVEIS, FEITOS A (i) VOCÊ, (ii) AO SEU } \\
\text { CÔNJUGE/COMPANHEIRO OU A QUALQUER OUTRO MEMBRO QUE RESIDA COM VOCÊ,, (iii) A QUALQUER PESSOA JURIDICA } \\
\text { EM QUE QUALQUER DESTES SEJA CONTROLADOR, SÓCIO, ACIONISTA OU PARTICIPANTE, DE FORMA DIRETA OU INDIRETA, } \\
\text { RECEBIMENTO POR PALESTRAS, AULAS, ATUAÇÃO COMO PROCTOR DE TREINAMENTOS, REMUNERAÇÕES, HONORÁRIOS PAGOS } \\
\text { POR PARTICIPAÇÕES EM CONSELHOS CONSULTIVOS, DE INVESTIGADORES, OU OUTROS COMITÊS, ETC. PROVENIENTES DA } \\
\text { INDÚSTRIA FARMACÊUTICA, DE ÓRTESES, PRÓTESES, EQUIPAMENTOS E IMPLANTES, BRASILEIRAS OU ESTRANGEIRAS: } \\
\text { - Bayer: câncer de tireoide } \\
\text { - Exelixis: câncer de tireoide } \\
\text { - Eli Lilly: câncer de tireoide } \\
\text { - United } \\
\text { B - FINANCIAMENTO DE PESQUISAS SOB SUA RESPONSABILIDADE DIRETAIPESSOAL (DIRECIONADO AO DEPARTAMENTO } \\
\text { OU INSTITUICCÃO) PROVENIENTES DA INDÚSTRIA FARMACÊUTICA, DE ÓRTESES, PRÓTESES, EQUIPAMENTOS E IMPLANTES, } \\
\text { BRASILEIRAS OU ESTRANGEIRAS: } \\
\text { - Exelixis: câncer de tireoide } \\
\text { - Eli Lilly: câncer de tireoide }\end{array}$ \\
\hline André Deeke Sasse & $\begin{array}{l}\text { DECLARAÇÃO FINANCEIRA } \\
\text { A- PAGAMENTO DE QUALQUER ESPÉCIE E DESDE QUE ECONOMICAMENTE APRECIÁVEIS, FEITOS A (i) VOCÊ, (ii) AO SEU } \\
\text { CÔNJUGE/COMPANHEIRO OU A QUALQUER OUTRO MEMBRO QUE RESIDA COM VOCÊ, (iii) A QUALQUER PESSOA JURIIDICA } \\
\text { EM QUE QUALQUER DESTES SEJA CONTROLADOR, SÓCIO, ACIONISTA OU PARTICIPANTE, DE FORMA DIRETA OU INDIRETA, } \\
\text { RECEBIMENTO POR PALESTRAS, AULAS, ATUAÇÃO COMO PROCTOR DE TREINAMENTOS, REMUNERAÇÕES, HONORÁRIOS PAGOS } \\
\text { POR PARTICIPAÇÕES EM CONSELHOS CONSULTIVOS, DE INVESTIGADORES, OU OUTROS COMITÊS, ETC. PROVENIENTES DA } \\
\text { INDÚSTRIA FARMACÊUTICA, DE ÓRTESES, PRÓTESES, EQUIPAMENTOS E IMPLANTES, BRASILEIRAS OU ESTRANGEIRAS: } \\
\text { - Astellas: oncologia } \\
\text { - Bayer: oncologia } \\
\text { - - Janssen: oncologia } \\
\text { - Merck Serono } \\
\text { - MSD } \\
\text { - Novartis } \\
\text { - Roche } \\
\text { OUTROS RELACIONAMENTOS } \\
\text { FINANCIAMENTO DE ATIVIDADES DE EDUCAÇÃO MÉDICA CONTINUADA, INCLUINDO VIAGENS, HOSPEDAGENSE INSCRIÇÕES } \\
\text { PARA CONGRESSOS E CURSOS, PROVENIENTES DA INDÚSTRIA FARMACÊUTICA, DE ÓRTESES, PRÓTESES, EQUIPAMENTOS E } \\
\text { IMPLANTES, BRASILEIRAS OU ESTRANGEIRAS: } \\
\text { - MSD: oncologia } \\
\text { - Janssen: oncologia } \\
\text { - Novartis: oncologia }\end{array}$ \\
\hline Anelisa Coutinho & $\begin{array}{l}\text { DECLARAÇÃO FINANCEIRA } \\
\text { A- PAGAMENTO DE QUALQUER ESPÉCIE E DESDE QUE ECONOMICAMENTE APRECIÁVEIS, FEITOS A (i) VOCÊ, (ii) AO SEU } \\
\text { CÔNJUGE/COMPANHEIRO OU A QUALQUER OUTRO MEMBRO QUE RESIDA COM VOCÊ,, (iii) A QUALQUER PESSOA JURIDICA } \\
\text { EM QUE QUALQUER DESTES SEJA CONTROLADOR, SÓCIO, ACIONISTA OU PARTICIPANTE, DE FORMA DIRETA OU INDIRETA, } \\
\text { RECEBIMENTO POR PALESTRAS, AULAS, ATUAÇÃO COMO PROCTOR DE TREINAMENTOS, REMUNERAÇÕES, HONORÁRIOS PAGOS } \\
\text { POR PARTICIPAÇÕES EM CONSELHOS CONSULTIVOS, DE INVESTIGADORES, OU OUTROS COMITÊS, ETC. PROVENIENTES DA } \\
\text { INDÚSTRIA FARMACÊUTICA, DE ÓRTESES, PRÓTESES, EQUIPAMENTOS E IMPLANTES, BRASILEIRAS OU ESTRANGEIRAS: } \\
\text { - Bayer: oncologia } \\
\text { - Amgen: oncologia } \\
\text { - Roche: oncologia } \\
\text { - Merck group } \\
\text { - MSD } \\
\text { - Lilly } \\
\text { - Servier } \\
\text { B - FINANCIAMENTO DE PESQUISAS SOB SUA RESPONSABILIDADE DIRETAIPESSOAL (DIRECIONADO AO DEPARTAMENTO } \\
\text { OU INSTITUIÇÃO) PROVENIENTES DA INDÚSTRIA FARMACÉUTICA, DE ÓRTESES, PRÓTESES, EQUIPAMENTOS E IMPLANTES, } \\
\text { BRASILEIRAS OU ESTRANGEIRAS: } \\
\text { - Bristol: oncologia } \\
\text { - Servier: oncologia } \\
\text { OUTROS RELACIONAMENTOS } \\
\text { FINANCIAMENTO DE ATIVIDADES DE EDUCAÇÃO MÉDICA CONTINUADA, INCLUINDO VIAGENS, HOSPEDAGENS E INSCRIÇÕES } \\
\text { PARA CONGRESSOS E CURSOS, PROVENIENTES DA INDÚSTRIA FARMACÉUTICA, DE ÓRTESES, PRÓTESES, EQUIPAMENTOS E } \\
\text { IMPLANTES, BRASILEIRAS OU ESTRANGEIRAS: } \\
\text { - Roche: oncologia } \\
\text { - Servier: oncologia } \\
\text { - Bayer: oncologia } \\
\text { - Merck group } \\
\text { - Amgen } \\
\text { - Sanofi }\end{array}$ \\
\hline
\end{tabular}


DECLARAÇÃO FINANCEIRA

A - PAGAMENTO DE QUALQUER ESPÉCIE E DESDE QUE ECONOMICAMENTE APRECIÁVEIS, FEITOS A (i) VOCÊ, (ii) AO SEU CÔNJUGE/COMPANHEIRO OU A QUALQUER OUTRO MEMBRO QUE RESIDA COM VOCÊ, (iii) A QUALQUER PESSOA JURÍDICA EM QUE QUALQUER DESTES SEJA CONTROLADOR, SÓCIO, ACIONISTA OU PARTICIPANTE, DE FORMA DIRETA OU INDIRETA, RECEBIMENTO POR PALESTRAS, AULAS, ATUAÇÃO COMO PROCTOR DE TREINAMENTOS, REMUNERACCÕES, HONORÁRIOS PAGOS POR PARTICIPAÇÕES EM CONSELHOS CONSULTIVOS, DE INVESTIGADORES, OU OUTROS COMITÊS, ETC PROVENIENTES DA INDÚSTRIA FARMACÊUTICA, DE ÓRTESES, PRÓTESES, EQUIPAMENTOS E IMPLANTES, BRASILEIRAS OU ESTRANGEIRAS:

- AstraZeneca: cardiologia

OUTROS RELACIONAMENTOS

FINANCIAMENTO DE ATIVIDADES DE EDUCAÇÃO MÉDICA CONTINUADA, INCLUINDO VIAGENS, HOSPEDAGENS E INSCRIÇÕES PARA CONGRESSOS E CURSOS, PROVENIENTES DA INDÚSTRIA FARMACÊUTICA, DE ÓRTESES, PRÓTESES, EQUIPAMENTOS E IMPLANTES, BRASILEIRAS OU ESTRANGEIRAS:

- AstraZeneca

- Bayer

\section{DECLARAÇÃO FINANCEIRA}

A - PAGAMENTO DE QUALQUER ESPÉCIE E DESDE QUE ECONOMICAMENTE APRECIÁVEIS, FEITOS A (i) VOCÊ, (ii) AO SEU CÔNJUGE/COMPANHEIRO OU A QUALQUER OUTRO MEMBRO QUE RESIDA COM VOCÊ, (iii) A QUALQUER PESSOA JURÍDICA EM QUE QUALQUER DESTES SEJA CONTROLADOR, SÓCIO, ACIONISTA OU PARTICIPANTE, DE FORMA DIRETA OU INDIRETA, RECEBIMENTO POR PALESTRAS, AULAS, ATUAÇÃO COMO PROCTOR DE TREINAMENTOS, REMUNERAÇÕES, HONORÁRIOS PAGOS POR PARTICIPACÕES EM CONSELHOS CONSULTIVOS, DE INVESTIGADORES, OU OUTROS COMITÊS, ETC. PROVENIENTES DA INDÚSTRIA FARMACÊUTICA, DE ÓRTESES, PRÓTESES, EQUIPAMENTOS E IMPLANTES, BRASILEIRAS OU ESTRANGEIRAS:

- Bayer: anticoagulantes

$\begin{array}{ll}\text { Ariane Vieira Scarlatelli } & \text { - Pfizer: anticoagulantes } \\ \text { Macedo } & \text { - Daichii Sankyo: anticoagulantes }\end{array}$

- AstraZeneca: anticoagulantes

OUTROS RELACIONAMENTOS

FINANCIAMENTO DE ATIVIDADES DE EDUCAÇÃO MÉDICA CONTINUADA, INCLUINDO VIAGENS, HOSPEDAGENS E INSCRIÇÕES PARA CONGRESSOS E CURSOS, PROVENIENTES DA INDÚSTRIA FARMACÊUTICA, DE ÓRTESES, PRÓTESES, EQUIPAMENTOS E IMPLANTES, BRASILEIRAS OU ESTRANGEIRAS:

- Bayer: anticoagulantes

- Pfizer: anticoagulantes

- Zodiac: quimioterápicos

- Ferring

DECLARAÇÃO FINANCEIRA

A - PAGAMENTO DE QUALQUER ESPÉCIE E DESDE QUE ECONOMICAMENTE APRECIÁVEIS, FEITOS A (i) VOCÊ, (ii) AO SEU CÔNJUGE/COMPANHEIRO OU A QUALQUER OUTRO MEMBRO QUE RESIDA COM VOCÊ, (iii) A QUALQUER PESSOA JURIIDICA EM QUE QUALQUER DESTES SEJA CONTROLADOR, SÓCIO, ACIONISTA OU PARTICIPANTE, DE FORMA DIRETA OU INDIRETA RECEBIMENTO POR PALESTRAS, AULAS, ATUAÇÃO COMO PROCTOR DE TREINAMENTOS, REMUNERAÇÕES, HONORÁRIOS PAGOS POR PARTICIPACCÕES EM CONSELHOS CONSULTIVOS, DE INVESTIGADORES, OU OUTROS COMITÊS, ETC. PROVENIENTES DA INDÚSTRIA FARMACÊUTICA, DE ÓRTESES, PRÓTESES, EQUIPAMENTOS E IMPLANTES, BRASILEIRAS OU ESTRANGEIRAS:

- Novartis: Entresto

- Sandoz: Pidezot

\begin{tabular}{ll}
\hline $\begin{array}{l}\text { Bruna Morhy Borges Leal } \\
\text { Assunção }\end{array}$ & Nada a ser declarado \\
\hline $\begin{array}{l}\text { Carlos Augusto Homem de } \\
\text { Magalhães Campos }\end{array}$ & Nada a ser declarado \\
\hline Carlos Eduardo Negrão & Nada a ser declarado \\
\hline Carlos Eduardo Rochitte & Nada a ser declarado \\
\hline $\begin{array}{l}\text { Carolina Maria Pinto } \\
\text { Domingues Carvalho Silva }\end{array}$ & Nada a ser declarado \\
\hline $\begin{array}{l}\text { Cecilia Beatriz Bittencourt } \\
\text { Viana Cruz }\end{array}$ & Nada a ser declarado \\
\hline Cesar Higa Nomura & Nada a ser declarado \\
\hline $\begin{array}{l}\text { Clarissa Maria de Cerqueira } \\
\text { Mathias }\end{array}$ & Nada a ser declarado \\
\hline Cristina Salvadori Bittar & Nada a ser declarado \\
\hline Diego Ribeiro Garcia & Nada a ser declarado \\
\hline
\end{tabular}




\begin{tabular}{|c|c|}
\hline Dirceu Rodrigues Almeida & Nada a ser declarado \\
\hline Evanius Garcia Wiermann & $\begin{array}{l}\text { DECLARAÇÃO FINANCEIRA } \\
\text { A - PAGAMENTO DE QUALQUER ESPÉCIE E DESDE QUE ECONOMICAMENTE APRECIÁVEIS, FEITOS A (i) VOCÊ, (ii) AO SEU } \\
\text { CÔNJUGE/COMPANHEIRO OU A QUALQUER OUTRO MEMBRO QUE RESIDA COM VOCÊ, (iii) A QUALQUER PESSOA JURIDICA } \\
\text { EM QUE QUALQUER DESTES SEJA CONTROLADOR, SÓCIO, ACIONISTA OU PARTICIPANTE, DE FORMA DIRETA OU INDIRETA, } \\
\text { RECEBIMENTO POR PALESTRAS, AULAS, ATUAÇÃO COMO PROCTOR DE TREINAMENTOS, REMUNERAÇÕES, HONORÁRIOS } \\
\text { PAGOS POR PARTICIPAÇÕES EM CONSELHOS CONSULTIVOS, DE INVESTIGADORES, OU OUTROS COMITÊS, ETC. } \\
\text { PROVENIENTES DA INDÚSTRIA FARMACÊUTICA, DE ÓRTESES, PRÓTESES, EQUIPAMENTOS E IMPLANTES, BRASILEIRAS OU } \\
\text { ESTRANGEIRAS: } \\
\text { - Sanofi: Xarelto } \\
\text { - Novartis: Alpelisib } \\
\text { OUTROS RELACIONAMENTOS } \\
\text { FINANCIAMENTO DE ATIVIDADES DE EDUCAÇÃO MÉDICA CONTINUADA, INCLUINDO VIAGENS, HOSPEDAGENS E INSCRIÇÕES } \\
\text { PARA CONGRESSOS E CURSOS, PROVENIENTES DA INDÚSTRIA FARMACEUUTICA, DE ÓRTESES, PRÓTESES, EQUIPAMENTOS } \\
\text { E IMPLANTES, BRASILEIRAS OU ESTRANGEIRAS: } \\
\text { - JanSSen: Abiraterona } \\
\text { - Bayer: Xofigo } \\
\text { - Libbs: Zedora }\end{array}$ \\
\hline $\begin{array}{l}\text { Fernando Meton de Alencar } \\
\text { Camara Vieira }\end{array}$ & $\begin{array}{l}\text { DECLARAÇÃO FINANCEIRA } \\
\text { A - PAGAMENTO DE QUALQUER ESPÉCIE E DESDE QUE ECONOMICAMENTE APRECIÁVEIS, FEITOS A (i) VOCÊ, (ii) AO SEU } \\
\text { CÔNJUGE/COMPANHEIRO OU A QUALQUER OUTRO MEMBRO QUE RESIDA COM VOCÊ, (iii) A QUALQUER PESSOA JURÍDICA } \\
\text { EM QUE QUALQUER DESTES SEJA CONTROLADOR, SÓCIO, ACIONISTA OU PARTICIPANTE, DE FORMA DIRETA OU INDIRETA, } \\
\text { RECEBIMENTO POR PALESTRAS, AULAS, ATUAÇÃO COMO PROCTOR DE TREINAMENTOS, REMUNERAÇÕES, HONORÁRIOS } \\
\text { PAGOS POR PARTICIPAÇÕES EM CONSELHOS CONSULTIVOS, DE INVESTIGADORES, OU OUTROS COMITÊS, ETC. } \\
\text { PROVENIENTES DA INDÚSTRIA FARMACÊUTICA, DE ÓRTESES, PRÓTESES, EQUIPAMENTOS E IMPLANTES, BRASILEIRAS OU } \\
\text { ESTRANGEIRAS: } \\
\text { - BMS: câncer colorretal (pesquisa clínica) }\end{array}$ \\
\hline $\begin{array}{l}\text { Gustavo dos Santos } \\
\text { Fernandes }\end{array}$ & $\begin{array}{l}\text { DECLARAÇÃO FINANCEIRA } \\
\text { A - PAGAMENTO DE QUALQUER ESPÉCIE E DESDE QUE ECONOMICAMENTE APRECIÁVEIS, FEITOS A (i) VOCÊ,, (ii) AO SEU } \\
\text { CÔNJUGE/COMPANHEIRO OU A QUALQUER OUTRO MEMBRO QUE RESIDA COM VOCÊ, (iii) A QUALQUER PESSOA JURÍDICA } \\
\text { EM QUE QUALQUER DESTES SEJA CONTROLADOR, SÓCIO, ACIONISTA OU PARTICIPANTE, DE FORMA DIRETA OU INDIRETA, } \\
\text { RECEBIMENTO POR PALESTRAS, AULAS, ATUAÇÃO COMO PROCTOR DE TREINAMENTOS, REMUNERAÇÕES, HONORÁRIOS } \\
\text { PAGOS POR PARTICIPAÇÕES EM CONSELHOS CONSULTIVOS, DE INVESTIGADORES, OU OUTROS COMITÊS, ETC. } \\
\text { PROVENIENTES DA INDÚSTRIA FARMACÊUTICA, DE ÓRTESES, PRÓTESES, EQUIPAMENTOS E IMPLANTES, BRASILEIRAS OU } \\
\text { ESTRANGEIRAS: } \\
\text { - Roche: Bevacizumab e TrastuzUmab } \\
\text { - MSD: imunoterapia } \\
\text { - BMS: imunoterapia } \\
\text { - Bayer } \\
\text { - Sanofi } \\
\text { - Novartis } \\
\text { B - FINANCIAMENTO DE PESQUISAS SOB SUA RESPONSABILIDADE DIRETAIPESSOAL (DIRECIONADO AO DEPARTAMENTO } \\
\text { OU INSTITUIÇÃO) PROVENIENTES DA INDÚSTRIA FARMACÊUTICA, DE ÓRTESES, PRÓTESES, EQUIPAMENTOS E IMPLANTES, } \\
\text { BRASILEIRAS OU ESTRANGEIRAS: } \\
\text { - BMS: imunoterapia } \\
\text { - MSD: imunoterapia } \\
\text { - Roche: imunoterapia }\end{array}$ \\
\hline Helano Freitas & Nada a ser declarado \\
\hline Ibraim Masciarelli F. Pinto & $\begin{array}{l}\text { DECLARAÇÃO FINANCEIRA } \\
\text { A - PAGAMENTO DE QUALQUER ESPÉCIE E DESDE QUE ECONOMICAMENTE APRECIÁVEIS, FEITOS A (i) VOCÊ,, (ii) AO SEU } \\
\text { CÔNJUGE/COMPANHEIRO OU A QUALQUER OUTRO MEMBRO QUE RESIDA COM VOCÊ, (iii) A QUALQUER PESSOA JURIDICA } \\
\text { EM QUE QUALQUER DESTES SEJA CONTROLADOR, SÓCIO, ACIONISTA OU PARTICIPANTE, DE FORMA DIRETA OU INDIRETA, } \\
\text { RECEBIMENTO POR PALESTRAS, AULAS, ATUAÇÃO COMO PROCTOR DE TREINAMENTOS, REMUNERAÇÕES, HONORÁRIOS } \\
\text { PAGOS POR PARTICIPAÇÕES EM CONSELHOS CONSULTIVOS, DE INVESTIGADORES, OU OUTROS COMITÊS, ETC. } \\
\text { PROVENIENTES DA INDÚSTRIA FARMACÊUTICA, DE ÓRTESES, PRÓTESES, EQUIPAMENTOS E IMPLANTES, BRASILEIRAS OU } \\
\text { ESTRANGEIRAS: } \\
\text { - GE Healthcare: tomografia } \\
\text { - Novo Nordisk: farma }\end{array}$ \\
\hline $\begin{array}{l}\text { Isabela Bispo Santos da } \\
\text { Silva da Costa }\end{array}$ & Nada a ser declarado \\
\hline João Cesar Nunes Sbano & Nada a ser declarado \\
\hline $\begin{array}{l}\text { José Antônio Franchini } \\
\text { Ramires }\end{array}$ & Nada a ser declarado \\
\hline Júlia Tizue Fukushima & Nada a ser declarado \\
\hline
\end{tabular}




\begin{tabular}{|c|c|}
\hline $\begin{array}{l}\text { Juliana Barbosa Sobral } \\
\text { Alves }\end{array}$ & $\begin{array}{l}\text { DECLARAÇÃO FINANCEIRA } \\
\text { A - PAGAMENTO DE QUALQUER ESPÉCIE E DESDE QUE ECONOMICAMENTE APRECIÁVEIS, FEITOS A (i) VOCÊ, (ii) AO SEU } \\
\text { CÔNJUGE/COMPANHEIRO OU A QUALQUER OUTRO MEMBRO QUE RESIDA COM VOCÊ, (iii) A QUALQUER PESSOA JURIDICA } \\
\text { EM QUE QUALQUER DESTES SEJA CONTROLADOR, SÓCIO, ACIONISTA OU PARTICIPANTE, DE FORMA DIRETA OU INDIRETA, } \\
\text { RECEBIMENTO POR PALESTRAS, AULAS, ATUAÇÃO COMO PROCTOR DE TREINAMENTOS, REMUNERAÇÕES, HONORÁRIOS } \\
\text { PAGOS POR PARTICIPAÇÕES EM CONSELHOS CONSULTIVOS, DE INVESTIGADORES, OU OUTROS COMITÊS, ETC. } \\
\text { PROVENIENTES DA INDÚSTRIA FARMACÊUTICA, DE ÓRTESES, PRÓTESES, EQUIPAMENTOS E IMPLANTES, BRASILEIRAS OU } \\
\text { ESTRANGEIRAS: } \\
\text { - Janssen: hipertensão pulmonar } \\
\text { - Bayer: hipertensão }\end{array}$ \\
\hline Juliana Pereira & Nada a ser declarado \\
\hline Laura Testa & $\begin{array}{l}\text { DECLARAÇÃO FINANCEIRA } \\
\text { A - PAGAMENTO DE QUALQUER ESPÉCIE E DESDE QUE ECONOMICAMENTE APRECIÁVEIS, FEITOS A (i) VOCÊ, (ii) AO SEU } \\
\text { CÔNJUGE/COMPANHEIRO OU A QUALQUER OUTRO MEMBRO QUE RESIDA COM VOCÊ, (iii) A QUALQUER PESSOA JURIDICA } \\
\text { EM QUE QUALQUER DESTES SEJA CONTROLADOR, SÓCIO, ACIONISTA OU PARTICIPANTE, DE FORMA DIRETA OU INDIRETA, } \\
\text { RECEBIMENTO POR PALESTRAS, AULAS, ATUAÇÃO COMO PROCTOR DE TREINAMENTOS, REMUNERAÇÕES, HONORÁRIOS } \\
\text { PAGOS POR PARTICIPAÇÕES EM CONSELHOS CONSULTIVOS, DE INVESTIGADORES, OU OUTROS COMITÊS, ETC. } \\
\text { PROVENIENTES DA INDÚSTRIA FARMACÊUTICA, DE ÓRTESES, PRÓTESES, EQUIPAMENTOS E IMPLANTES, BRASILEIRAS OU } \\
\text { ESTRANGEIRAS: } \\
\text { - Libbs: oncologia } \\
\text { - Novartis: oncologia } \\
\text { - Roche: oncologia } \\
\text { - Pfizer: oncologia } \\
\text { B - FINANCIAMENTO DE PESQUISAS SOB SUA RESPONSABILIDADE DIRETA/PESSOAL (DIRECIONADO AO DEPARTAMENTO } \\
\text { OU INSTITUIÇÃO) PROVENIENTES DA INDÚSTRIA FARMACÊUTICA, DE ÓRTESES, PRÓTESES, EQUIPAMENTOS E IMPLANTES, } \\
\text { BRASILEIRAS OU ESTRANGEIRAS: } \\
\text { - Roche: oncologia - financiamento institucional } \\
\text { - Lilly: oncologia - financiamento institucional } \\
\text { - Novartis: oncologia - financiamento institucional } \\
\text { - MSD: oncologia - financiamento institucional } \\
\text { OUTROS RELACIONAMENTOS } \\
\text { FINANCIAMENTO DE ATIVIDADES DE EDUCAÇÃO MÉDICA CONTINUADA, INCLUINDO VIAGENS, HOSPEDAGENS E INSCRIÇÕES } \\
\text { PARA CONGRESSOS E CURSOS, PROVENIENTES DA INDÚSTRIA FARMACÊUTICA, DE ÓRTESES, PRÓTESES, EQUIPAMENTOS } \\
\text { E IMPLANTES, BRASILEIRAS OU ESTRANGEIRAS: } \\
\text { - Pfizer: oncologia } \\
\text { - Libbs: oncologia } \\
\text { - United Medical: oncologia }\end{array}$ \\
\hline Ludhmila Abrahão Hajjar & Nada a ser declarado \\
\hline Luís Beck-da-Silva & $\begin{array}{l}\text { DECLARAÇÃO FINANCEIRA } \\
\text { A - PAGAMENTO DE QUALQUER ESPÉCIE E DESDE QUE ECONOMICAMENTE APRECIÁVEIS, FEITOS A (i) VOCÊ, (ii) AO SEU } \\
\text { CÔNJUGE/COMPANHEIRO OU A QUALQUER OUTRO MEMBRO QUE RESIDA COM VOCÊ, (iii) A QUALQUER PESSOA JURIDICA } \\
\text { EM QUE QUALQUER DESTES SEJA CONTROLADOR, SÓCIO, ACIONISTA OU PARTICIPANTE, DE FORMA DIRETA OU INDIRETA, } \\
\text { RECEBIMENTO POR PALESTRAS, AULAS, ATUAÇÃO COMO PROCTOR DE TREINAMENTOS, REMUNERAÇÕES, HONORÁRIOS } \\
\text { PAGOS POR PARTICIPAÇÕES EM CONSELHOS CONSULTIVOS, DE INVESTIGADORES, OU OUTROS COMITÊS, ETC. } \\
\text { PROVENIENTES DA INDÚSTRIA FARMACÊUTICA, DE ÓRTESES, PRÓTESES, EQUIPAMENTOS E IMPLANTES, BRASILEIRAS OU } \\
\text { ESTRANGEIRAS: } \\
\text { - Novartis: insuficiência cardíaca } \\
\text { - Merck: insuficiência cardíaca } \\
\text { B - FINANCIAMENTO DE PESQUISAS SOB SUA RESPONSABILIDADE DIRETA/PESSOAL (DIRECIONADO AO DEPARTAMENTO } \\
\text { OU INSTITUIÇÃO) PROVENIENTES DA INDÚSTRIA FARMACÊUTICA, DE ÓRTESES, PRÓTESES, EQUIPAMENTOS E IMPLANTES, } \\
\text { BRASILEIRAS OU ESTRANGEIRAS: } \\
\text { - AMGEN: insuficiência cardíaca } \\
\text { - Novartis: insuficiência cardíaca }\end{array}$ \\
\hline $\begin{array}{l}\text { Manuel Maria Ramos } \\
\text { Valente Neto }\end{array}$ & Nada a ser declarado \\
\hline $\begin{array}{l}\text { Marcelo Antônio Cartaxo } \\
\text { Queiroga Lopes }\end{array}$ & Nada a ser declarado \\
\hline $\begin{array}{l}\text { Marcelo Westerlund } \\
\text { Montera }\end{array}$ & Nada a ser declarado \\
\hline
\end{tabular}




\begin{tabular}{|c|c|}
\hline $\begin{array}{l}\text { Marcus Vinicius Bolivar } \\
\text { Malachias }\end{array}$ & $\begin{array}{l}\text { DECLARAÇÃO FINANCEIRA } \\
\text { A - PAGAMENTO DE QUALQUER ESPÉCIE E DESDE QUE ECONOMICAMENTE APRECIÁVEIS, FEITOS A (i) VOCÊ, (ii) AO SEU } \\
\text { CÔNJUGE/COMPANHEIRO OU A QUALQUER OUTRO MEMBRO QUE RESIDA COM VOCÊ, (iii) A QUALQUER PESSOA JURIDICA } \\
\text { EM QUE QUALQUER DESTES SEJA CONTROLADOR, SÓCIO, ACIONISTA OU PARTICIPANTE, DE FORMA DIRETA OU INDIRETA, } \\
\text { RECEBIMENTO POR PALESTRAS, AULAS, ATUAÇÃO COMO PROCTOR DE TREINAMENTOS, REMUNERAÇÕES, HONORÁRIOS } \\
\text { PAGOS POR PARTICIPAÇÕES EM CONSELHOS CONSULTIVOS, DE INVESTIGADORES, OU OUTROS COMITÊS, ETC. } \\
\text { PROVENIENTES DA INDÚSTRIA FARMACÊUTICA, DE ÓRTESES, PRÓTESES, EQUIPAMENTOS E IMPLANTES, BRASILEIRAS OU } \\
\text { ESTRANGEIRAS: } \\
\text { - Abbott: cardiologia } \\
\text { - Libbs: cardiologia } \\
\text { - Bayewr: cardiologia } \\
\text { - Novo Nordisk: cardiologia } \\
\text { OUTROS RELACIONAMENTOS } \\
\text { FINANCIAMENTO DE ATIVIDADES DE EDUCAÇÃO MÉDICA CONTINUADA, INCLUINDO VIAGENS, HOSPEDAGENS E INSCRIÇÕES } \\
\text { PARA CONGRESSOS E CURSOS, PROVENIENTES DA INDÚSTRIA FARMACÉUTICA, DE ÓRTESES, PRÓTESES, EQUIPAMENTOS } \\
\text { E IMPLANTES, BRASILEIRAS OU ESTRANGEIRAS: } \\
\text { - AstraZeneca } \\
\text { - Bayer } \\
\text { PARTICIPAÇÃO SOCIETÁRIA DE QUALQUER NATUREZA E QUALQUER VALOR ECONOMICAMENTE APRECIÁVEL DE EMPRESAS } \\
\text { NAÁREA DE SAÚDE, DE ENSINO OU EM EMPRESAS CONCORRENTES OU FORNECEDORAS DA SBC: } \\
\text { - Instituto de Hipertensão de Minas Gerais, Cardio Check Up }\end{array}$ \\
\hline $\begin{array}{l}\text { Maria Carolina Feres de } \\
\text { Almeida Soeiro }\end{array}$ & Nada a ser declarado \\
\hline $\begin{array}{l}\text { Maria da Consolação Vieira } \\
\text { Moreira }\end{array}$ & Nada a ser declarado \\
\hline Maria Del Pilar Estevez Diz & Nada a ser declarado \\
\hline $\begin{array}{l}\text { Maria Verônica Câmara dos } \\
\text { Santos }\end{array}$ & Nada a ser declarado \\
\hline
\end{tabular}

\section{DECLARAÇÃO FINANCEIRA}

A - PAGAMENTO DE QUALQUER ESPÉCIE E DESDE QUE ECONOMICAMENTE APRECIÁVEIS, FEITOS A (i) VOCÊ, (ii) AO SEU CÔNJUGE/COMPANHEIRO OU A QUALQUER OUTRO MEMBRO QUE RESIDA COM VOCÊ, (iii) A QUALQUER PESSOA JURÍDICA EM QUE QUALQUER DESTES SEJA CONTROLADOR, SÓCIO, ACIONISTA OU PARTICIPANTE, DE FORMA DIRETA OU INDIRETA, RECEBIMENTO POR PALESTRAS, AULAS, ATUAÇÃO COMO PROCTOR DE TREINAMENTOS, REMUNERAÇÕES, HONORÁRIOS PAGOS POR PARTICIPAÇÕES EM CONSELHOS CONSULTIVOS, DE INVESTIGADORES, OU OUTROS COMITÊS, ETC. PROVENIENTES DA INDÚSTRIA FARMACÊUTICA, DE ÓRTESES, PRÓTESES, EQUIPAMENTOS E IMPLANTES, BRASILEIRAS OU Marianna Deway Andrade ESTRANGEIRAS:

Dracoulakis $\quad$ - Pfizer: cardiologia

- Bayer: Xarelto

- Daichii: Lixiana

- Servier: cardiologia

OUTROS RELACIONAMENTOS

FINANCIAMENTO DE ATIVIDADES DE EDUCAÇÃO MÉDICA CONTINUADA, INCLUINDO VIAGENS, HOSPEDAGENS E INSCRIÇÕES PARA CONGRESSOS E CURSOS, PROVENIENTES DA INDÚSTRIA FARMACÊUTICA, DE ÓRTESES, PRÓTESES, EQUIPAMENTOS E IMPLANTES, BRASILEIRAS OU ESTRANGEIRAS:

- Pfizer: Eliquis

Marília Harumi Higuchi dos Santos Rehder
DECLARAÇÃO FINANCEIRA

A - PAGAMENTO DE QUALQUER ESPÉCIE E DESDE QUE ECONOMICAMENTE APRECIÁVEIS, FEITOS A (i) VOCÊ, (ii) AO SEU CÔNJUGE/COMPANHEIRO OU A QUALQUER OUTRO MEMBRO QUE RESIDA COM VOCÊ, (iii) A QUALQUER PESSOA JURÍDICA EM QUE QUALQUER DESTES SEJA CONTROLADOR, SÓCIO, ACIONISTA OU PARTICIPANTE, DE FORMA DIRETA OU INDIRETA, RECEBIMENTO POR PALESTRAS, AULAS, ATUAÇÃO COMO PROCTOR DE TREINAMENTOS, REMUNERAÇÕES, HONORÁRIOS PAGOS POR PARTICIPAÇÕES EM CONSELHOS CONSULTIVOS, DE INVESTIGADORES, OU OUTROS COMITÊS, ETC. PROVENIENTES DA INDÚSTRIA FARMACÊUTICA, DE ÓRTESES, PRÓTESES, EQUIPAMENTOS E IMPLANTES, BRASILEIRAS OU ESTRANGEIRAS:

- Eli Lilly do Brasil OUTROS RELACIONAMENTOS VÍNCULO EMPREGATÍCIO COM A INDÚSTRIA FARMACÊUTICA, DE ÓRTESES, PRÓTESES, EQUIPAMENTOS E IMPLANTES, BRASILEIRAS OU ESTRANGEIRAS, ASSIM COMO SE TEM RELAÇÃO VÍNCULO EMPREGATÍCIO COM OPERADORAS DE PLANOS DE SAÚDE OU EM AUDITORIAS MÉDICAS (INCLUINDO MEIO PERÍODO) DURANTE O ANO PARA O QUAL VOCÊ ESTÁ DECLARANDO: - Gerente médico farmacovigilância 


\begin{tabular}{|c|c|}
\hline Paulo Marcelo Gehm Hoff & 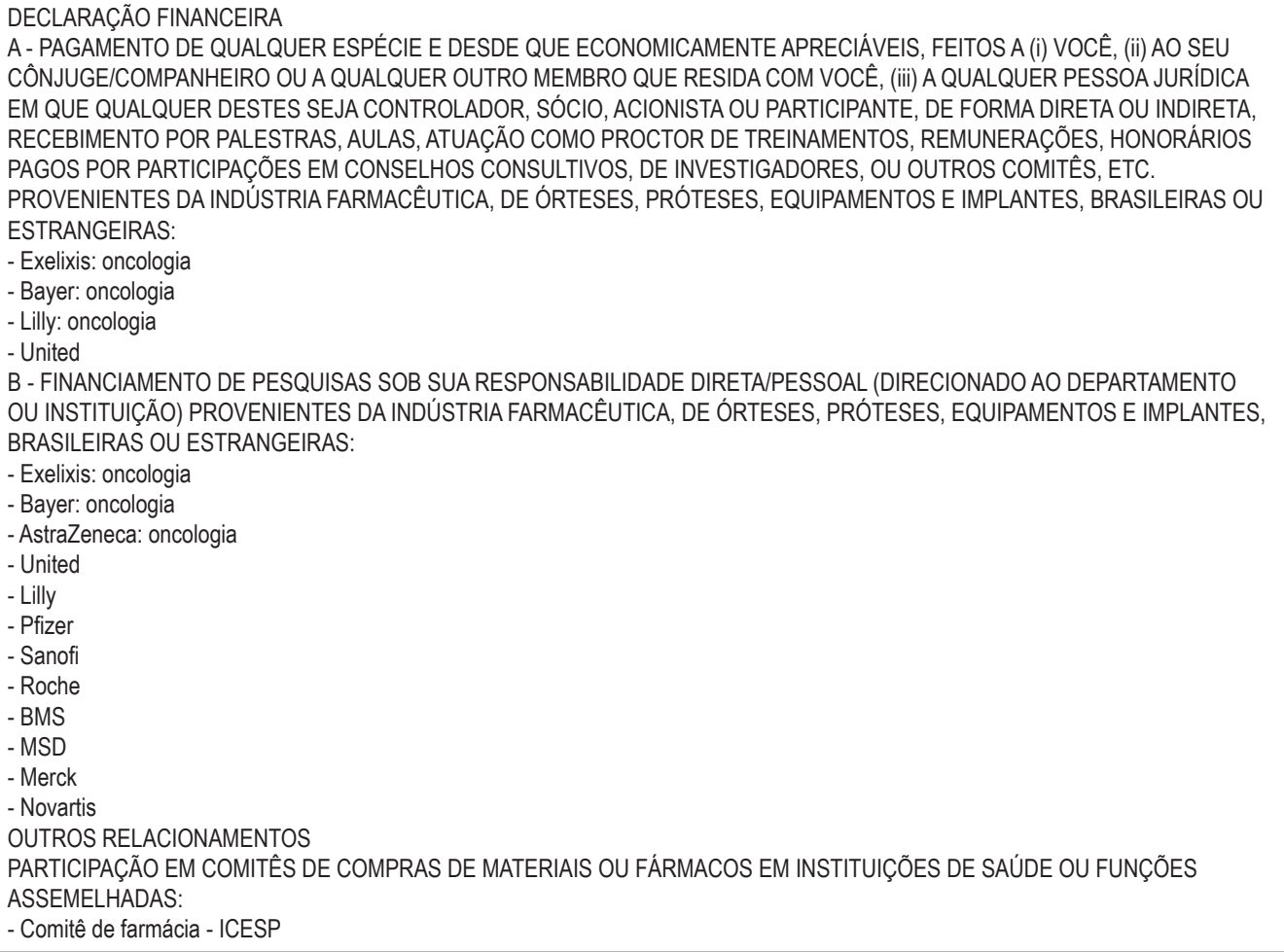 \\
\hline Renata do Val & Nada a ser declarado \\
\hline Ricardo Pavanello & $\begin{array}{l}\text { OUTROS RELACIONAMENTOS } \\
\text { FINANCIAMENTO DE ATIVIDADES DE EDUCAÇÃO MÉDICA CONTINUADA, INCLUINDO VIAGENS, HOSPEDAGENS E INSCRIÇÕES } \\
\text { PARA CONGRESSOS E CURSOS, PROVENIENTES DA INDÚSTRIA FARMACÊUTICA, DE ÓRTESES, PRÓTESES, EQUIPAMENTOS } \\
\text { E IMPLANTES, BRASILEIRAS OU ESTRANGEIRAS: } \\
\text { - Bayer: Programa de Educação Continuada a Distância }\end{array}$ \\
\hline Roberto Kalil Filho & Nada a ser declarado \\
\hline $\begin{array}{l}\text { Sílvia Marinho Martins } \\
\text { Alves }\end{array}$ & Nada a ser declarado \\
\hline Silvia Moreira Ayub Ferreira & $\begin{array}{l}\text { DECLARAÇÃO FINANCEIRA } \\
\text { A - PAGAMENTO DE QUALQUER ESPÉCIE E DESDE QUE ECONOMICAMENTE APRECIÁVEIS, FEITOS A (i) VOCÊ, (ii) AO SEU } \\
\text { CÔNJUGE/COMPANHEIRO OU A QUALQUER OUTRO MEMBRO QUE RESIDA COM VOCÊ, (iii) A QUALQUER PESSOA JURÍDICA } \\
\text { EM QUE QUALQUER DESTES SEJA CONTROLADOR, SÓCIO, ACIONISTA OU PARTICIPANTE, DE FORMA DIRETA OU INDIRETA, } \\
\text { RECEBIMENTO POR PALESTRAS, AULAS, ATUAÇÃO COMO PROCTOR DE TREINAMENTOS, REMUNERAÇÕES, HONORÁRIOS } \\
\text { PAGOS POR PARTICIPAÇÕES EM CONSELHOS CONSULTIVOS, DE INVESTIGADORES, OU OUTROS COMITÊS, ETC. } \\
\text { PROVENIENTES DA INDÚSTRIA FARMACÊUTICA, DE ÓRTESES, PRÓTESES, EQUIPAMENTOS E IMPLANTES, BRASILEIRAS OU } \\
\text { ESTRANGEIRAS: } \\
\text { - Abbott: MitraClip } \\
\text { OUTROS RELACIONAMENTOS } \\
\text { FINANCIAMENTO DE ATIVIDADES DE EDUCAÇÃO MÉDICA CONTINUADA, INCLUINDO VIAGENS, HOSPEDAGENS E INSCRIÇÕES } \\
\text { PARA CONGRESSOS E CURSOS, PROVENIENTES DA INDÚSTRIA FARMACÊUTICA, DE ÓRTESES, PRÓTESES, EQUIPAMENTOS } \\
\text { E IMPLANTES, BRASILEIRAS OU ESTRANGEIRAS: } \\
\text { - Abbott: asSIStência circulatória mecânica }\end{array}$ \\
\hline $\begin{array}{l}\text { Silvia Moulin Ribeiro } \\
\text { Fonseca }\end{array}$ & Nada a ser declarado \\
\hline Stephanie Itala Rizk & Nada a ser declarado \\
\hline $\begin{array}{l}\text { Thiago Liguori Feliciano } \\
\text { da Silva }\end{array}$ & Nada a ser declarado \\
\hline Vanderson Rocha & Nada a ser declarado \\
\hline $\begin{array}{l}\text { Veronica Cristina Quiroga } \\
\text { Fonseca }\end{array}$ & Nada a ser declarado \\
\hline Wilson Mathias Junior & Nada a ser declarado \\
\hline Yana Novis & Nada a ser declarado \\
\hline
\end{tabular}




\section{Sumário}

\section{Introdução.} 1014

2. Métodos. 1015 3. Diagnóstico e Manejo de Complicações Cardiovasculares no Paciente com Câncer .................................................................. 1016

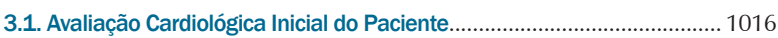
3.2. Diagnóstico de Cardiotoxicidade nos Pacientes com Câncer.................. 1016

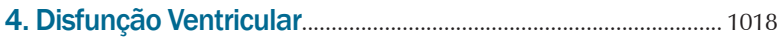

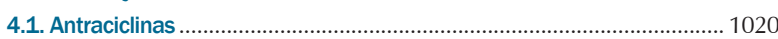

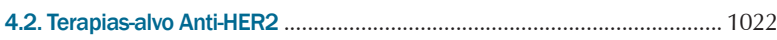

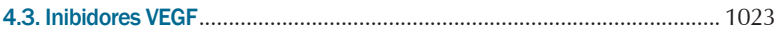

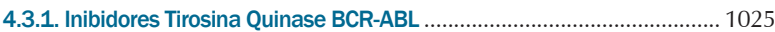

4.4. Terapias para Mieloma Múltiplo.............................................................. 1025

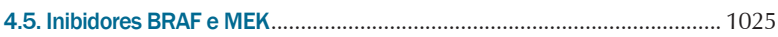

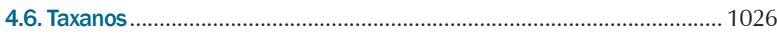

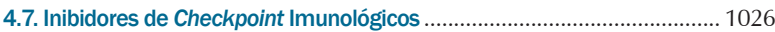

5. Radioterapia ..................................................................................... 1026

6. Prevenção e Tratamento da Cardiotoxicidade ...................... 1026

7. Tromboembolismo Arterial e Venoso ........................................ 1030

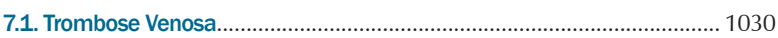

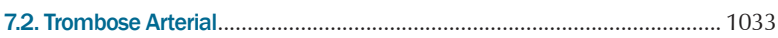

8. Síndrome Metabólica Associada à Terapia de Privação

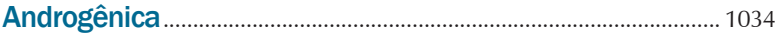

9. Arritmia Cardíaca ......................................................................... 1034

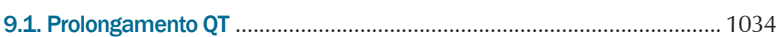

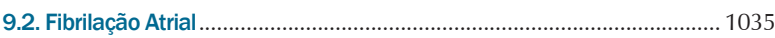

10. Doença Arterial Coronariana.................................................... 1036

11. Hipertensão Arterial ................................................................ 1039

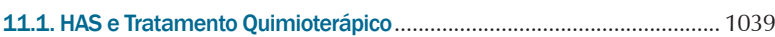

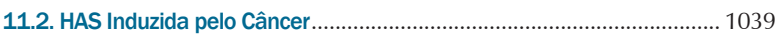

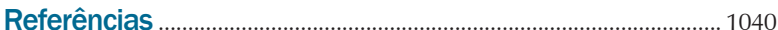

\section{Introdução}

Atualmente, doenças cardiovasculares (DCV) e câncer são as principais causas de mortalidade em todo o mundo e no Brasil. ${ }^{1-3}$ As transições demográfica e epidemiológica ocorridas recentemente no nosso país resultaram no aumento da expectativa de vida da população, hoje em torno de 76 anos, e na modificação no perfil de saúde, em que doenças crônicas e suas complicações são prevalentes. ${ }^{4}$

Esses fatores ocasionam importantes desafios e a necessidade de uma agenda para as políticas de saúde que possam lidar com as várias transições em curso. A escalada tecnológica, a escassez de análises de custo-efetividade e a pouca valorização na educação quanto aos aspectos referentes ao acesso à saúde e à promoção e prevenção em saúde impõem a necessidade da implementação de diretrizes e consensos para auxiliar na utilização de protocolos sistematizados, com o objetivo de adequar a prática clínica independentemente da localização geográfica da instituição de saúde e da heterogeneidade de recursos.

Avanços recentes na detecção e no tratamento do câncer tiveram como consequência o aumento exponencial no número de sobreviventes em todo o mundo. Em recente projeção, estima-se para 2026, nos Estados Unidos, uma população de 20 milhões de sobreviventes de câncer, 50\% dos quais terão mais de 70 anos de idade. , $^{6}$ Uma população mais idosa com história de câncer e de DCV associada ao potencial de toxicidade cardiovascular do tratamento oncológico impõe a necessidade de especialistas com conhecimento a respeito da interação câncer e DCV. ${ }^{7}$

Em 1967, foi feita a primeira descrição de toxicidade cardíaca associada a antraciclina. ${ }^{8}$ Em 1971, descreveuse que a cardiotoxicidade por antraciclina seria dosedependente e o dano cardíaco possivelmente irreversível. ${ }^{9}$ Alguns anos depois, foram identificados fatores de risco para disfunção ventricular associada à quimioterapia, tendose relacionado biomarcadores, como troponina e BNP, à predição de eventos cardiovasculares. ${ }^{10,11}$ Esses foram os primeiros achados que nortearam a cardio-oncologia.

Cardio-oncologia é o campo da ciência voltado para o diagnóstico precoce e o manejo adequado da DCV em pacientes com diagnóstico atual ou pregresso de câncer. A cardio-oncologia ocupa-se ainda da análise do risco cardiovascular frente ao diagnóstico oncológico, além das necessidades do paciente antes, durante e após o tratamento. O time de especialistas em cardio-oncologia deve seguir o paciente desde o diagnóstico, passando por todas as fases do tratamento, e acompanhá-lo mesmo após sua cura, quando é denominado sobrevivente do câncer. A necessidade crescente da expansão da cardio-oncologia guarda relação direta com a epidemiologia do câncer e das DCV, os seus fatores de risco em comum e a multiplicidade de tratamentos com distintas toxicidades ao sistema cardiovascular (Figura 1). ${ }^{12,13}$

Em 2011, a Sociedade Brasileira de Cardiologia (SBC) e a Sociedade Brasileira de Oncologia Clínica (SBOC) foram pioneiras ao publicarem em conjunto a I Diretriz de Cardio-Oncologia. ${ }^{14}$ Em 9 anos, pudemos observar o crescimento significativo da disciplina de cardiooncologia. Isso ocorreu devido a alguns fatores: a) avanços consideráveis no tratamento do câncer; b) entendimento da multidisciplinaridade e da integração entre cardiologia, oncologia e hematologia como essenciais ao cuidado do paciente com câncer; c) implementação de programas de fellowship em todo o mundo e inserção da cardio-oncologia na matriz curricular da residência em cardiologia em algumas instituições; d) crescimento da pesquisa na área tanto básica quanto clínica; e e) criação de importantes periódicos dedicados ao tema, como JACC CardioOncology e Cardio-Oncology. ${ }^{15,16}$

Destaca-se o fato de, em 2019, o Brasil ter sido a sede do V Global Cardio-Oncology Summit, que contou com a participação de especialistas de diversos países e de aproximadamente 600 profissionais (cardiologistas, oncologistas, hematologistas, enfermeiros, fisioterapeutas, farmacêuticos, educadores físicos). Foram publicados 89 resumos no jornal Frontiers in Cardiovascular Medicine, tendo o periódico JACC CardioOncology publicado "Proceedings From the Global Cardio-Oncology Summit - The Top 10 Priorities to Actualize for CardioOncology" ${ }^{17,18}$

A SBC e a SBOC, com o objetivo de renovar o conhecimento e promover a implementação da abordagem racional e sistemática das complicações cardiovasculares no paciente oncológico, reuniram um grupo de especialistas para abordar 


\section{CARDIO-ONCOLOGIA}

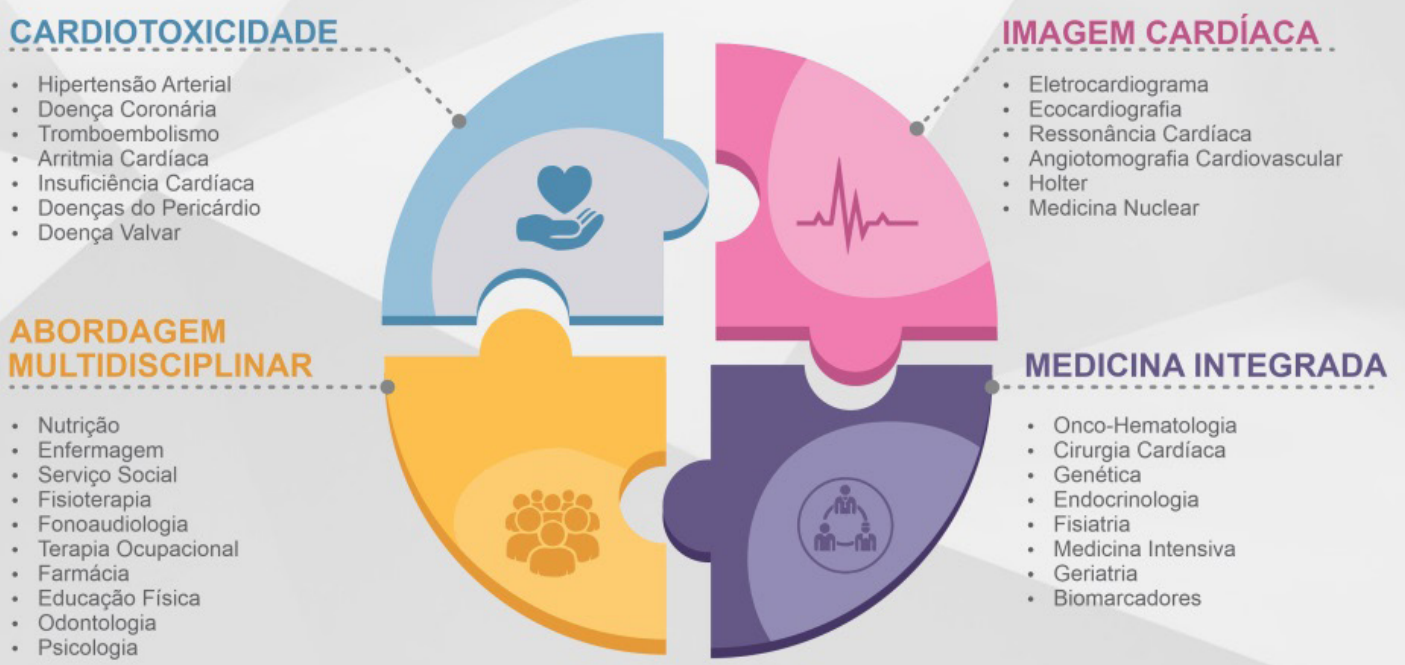

Figura 1 - As fronteiras da cardio-oncologia da atualidade.

novas estratégias, propor recomendações baseadas em evidências e desenvolver o cuidado multidisciplinar, que permitirão o manejo adequado dessa categoria crescente de pacientes.

A Diretriz Brasileira de Cardio-Oncologia - 2020 tem como metas: 1) desmistificar a visão da DCV como uma barreira ao tratamento efetivo do paciente com câncer; 2) prevenir e reduzir os riscos da cardiotoxicidade do tratamento; 3) promover a interação das especialidades (cardiologia, hematologia e oncologia) para obter a melhor estratégia de cuidado para o paciente, considerando os riscos e os benefícios do tratamento; 4) propor a unificação de terminologias e definições das complicações cardiovasculares no paciente com câncer, com o objetivo de homogeneizar a assistência e a pesquisa; 5) divulgar as evidências disponíveis em relação ao manejo das complicações cardiovasculares no paciente oncológico, buscando diagnóstico precoce por meio da monitorização da função cardiovascular antes, durante e após o tratamento do paciente; 6) promover tratamento adequado em conjunto com a oncologia e a hematologia com base em evidências científicas, em análise de risco e na personalização do cuidado, levando-se em consideração as preferências do paciente; e 7) estimular a pesquisa e a disseminação do conhecimento na área de cardio-oncologia.
A Diretriz Brasileira de Cardio-Oncologia - 2020 reúne a evidência disponível até 2020 no que se refere às complicações cardiovasculares dos pacientes com câncer.

\section{Métodos}

A Diretriz Brasileira de Cardio-Oncologia - 2020 foi realizada de acordo com as recomendações vigentes. Um grupo de especialistas dos campos da cardiologia, oncologia e hematologia formou o comitê responsável pelo manuscrito. Os participantes foram escolhidos por seu destaque na área, sua participação na International Cardio-Oncology Society (ICOS), na SBC e na SBOC, além de sua produção científica.

Foi realizada pesquisa bibliográfica no PubMed no período de 1975 a julho de 2020 com as seguintes palavras-chave: cardiotoxicity, cancer, immunotherapy, cardiooncology, cardiovascular complications, targeted therapy, radiotherapy, vascular toxicity, heart failure, ventricular dysfunction, pericardial disease, coronary disease, thromboembolism, arrhythmias, hypertension, individual drug names. O manuscrito foi enviado eletronicamente para todos os participantes e, após a concordância de todos com o conteúdo, foi formatado e encaminhado para publicação.

Seguem as classes de recomendação e níveis de evidência utilizados por esta diretriz. 
Classes (graus) de recomendação:

Classe I - Condições para as quais há evidências conclusivas, ou, na sua falta, consenso geral de que o procedimento é seguro e útil/eficaz.

Classe II - Condições para as quais há evidências conflitantes e/ou divergência de opinião sobre segurança e utilidade/eficácia do procedimento.

- Classe Ila - Peso ou evidência/opinião a favor do procedimento. A maioria aprova.

- Classe IIb - Segurança e utilidade/eficácia menos bem estabelecida, não havendo predomínio de opiniões a favor.

Classe III - Condições para as quais há evidências e/ou consenso de que o procedimento não é útil/eficaz e, em alguns casos, pode ser prejudicial Níveis de evidência.

Níveis de evidência:

Nível A - Dados obtidos a partir de múltiplos estudos randomizados de bom porte, concordantes e/ou de metanálise robusta de estudos clínicos randomizados.

Nível B - Dados obtidos a partir de metanálise menos robusta, a partir de um único estudo randomizado ou de estudos não randomizados (observacionais).

Nível C - Dados obtidos de opiniões consensuais de especialistas.

\section{Diagnóstico e Manejo de Complicações Cardiovasculares no Paciente com Câncer}

\subsection{Avaliação Cardiológica Inicial do Paciente}

O tratamento do câncer, em suas diversas modalidades (quimioterapia, imunoterapia, radioterapia, dentre outras), pode resultar em dano ao sistema cardiovascular. Pacientes com DCV prévia ou fatores de risco cardiovasculares representam o grupo com maior possibilidade para complicações decorrentes do tratamento. Portanto, recomenda-se o tratamento e o controle dos fatores de risco cardiovasculares na população de pacientes com câncer. ${ }^{19-21}$

A consulta com o cardiologista deve abordar controle dos fatores de risco cardiovasculares, medidas de cardioproteção, adesão ao tratamento e estratégia para permitir o diagnóstico precoce de dano cardíaco (I, B).

Pacientes com fatores de risco cardiovasculares ou DCV já estabelecida e que serão submetidos a tratamento com potencial de cardiotoxicidade [antraciclinas, agentes anti-HER2 (receptor tipo 2 do fator de crescimento epidérmico humano), agentes alquilantes, inibidores de sinalização VEGF (fator de crescimento endotelial vascular), inibidores de proteassoma e inibidores de checkpoint imunológicos (ICls)] devem ser avaliados pelo cardiologista no início da terapia e acompanhados de acordo com protocolos de seguimento específicos (I,B). A Tabela 1 apresenta os tratamentos antineoplásicos mais comumente associados a toxicidade cardiovascular e a Figura 2, os fatores associados a maior risco de cardiotoxicidade.

A equipe multidisciplinar, ao avaliar o paciente, deve analisar os riscos e os supostos benefícios da terapia e implementar estratégias de prevenção de dano cardiovascular (Ila, C).
Mensuração de fatores de risco cardiovasculares e sua abordagem de acordo com consensos e diretrizes são recomendados $(\mathrm{I}, \mathrm{A})$.

$\mathrm{Na}$ avaliação inicial do cardiologista, recomenda-se realizar anamnese, exame físico, eletrocardiograma (ECG), radiografia de tórax, hemograma completo, dosagem de eletrólitos e biomarcadores [fragmento N-terminal do BNP (NT-proBNP) e troponina I ou T ultrassensível], ácido fólico, vitaminas D e B12, além de verificar glicemia, perfil lipídico e funções renal, hepática e tireoidiana (I,A) (Figura 3).

Recomenda-se ainda realizar, na avaliação basal e seriada de acordo com o regime de tratamento, um ecocardiograma transtorácico com Doppler colorido, idealmente tridimensional, com análise da fração de ejeção do ventrículo esquerdo (FEVE), da função diastólica e da deformação miocárdica com mensuração do strain pela técnica speckle tracking $(\mathrm{I}, \mathrm{A})$.

Colaboração entre cardiologistas, oncologistas e hematologistas é recomendada para assegurar tratamento adequado e benéfico aos pacientes com câncer (Ila, A).

\subsection{Diagnóstico de Cardiotoxicidade nos Pacientes com Câncer}

O diagnóstico de cardiotoxicidade pode ser realizado pela confirmação de alteração cardiovascular nova durante ou após o tratamento, seja de natureza clínica e/ou alteração em biomarcadores e/ou em exame de imagem cardiovascular, tendo sido excluídas outras etiologias (I, B).

A ecocardiografia é o método de escolha para detectar disfunção miocárdica relacionada ao tratamento do câncer. A ecocardiografia tridimensional é o melhor método ecocardiográfico para medir a FEVE no paciente com câncer. Quando indisponível ou na presença de limitação, o método bidimensional de Simpson é recomendado (I, A).

Disfunção ventricular relacionada à terapia do câncer é definida como uma redução $\geq 10 \%$ na FEVE para um valor abaixo do limite inferior da normalidade (FEVE $<50 \%$ ). Recomenda-se repetir a imagem cardiovascular em 2 a 3 semanas (I, B).

A redução da FEVE deve ocorrer durante a evolução, sendo classificada como sintomática ou assintomática e reversível ou irreversível (I, B).

O strain longitudinal global (SLG) é ferramenta que prediz com alta sensibilidade a posterior redução da FEVE. Redução $\geq 15 \%$ no SLG em relação ao basal é considerada anormal, sendo um marcador precoce de disfunção ventricular (I, B).

Recomenda-se realizar a análise da função diastólica nos pacientes oncológicos, tanto antes do início da terapia quanto no seguimento (Ila,C). Porém, não há evidência de que o tratamento deva ser interrompido com base na função diastólica.

A ventriculografia radioisotópica não é recomendada de rotina no paciente com câncer, em virtude da necessidade de radiação, devendo ser reservada para situações especiais, nas quais outras metodologias não estejam disponíveis (IIB, C).

A ressonância magnética cardíaca (RMC) é o método padrãoouro para verificação da função cardíaca, capaz de avaliar estrutura e caracterização tecidual, sendo recomendada em casos com limitação da ecocardiografia, em situações de doenças infiltrativas, na avaliação do pericárdio e miocárdio e na detecção de massas e tumores (Ila, B). A RMC também pode ter valor prognóstico, por meio da análise de fibrose miocárdica.

$\mathrm{O}$ uso dos biomarcadores de rotina durante tratamento com potencial de cardiotoxicidade não está bem estabelecido. 
Tabela 1 - Terapias antineoplásicas associadas à toxicidade cardiovascular

\begin{tabular}{|c|c|}
\hline Classes de medicações antineoplásicas & Toxicidade cardiovascular \\
\hline Radioterapia & $\begin{array}{l}\text { Isquemia e infarto do miocárdio } \\
\text { Doença pericárdica } \\
\text { Doença valvar } \\
\text { Miocardite } \\
\text { Arritmia cardíaca }\end{array}$ \\
\hline $\begin{array}{l}\text { Antraciclinas } \\
\text { (doxorrubicina, epirrubicina, daunorrubicina, idarrubicina, mitoxantrona) }\end{array}$ & $\begin{array}{c}\text { Insuficiência cardíaca } \\
\text { Disfunção ventricular assintomática } \\
\text { Miocardite } \\
\text { Pericardite } \\
\text { Arritmias atriais e ventriculares }\end{array}$ \\
\hline $\begin{array}{l}\text { Agentes alquilantes } \\
\text { (ciclofosfamida, ifosfamida, melfalan) }\end{array}$ & $\begin{array}{c}\text { Arritmias } \\
\text { Disfunção ventricular } \\
\text { Doença arterial coronariana }\end{array}$ \\
\hline $\begin{array}{l}\text { Platina } \\
\text { (cisplatina, carboplatina, oxaliplatina) }\end{array}$ & $\begin{array}{l}\text { Trombose coronária } \\
\text { Isquemia miocárdica } \\
\text { Hipertensão arterial }\end{array}$ \\
\hline $\begin{array}{l}\text { Antimetabólitos } \\
\text { (5-fluorouracil, capecitabina) }\end{array}$ & $\begin{array}{c}\text { Isquemia miocárdica } \\
\text { Vasoespasmo coronário } \\
\text { Arritmias atriais e ventriculares }\end{array}$ \\
\hline $\begin{array}{l}\text { Terapias-alvo anti-HER2 } \\
\text { (trastuzumabe, pertuzumabe, T-DM1, lapatinibe, neratinibe) }\end{array}$ & $\begin{array}{c}\text { Insuficiência cardiaca } \\
\text { Disfunção ventricular assintomática } \\
\text { Hipertensão arterial }\end{array}$ \\
\hline $\begin{array}{l}\text { Inibidores de sinalização VEGF: } \\
\text { - Inibidores de tirosina quinase (sunitinibe, pazopanibe, sorafenibe, axitinibe, } \\
\text { tivozanibe, cabozantinibe, regorafenibe, lenvatinibe, vandetinibe) } \\
\text { - Anticorpos monoclonais (bevacizumabe, ramucirumabe) }\end{array}$ & $\begin{array}{l}\text { Hipertensão arterial } \\
\text { Insuficiência cardíaca } \\
\text { Disfunção ventricular assintomática } \\
\text { Isquemia e infarto do miocárdio } \\
\text { Prolongamento do QTc }\end{array}$ \\
\hline
\end{tabular}

(infarto do miocárdio, acidente vascular cerebral e doença vascular periférica oclusiva*)

- Inibidores de tirosina quinase multi-alvo:

Tromboembolismo venoso

Hipertensão arterial

Insuficiência cardíaca

(ponatinibe, nilotinibe, dasatinibe, bosutinibe)

Disfunção ventricular assintomática Aterosclerose ${ }^{* *}$

Prolongamento do QTc**

Hipertensão pulmonar***

Bradicardia, prolongamento do QTC

Outros inibidores de tirosina quinase multi-alvo:

- Inibidores de ALK (crizotinibe, ceritinibe)

Hiperglicemia, dislipidemia

- Inibidores de PI3-AKT-mTor (everolimus, sirolimus)

- Inibidores de tirosina quinase de Bruton (ibrutinibe)

Fibrilação atrial

- Inibidor de tirosina quinase EGFR (osimertinibe)

Insuficiência cardíaca, fibrilação atrial, prolongamento do QTc

Fibrilação atrial, insuficiência cardíaca

Terapia do mieloma múltiplo:

- Inibidores de proteassoma (carfilzomibe, bortezomibe, ixazomibe)

- Imunomoduladores (lenalidomide, talidomida, pomalidomide)
Insuficiência cardíaca***

Disfunção ventricular assintomática****

Isquemia e infarto do miocárdio

Arritmias atriais e ventriculares

Tromboembolismo venoso

Trombose arterial

Hipertensão arterial

Insuficiência cardíaca

Inibidores BRAF e MEK:

(dabrafenibe + trametinibe, vemurafenibe + cobimetinibe, encorafenibe + binimetinibe)

Terapias antiandrogênicas:

- Agonistas GnRH (goserelina, leuprolide)

- Antagonistas GnRH (degarelix)

-Antiandrogênicos (abiraterone)

Inibidores de checkpoint imunológicos:

(nivolumabe, ipilimumabe, durvalumabe, pembrolizumabe, atezolizumabe, avelumabe)
Hipertensão arterial

Prolongamento $\mathrm{QTc} c^{* * * * *}$

\section{Aterosclerose}

Isquemia e infarto do miocárdio

Diabetes mellitus

Hipertensão arterial

Miocardite

Insuficiência cardíaca

Arritmias atriais e ventriculares

Isquemia miocárdica cão ventricular assintoma

${ }^{*}$ Associado com ponatinibe, ${ }^{* *}$ Associado com ponatinibe e nilotinibe, ${ }^{* * *}$ Associado com dasatinibe, ${ }^{* * * *}$ Associado com carfilzomibe, ${ }^{* * * * *}$ Associado com vemurafenibe e cobimetinibe. EGFR: receptor do fator de crescimento epidérmico; GnRH: hormônio liberador de gonadotrofina; HER2: receptor tipo 2 do fator de crescimento epidérmico humano; QTC: QT corrigido; T-DM1: ado-trastuzumabe entansina; VEGF: fator de crescimento endotelial vascular. 


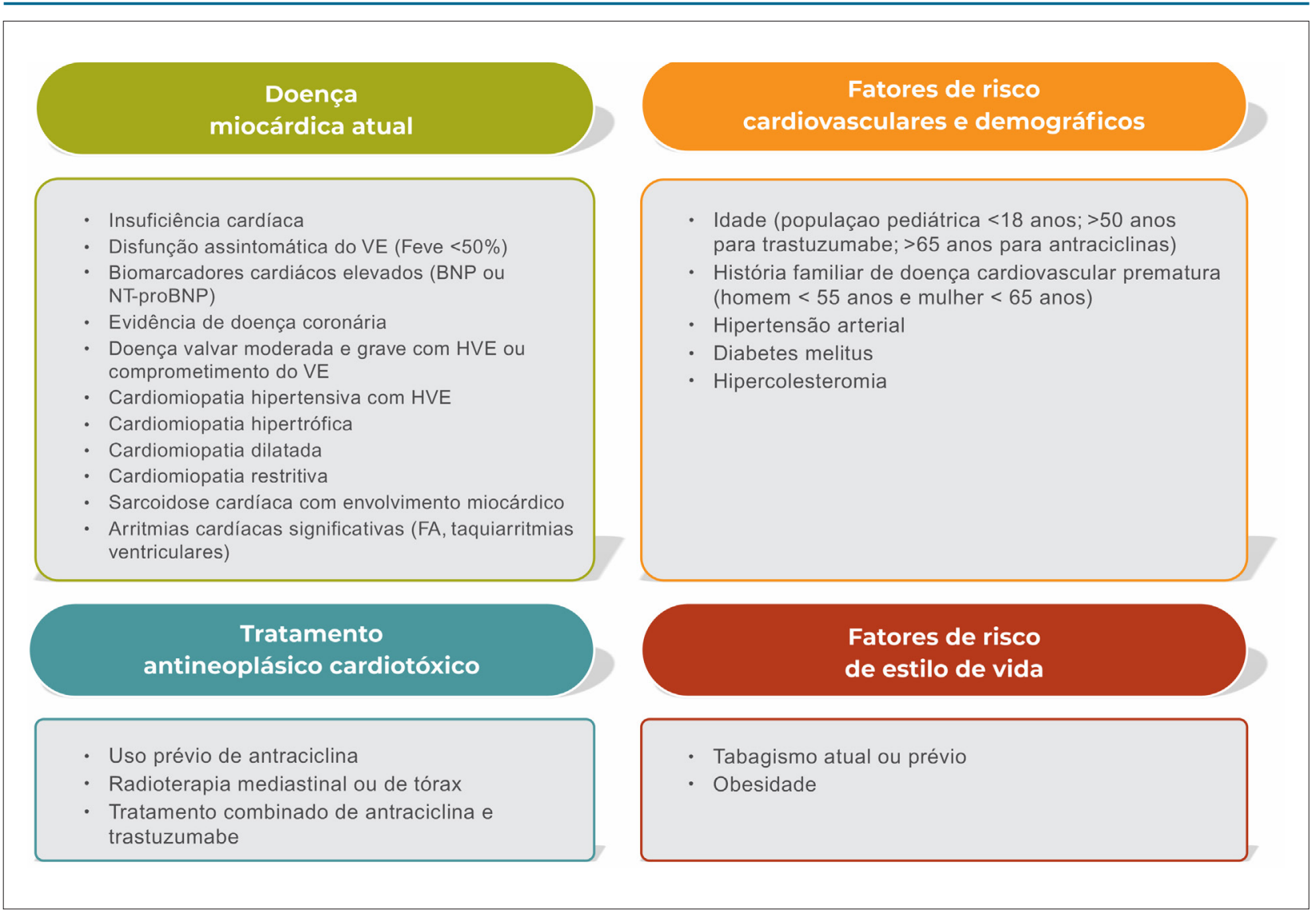

Figura 2 - Fatores de risco presentes no paciente com câncer que predispõem a cardiotoxicidade. Adaptado de Zamorano et al.22 BNP: peptídeo natriurético tipo B; FEVE: fração de ejeção do ventrículo esquerdo; HVE: hipertrofia ventricular esquerda; FA: fibrilação atrial; NT-proBNP: fragmento N-terminal do peptídeo natriurético tipo $B$; VE: ventrículo esquerdo.

A monitorização da cardiotoxicidade por meio da dosagem de biomarcadores pode ser considerada para a detecção de lesão miocárdica precoce em pacientes de alto risco, devido a fatores prévios, ou expostos a fármacos como antraciclinas e trastuzumabe (Ila, B). Não se sabe ainda o melhor momento, em relação à quimioterapia, para a dosagem dos biomarcadores (durante a quimioterapia, 24h após, 48h após ou mais tardio) nem qual a conduta a ser tomada frente à detecção de níveis elevados. Além disso, sugere-se que sejam utilizados os mesmos kits de análise, por exemplo, de troponina ultrassensível e NT-proBNP durante a evolução do tratamento (Ila, C).

A presença de níveis elevados de biomarcadores (NTproBNP e troponina) é indicativa de risco aumentado de cardiotoxicidade (I, A).

O ECG deve ser realizado na avaliação inicial e durante o tratamento. Deve-se calcular o QTc pela fórmula de Bazett QT / $(\mathrm{RR})^{1 / 2}$ ou Fridericia QT / (RR) ${ }^{1 / 3}$ e utilizar o mesmo método durante a avaliação seriada do paciente. Nos pacientes com câncer, a fórmula de Fridericia é preferível, pois sofre menos alterações na presença de taquicardia ou bradicardia (Ila, C).

Na Tabela 2, estão descritos os métodos de diagnóstico cardiovascular, suas principais vantagens, aplicações e limitações.

\section{Disfunção Ventricular}

A disfunção ventricular é uma das complicações mais graves do tratamento do câncer, caracterizando-se por altas taxas de morbidade e mortalidade. Pode surgir durante a terapia ou mesmo anos após seu término e ainda assim ser decorrente da toxicidade medicamentosa. ${ }^{23} \mathrm{O}$ modelo clássico de disfunção ventricular como forma de cardiotoxicidade é secundário ao uso das antraciclinas, quimioterápicos amplamente utilizados no tratamento do sarcoma, linfoma, leucemia e câncer de mama. ${ }^{24,25}$

Os diferentes quimioterápicos e imunoterápicos associados à disfunção ventricular resultam em fenótipos distintos nos pacientes, desde disfunção leve assintomática e reversível até casos graves de insuficiência cardíaca clinicamente manifesta e irreversível. Sobreviventes de câncer pediátricos têm até 15 vezes mais chance de desenvolver insuficiência cardíaca que controles pareados para outros fatores de risco. ${ }^{26}$

A predição de cardiotoxicidade é desafiadora, dada a multiplicidade de fármacos aos quais o paciente é exposto ao longo de sua vida, além dos fatores de risco cardiovasculares muitas vezes presentes. Chamam a atenção as múltiplas interações medicamentosas das diversas modalidades terapêuticas, como os regimes de antraciclinas com ciclofosfamida e antraciclinas com trastuzumabe. 


\section{QUANDO ESTÁ INDICADA AVALIAÇÃO DO CARDIOLOGISTA?}

Cardiopatas crônicos, FEVE limítrofe, presença de sintomas de IC, 2 ou mais fatores de risco para DCV, dose de antraciclina elevada (dose cumulativa de doxorrubicina $>250 \mathrm{mg} / \mathrm{m}^{2}$ )

\section{COMO AVALIIAR?}

ECG, ECO transtorácico*, RX tórax, hemograma completo, ureia, creatinina, NA, K, Mg, Cal, bilirrubina, ácido úrico, troponina, NT-proBNP, glicemia, vitaminas D e B12, ácido fólico, perfil lipídico e função tireoidiana. Se ECO com avaliação limitada, considerar RMC

\section{IDENTIFICADA DISFUNÇÃO DO VE?}

Indicado iniciar tratamento para IC, interagir com equipe da oncologia e/ou hematologia, acompanhamento durante intervenção oncológica

Figura 3 - Avaliação inicial do cardiologista. *Idealmente com avaliação tridimensional da FEVE e strain miocárdico pela técnica speckle tracking. Cal: cálcio iônico sérico; DCV: doença cardiovascular; ECG: eletrocardiograma; ECO: ecocardiograma; FEVE: fração de ejeção do ventrículo esquerdo; IC: insuficiência cardíaca; K: potássio sérico; Mg: magnésio sérico; Na: sódio sérico; NT-proBNP: fragmento N-terminal do peptídeo natriurético tipo B; RMC: ressonância magnética cardíaca; $R X$ : radiografia; $V E$ : ventrículo esquerdo. 


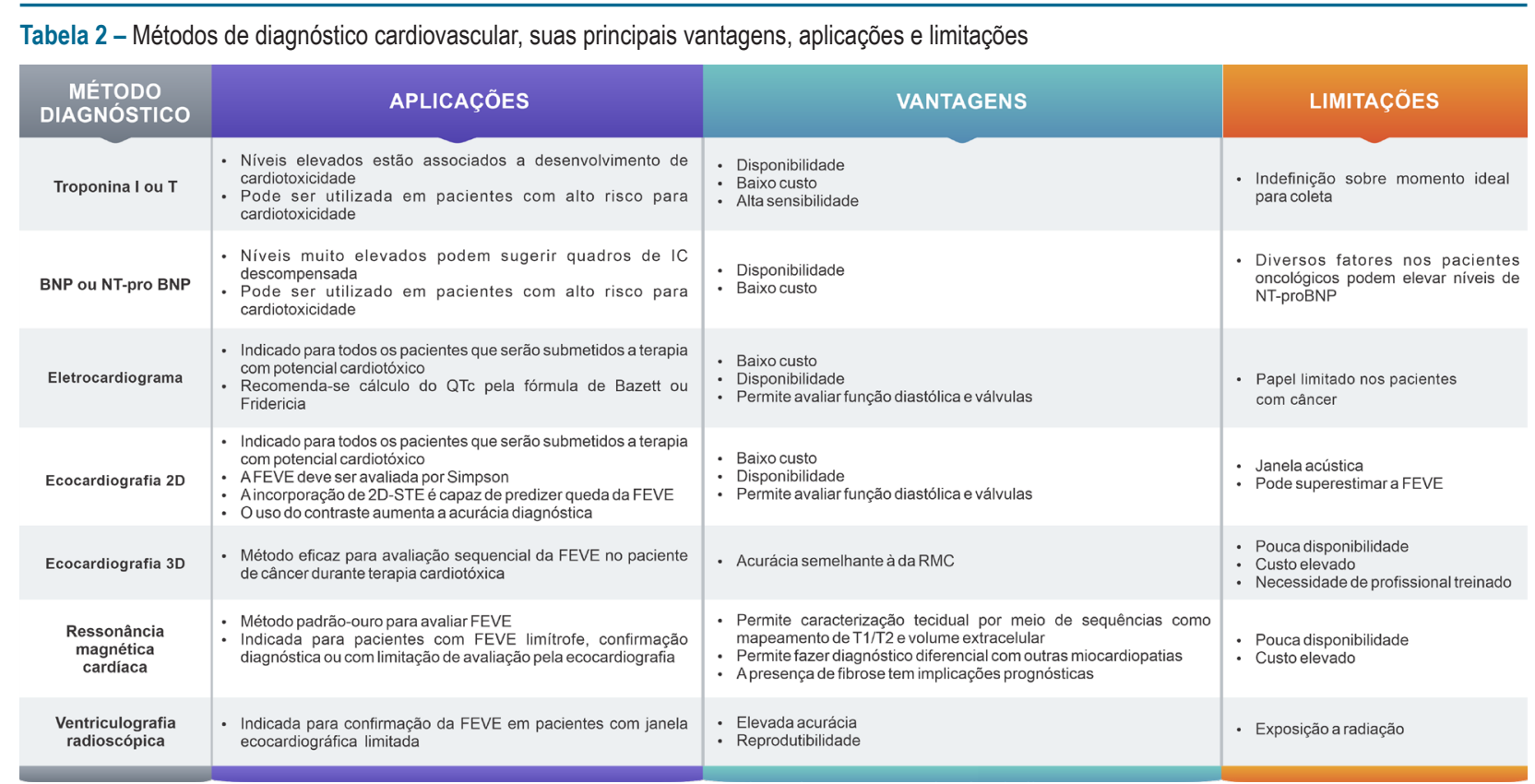

2D: bidimensional; 3D: tridimensional; BNP: peptídeo natriurético tipo B; FEVE: fração de ejeção do ventrículo esquerdo; IC: insuficiência cardíaca; NT-proBNP: fragmento N-terminal do peptídeo natriurético tipo B; STE: Speckle Tracking Echocardiography.

Nos últimos anos, com a introdução de novas drogas quimioterápicas e o advento da imunoterapia, além da introdução de protocolos de detecção precoce, houve aumento crescente no diagnóstico de disfunção ventricular. Na Tabela 3, observam-se os fármacos antineoplásicos mais associados à disfunção ventricular.

\subsection{Antraciclinas}

As antraciclinas constituem um grupo de antineoplásicos reconhecidamente eficazes no tratamento de linfomas, leucemias, sarcomas e câncer de mama. Seu uso clínico é limitado por cardiotoxicidade caracterizada por disfunção ventricular e insuficiência cardíaca, sendo essa a principal causa de mortalidade nos sobreviventes do câncer.

A toxicidade por antraciclinas é bastante variável, podendo ocorrer em até $50 \%$ dos pacientes, a depender de fatores de risco do paciente e relacionados às propriedades farmacológicas dos quimioterápicos, como dose cumulativa. Por exemplo, a doxorrubicina é associada a uma incidência de $5 \%$ de insuficiência cardíaca com dose cumulativa de até $400 \mathrm{mg} / \mathrm{m} 2$, mas essa incidência pode chegar a $50 \%$ se a dose cumulativa de doxorrubicina ultrapassar $700 \mathrm{mg} / \mathrm{m}^{2} .{ }^{27}$ Estudo recente com 2.625 pacientes em seguimento de 5 anos demonstrou incidência geral de cardiotoxicidade por antraciclinas em torno de $9 \%$, sendo que $98 \%$ dos casos ocorreram no primeiro ano e foram assintomáticos. ${ }^{24}$

A cardiotoxicidade pode ser aguda, precoce ou tardia, reversível ou irreversível. A toxicidade aguda é caracterizada pela presença de arritmia supraventricular, disfunção ventricular esquerda e alterações eletrocardiográficas, que surgem logo após a infusão da antraciclina em até $1 \%$ dos pacientes, sendo em geral reversível. A disfunção ventricular aguda pode ser um preditor de insuficiência cardíaca que poderá ocorrer de forma subaguda ou crônica. A cardiotoxicidade precoce surge no primeiro ano do tratamento, enquanto a tardia, anos após o tratamento (em média, 7 anos após término do tratamento). ${ }^{28}$

Não há preditores capazes de identificar se a toxicidade das antraciclinas será reversível ou irreversível. A elevação de biomarcadores e sua persistência podem identificar pacientes de alto risco para irreversibilidade..$^{29}$

A propensão para cardiotoxicidade varia com os diferentes regimes de tratamento, sendo a doxorrubicina a antraciclina mais comumente associada a disfunção ventricular. A cardiotoxicidade é dose-dependente, sendo a redução da dose cumulativa uma maneira de minimizá-la. Modificações na infusão, como prolongar sua duração, fracionar a dose e utilizar formulações lipossomais, têm potencial de prevenir cardiotoxicidade. ${ }^{24}$ Recente estudo experimental sugeriu que o pré-condicionamento isquêmico possa ser eficaz na prevenção da cardiotoxicidade. ${ }^{30}$

Estudos mecanísticos demonstram que a disfunção ventricular relacionada às antraciclinas está associada a: 1) lesão do retículo sarcoplasmático e das mitocôndrias; 2) modificação estrutural e funcional de miofibrilas; 3) perda total ou parcial da matriz intercalada com placas de colágeno no interstício; 4) modificação do acoplamento excitação-contração e do fluxo do cálcio; 5) apoptose; 6) alterações do metabolismo do ferro; e 7) perda da capacidade de regeneração do músculo cardíaco e de células endoteliais coronarianas. Consequentemente, há disfunção e hipertrofia dos miócitos remanescentes. ${ }^{31} \mathrm{O}$ gatilho comum desses eventos parece estar ligado ao estresse oxidativo causado pela produção de espécies reativas de oxigênio, além da inibição da topoisomerase $2 \beta$, resultando em dano às membranas, proteínas e DNA. Algumas observações dão consistência à importância do estresse oxidativo na cardiotoxicidade das antraciclinas: a) super expressão da metalotioneína, um antirradical livre, no coração de camundongo transgênico 
Tabela 3 - Agentes quimioterápicos associados à disfunção ventricular

\begin{tabular}{|c|c|}
\hline Agentes quimioterápicos & Incidência (\%) \\
\hline \multicolumn{2}{|l|}{ Antraciclinas (dose-dependente) } \\
\hline \multicolumn{2}{|l|}{ Doxorrubicina (Adriamicina) } \\
\hline $400 \mathrm{mg} / \mathrm{m}^{2}$ & $3-5$ \\
\hline $550 \mathrm{mg} / \mathrm{m}^{2}$ & $7-26$ \\
\hline $700 \mathrm{mg} / \mathrm{m}^{2}$ & $18-48$ \\
\hline Idarrubicina $>90 \mathrm{mg} / \mathrm{m}^{2}$ & $5-18$ \\
\hline Epirrubicina $>900 \mathrm{mg} / \mathrm{m}^{2}$ & $0,9-11,4$ \\
\hline Mitoxantrona $>120 \mathrm{mg} / \mathrm{m}^{2}$ & 2,6 \\
\hline Doxorrubicina lipossomal >900 mg/m² & 2 \\
\hline \multicolumn{2}{|l|}{ Agentes alquilantes } \\
\hline Ciclofosfamida & $7-28$ \\
\hline \multicolumn{2}{|l|}{ Ifosfamida } \\
\hline$<10 \mathrm{~g} / \mathrm{m}^{2}$ & 0,5 \\
\hline $12,5-16 \mathrm{~g} / \mathrm{m}^{2}$ & 17 \\
\hline \multicolumn{2}{|l|}{ Antimetabólitos } \\
\hline Clofarabina & 27 \\
\hline \multicolumn{2}{|l|}{ Agentes antimicrotúbulos } \\
\hline Docetaxel & $2,3-13$ \\
\hline Paclitaxel & $<1$ \\
\hline \multicolumn{2}{|l|}{ Terapias-alvo anti-HER2 } \\
\hline Trastuzumabe & $1,7-20,1$ \\
\hline Pertuzumabe & $0,7-1,2$ \\
\hline \multicolumn{2}{|l|}{ Anticorpo monoclonal } \\
\hline Bevacizumabe & $1,6-4$ \\
\hline \multicolumn{2}{|l|}{ Inibidores de tirosina quinase } \\
\hline Sunitinibe & $2,7-19$ \\
\hline Pazopanibe & $7-11$ \\
\hline Sorafenibe & $4-8$ \\
\hline Dasatinibe & $2-4$ \\
\hline Imatinibe & $0,2-2,7$ \\
\hline Lapatinibe & $0,2-1,5$ \\
\hline Nilotinibe & 1 \\
\hline \multicolumn{2}{|l|}{ Inibidores de proteassoma } \\
\hline Carfilzomibe & $11-25$ \\
\hline Bortezomibe & $2-5$ \\
\hline
\end{tabular}

HER2: receptor tipo 2 do fator de crescimento epidérmico humano. Adaptado de Zamorano et al. ${ }^{22}$

minimiza a injúria induzida pela doxorrubicina; b) a inibição da formação de peroxinitrito, um oxidante reativo produzido do óxido nítrico e do superóxido, melhora a função cardíaca de camundongos expostos a doxorrubicina; c) o probucol, um forte antioxidante, impede a redução em glutationa peroxidase e reduz a peroxidação lipídica miocárdica associada à doxorrubicina em modelo murino; d) o dexrazoxano é um quelante EDTA-like que pode impedir o dano por antraciclinas por meio da ligação com ferro, que é o cofator para os radicais livres. ${ }^{32}$ Disfunção diastólica por toxicidade cumulativa dose-dependente pode ser observada com dose cumulativa equivalente a $200 \mathrm{mg}$ $\mathrm{m}^{2}$, enquanto disfunção sistólica é observada usualmente com doses acima de $400 \mathrm{mg} / \mathrm{m}^{2}$, com variabilidade segundo limiar individual. Entretanto, prejuízo na função diastólica foi observado com dose cumulativa de apenas $120 \mathrm{mg} / \mathrm{m}^{2}$. $^{33}$

Fatores de risco associados com maior chance de toxicidade por antraciclinas estão apontados na Tabela 4. Dentre eles, destacam-se cardiopatia prévia, dose cumulativa 


\begin{tabular}{|c|c|c|c|}
\hline & Fatores de risco & \multicolumn{2}{|c|}{ Risco aumentado no caso de } \\
\hline & Idade & \multicolumn{2}{|c|}{$<18$ anos ou $>65$ anos } \\
\hline$>$ & sexo & \multicolumn{2}{|l|}{ Feminino } \\
\hline$>$ & Modo de administração & \multicolumn{2}{|l|}{ Injeção rápida } \\
\hline & \multirow{4}{*}{ Dose cumulativa } & Daunorrubicina & $550-800 \mathrm{mg} / \mathrm{m}^{2}$ \\
\hline & & Doxorrubicina & $\geq 250 \mathrm{mg} / \mathrm{m}^{2}$ \\
\hline & & Epirrubicina & $900-1000 \mathrm{mg} / \mathrm{m}^{2}$ \\
\hline & & Idarrubicina & $150-225 \mathrm{mg} / \mathrm{m}^{2}$ \\
\hline 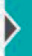 & Irradiação mediastinal & \multicolumn{2}{|c|}{ Irradiação mediastinal precoce ou concomitante } \\
\hline$>$ & Doenças cardiovasculares prévias & \multicolumn{2}{|c|}{$\begin{array}{l}\text { Miocardiopatia isquêmica e não isquêmica, } \\
\text { doença arterial coronária e hipertensão arteria }\end{array}$} \\
\hline 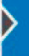 & Distúrbios eletrolíticos & \multicolumn{2}{|c|}{ Hipocalcemia, hipomagnesemia } \\
\hline$>$ & Fração de ejeção & \multicolumn{2}{|l|}{$<50 \%$} \\
\hline & Terapia concomitante & \multicolumn{2}{|c|}{$\begin{array}{l}\text { Trastuzumabe, agentes alquilantes, } \\
\text { inibidores de sinalização }\end{array}$} \\
\hline
\end{tabular}

e velocidade rápida de infusão do fármaco. Entretanto, na presença dos mesmos fatores de risco, nota-se importante variabilidade entre os pacientes em relação à ocorrência de cardiotoxicidade, possivelmente relacionada a fatores genéticos e a interações com outros fatores desconhecidos.

Polimorfismos nos genes transportadores de cassetes de ligação de ATP (ABC) são associados a cardiomiopatia da antraciclina. Tais transportadores são importantes na resistência às drogas via efluxo celular, incluindo antraciclinas. Atividade reduzida pode levar ao acúmulo intracelular de antraciclina e toxicidade celular. Variantes nessa família de genes replicados nas coortes de cânceres pediátricos incluem ABCC5 (A-1629T, rs7627754), associado à redução substancial na FEVE em sobreviventes homozigóticos para o alelo T. ${ }^{34}$ Além disso, uma variante na metiltransferase de histamina (HNMT, rs17583889) confere risco em pacientes jovens expostos às antraciclinas. ${ }^{35}$ Na Tabela 5, estão descritas as variantes farmacogenéticas que predispõem à cardiotoxicidade relacionada às antraciclinas.

Durante o tratamento com antraciclinas, monitoramento clínico e ecocardiográfico é recomendado em periodicidade pré-estabelecida ou fora do protocolo, se surgirem sinais e sintomas de insuficiência cardíaca. ${ }^{21}$ Idealmente, o ecocardiograma deve incluir análise de função sistólica biventricular e avaliação da função diastólica (I, A) (Figura 4).

\subsection{Terapias-alvo Anti-HER2}

O trastuzumabe é um anticorpo monoclonal cujo alvo é o receptor 2 do fator de crescimento epidérmico humano (HER2 ou ErbB2). Para os 15-20\% de pacientes com câncer de mama cujos tumores super expressam o HER2, a terapia com trastuzumabe reduz de maneira significativa a mortalidade. ${ }^{36,37}$ Seu uso está associado a um risco considerável de cardiotoxicidade, clinicamente manifestada por um declínio assintomático da FEVE e, mais incomumente, pela ocorrência de insuficiência cardíaca sintomática. ${ }^{38}$ Após a introdução do trastuzumabe, três outros agentes anti-HER2 foram desenvolvidos: lapatinibe, um inibidor de tirosina quinase do fator de crescimento epidérmico (EGFR), ERBB1 e HER2; ado-trastuzumabe entansina (T-DM1), um anticorpo conjugado composto por trastuzumabe, um ligante tioéster e um derivado antimitótico de maitansina; e pertuzumabe, um anticorpo monoclonal que se liga ao subdomínio Il do domínio extracelular HER2 e previne a homo- e a heterodimerização do HER2 com outros receptores HER. Embora os dados ainda sejam escassos sobre esses novos fármacos, a evidência até o momento é que o T-DM1 e o pertuzumabe sejam menos cardiotóxicos que o trastuzumabe. ${ }^{39}$

A taxa de declínio da FEVE consequente ao uso do trastuzumabe é variável na literatura. Estudos mais recentes 
Tabela 5 - Variantes farmacogenéticas associadas à cardiotoxicidade das antraciclinas

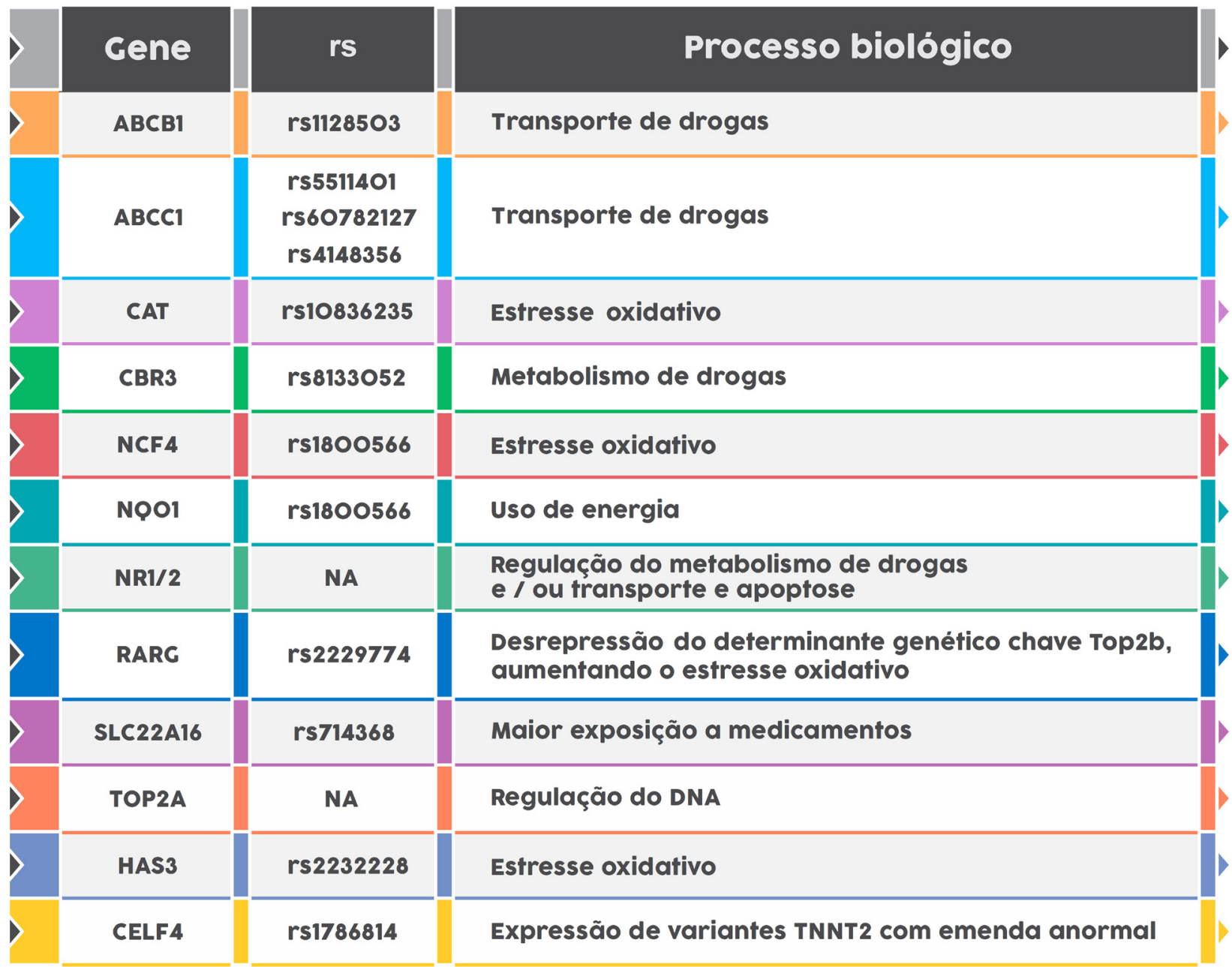

apontam para taxas entre 15\% e 40\% de ocorrência de redução de pelo menos $10 \%$ na FEVE relacionada ao uso do trastuzumabe e, em $18 \%$ dos pacientes, a FEVE cai para menos de 53\%. ${ }^{40,41}$ A ocorrência de insuficiência cardíaca sintomática é relatada em $0,6 \%$ a $8,7 \%$ dos pacientes. ${ }^{40}$

Uma das características da toxicidade dos agentes antiHER2 que diferem da cardiotoxicidade das antraciclinas é sua reversibilidade na maioria dos casos. Os determinantes da reversibilidade são a função cardiovascular prévia e a extensão do declínio da FEVE relacionado ao tratamento. Estudo recente demonstrou que todos os declínios de FEVE menores de $10 \%$ foram reversíveis. Porém, em casos de quedas da FEVE maiores que $10 \%$, a reversibilidade foi observada em 91\% dos pacientes com função cardiovascular basal normal e em apenas 71,4\% daqueles com FEVE reduzida previamente à exposição. ${ }^{42}$ Estudos apontam que, mesmo na presença de cardiotoxicidade, $70 \%$ a $80 \%$ dos pacientes continuam recebendo trastuzumabe e que o subgrupo que apresenta maior chance de toxicidade e mortalidade cardiovascular relacionada ao tratamento é formado por pacientes com FEVE reduzida previamente. ${ }^{43}$
A disfunção ventricular e a insuficiência cardíaca clinicamente manifesta induzidas pelo trastuzumabe são geralmente reversíveis após a interrupção da quimioterapia e/ou após início do tratamento da insuficiência cardíaca. Os mecanismos de cardiotoxicidade induzida pela terapia anti-HER2 incluem alterações estruturais e funcionais nas proteínas contráteis e nas mitocôndrias, mas raramente levam à morte celular, explicando a potencial reversibilidade. A interrupção do tratamento com trastuzumabe está associada a aumento da recorrência do câncer, sendo a cardiotoxicidade a maior responsável pela suspensão do fármaco. ${ }^{44}$

Na Tabela 6, citam-se os fatores de risco para cardiotoxicidade da terapia anti-HER2.

Durante o tratamento com trastuzumabe, recomenda-se monitoramento clínico e ecocardiográfico, respeitando-se a periodicidade ou se surgirem sinais e sintomas de insuficiência cardíaca (I, A) (Figura 5).

\subsection{Inibidores VEGF}

A inibição das vias de sinalização VEGF beneficia milhares de pacientes com câncer, mas alguns dos quimioterápicos 


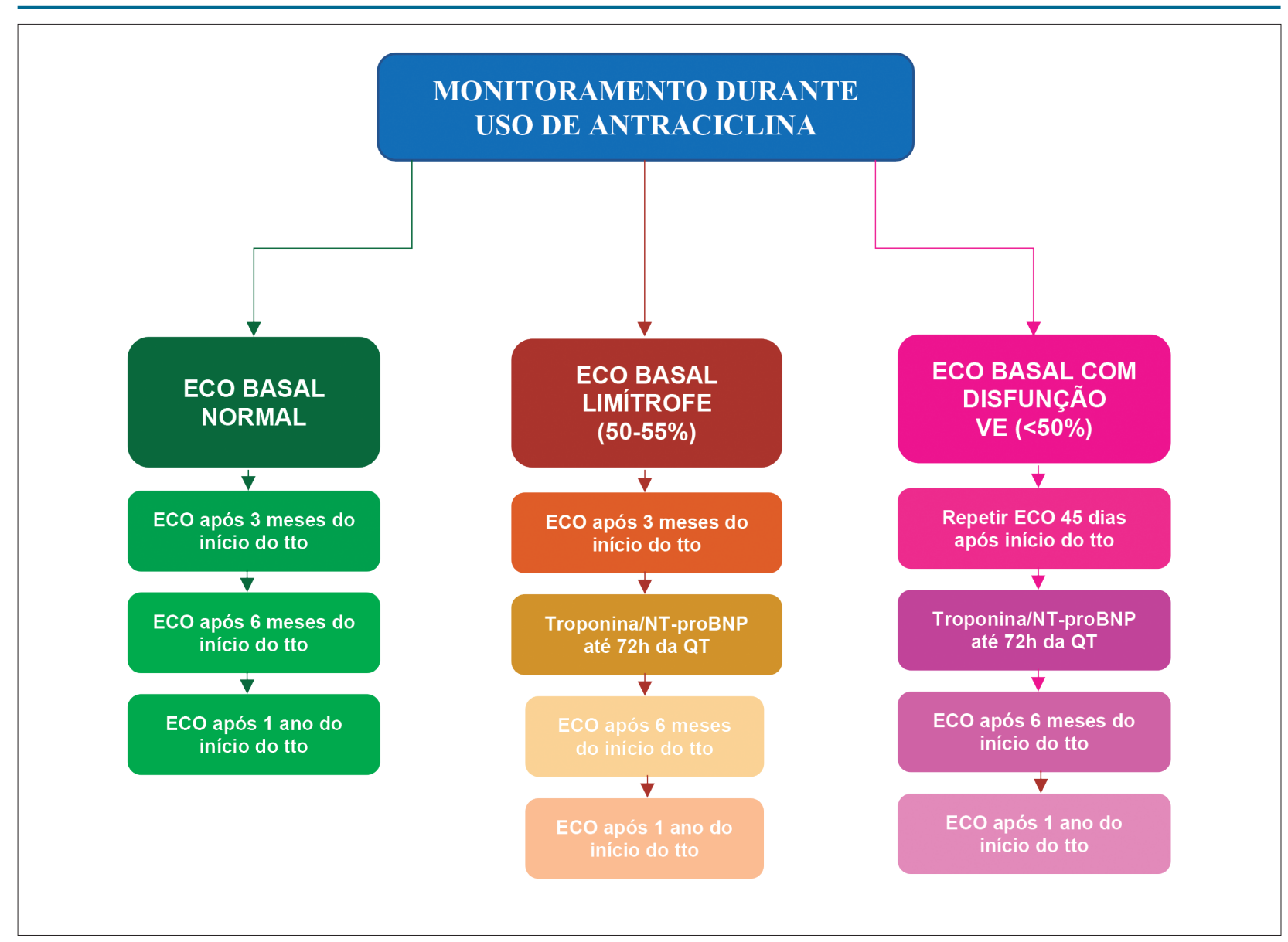

Figura 4 - Monitoramento ecocardiográfico e análise de biomarcadores em pacientes em uso de antraciclinas. ECO: ecocardiograma; NT-proBNP: fragmento N-terminal do peptídeo natriurético tipo B; QT: quimioterapia; tto: tratamento.

Tabela 6 - Terapia anti-HER2 e fatores de risco de cardiotoxicidade.

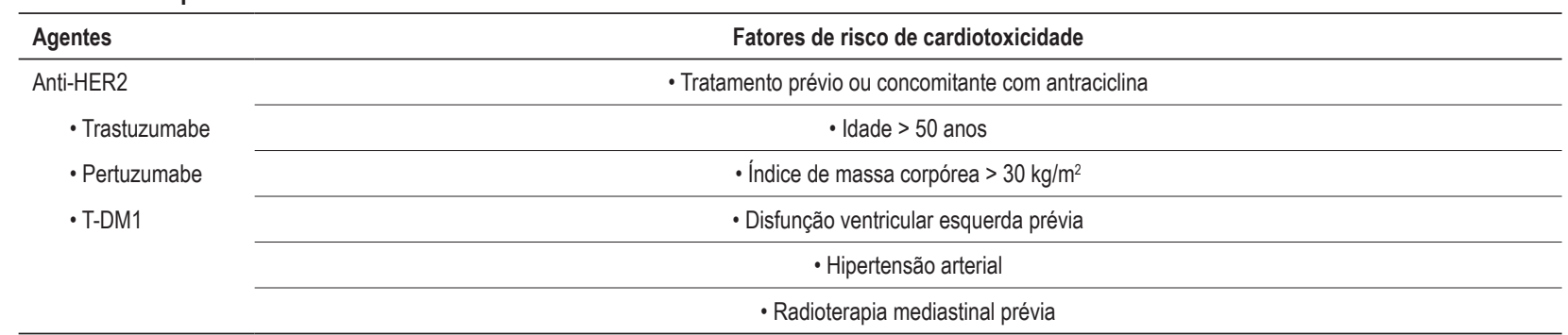

HER2: receptor tipo 2 do fator de crescimento epidérmico humano; T-DM1: ado-trastuzumabe entansina.

dessa classe estão ligados a risco de cardiotoxicidade, que pode ser reversível ou irreversível, particularmente quando associados a tratamento concomitante ou prévio com outros quimioterápicos. ${ }^{45-47}$

Os pacientes tratados com bevacizumabe apresentam risco de 4,74 (IC 95\%: 1,6-11,18, p = 0,001) de desenvolverem quadros de insuficiência cardíaca congestiva quando comparados ao grupo placebo. ${ }^{45}$ Fármacos como sunitinibe, pazopanibe e axitinibe também têm sido relacionados ao desenvolvimento de disfunção ventricular.
Uma meta-análise incluindo um total de 10.553 pacientes observou uma incidência de insuficiência cardíaca congestiva de 3,2\% (IC 95\%: 1,8\% - 5,8\%) com o uso de inibidor de tirosina quinase VEGF. ${ }^{47}$

Hipertensão arterial sistêmica (HAS) é complicação comum dessa classe de quimioterápicos e estudos sugerem que o tratamento adequado da HAS possa reduzir o risco de insuficiência cardíaca. ${ }^{48} \mathrm{O}$ prognóstico de pacientes que desenvolvem cardiotoxicidade associada aos inibidores VEGF é difícil de analisar, pois os candidatos a esses fármacos 


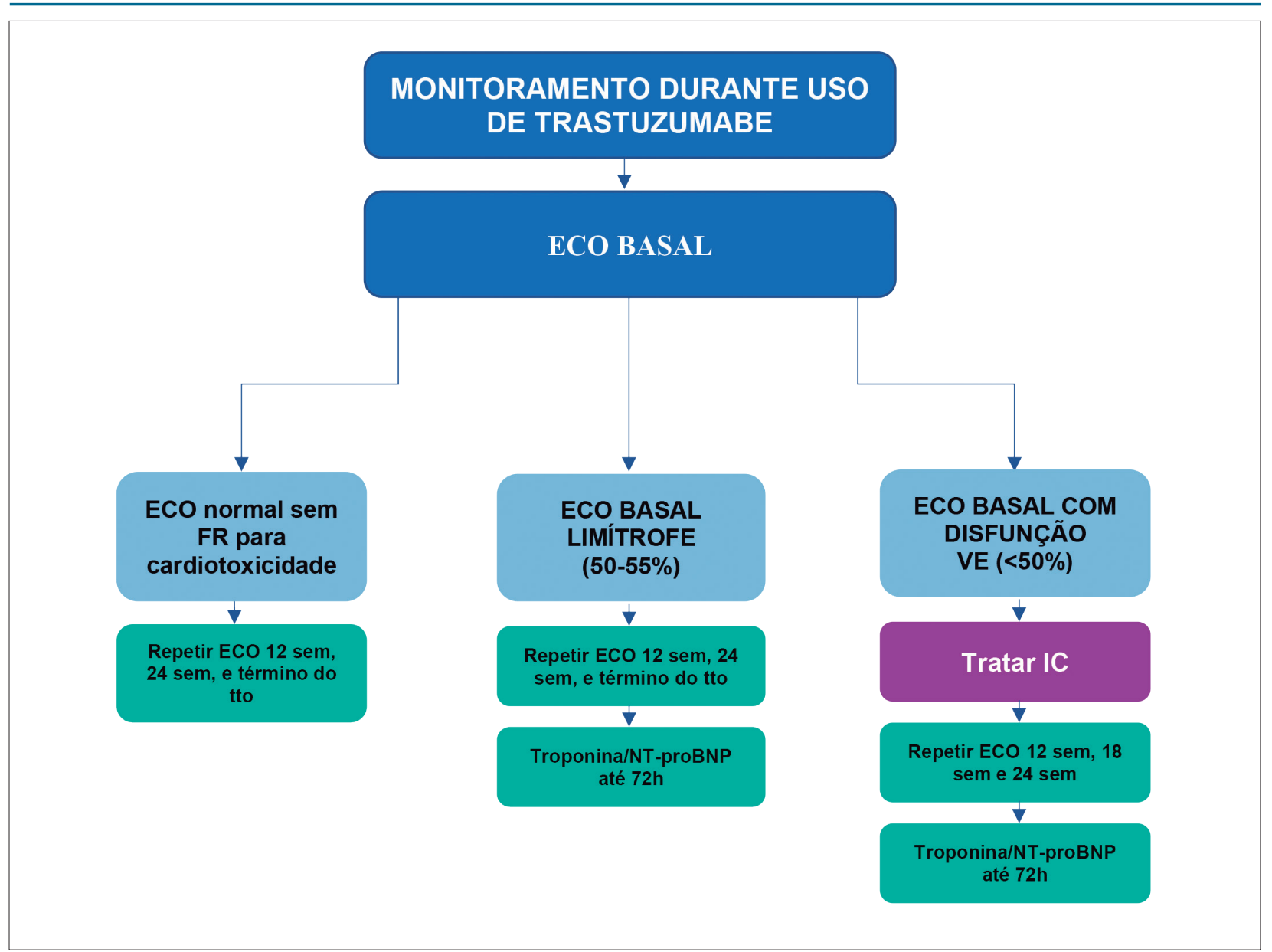

Figura 5 - Monitoramento ecocardiográfico e análise de biomarcadores em pacientes em uso de fármacos anti-HER2. ECO: ecocardiograma; FR: fatores de risco; IC: insuficiência cardíaca; sem: semanas; tto: tratamento; VE: ventricular esquerda.

geralmente apresentam doença metastática e expectativa de vida reduzida. A maioria dos casos é reversível com o tratamento da disfunção ventricular. Os fatores de risco para cardiotoxicidade estão descritos na Tabela 7.

\subsubsection{Inibidores Tirosina Quinase BCR-ABL}

Fármacos como os inibidores de tirosina quinase BCRABL modificaram o prognóstico de pacientes com leucemia mieloide crônica e tumores estromais gastrointestinais. Não há confirmação de cardiotoxicidade envolvendo imatinibe, porém nilotinibe e ponatinibe podem estar associados à cardiotoxicidade do tipo insuficiência cardíaca, HAS, arritmias e tromboembolismo. ${ }^{49}$

\subsection{Terapias para Mieloma Múltiplo}

Os inibidores de proteassoma são drogas relativamente novas no tratamento do mieloma múltiplo. Bortezomibe e carfilzomibe são os fármacos dessa classe e podem causar disfunção cardiovascular. Os proteassomas são complexos proteicos responsáveis por degradar proteínas disfuncionais e, além disso, essenciais para a sobrevivência do cardiomiócito. A incidência de insuficiência cardíaca com bortezomibe é de
$4 \%$ e pode ser agravada pelo uso de esteroides. ${ }^{50}$ Carfilzomibe é um inibidor irreversível e o mais potente dos proteassomas, podendo causar insuficiência cardíaca em até 25\% dos pacientes. ${ }^{51,52}$

\subsection{Inibidores BRAF e MEK}

A combinação da terapia com inibidores BRAF e MEK é, no momento, a primeira escolha no melanoma metastático com a mutação BRAF, apresentando significativa melhora na sobrevida dos pacientes. Atualmente, 3 inibidores BRAF (dabrafenibe, vemurafenibe e encorafenibe) e 3 inibidores MEK (trametinibe, cobimetinibe e binimetinibe) estão aprovados para o tratamento do melanoma. ${ }^{53-55}$

Efeitos adversos cardiovasculares associados a esses inibidores têm sido relatados em vários estudos, especialmente redução na FEVE (5-11\%), HAS (10-15\%) e prolongamento do intervalo QT. ${ }^{56,57} \mathrm{~A}$ inibição do BRAF e do MEK interfere com a sinalização cardiovascular MAPK, resultando em estresse oxidativo, apoptose de miócito e inibição de angiogênese. ${ }^{56,57}$

Em meta-análise recente que inclui 5 estudos clínicos randomizados e 2.317 pacientes com melanoma em uso dos inibidores BRAF e MEK, demonstrou-se que o tratamento 


\begin{tabular}{ll}
$\begin{array}{l}\text { Tabela } 7 \text { - Terapia com inibidores VEGF e fatores de risco de } \\
\text { cardiotoxicidade }\end{array}$ \\
\hline Inibidores VEGF & IC pré-existente, doença coronária, doença \\
\hline Anticorpos & valvar, cardiopatia isquêmica \\
- Bevacizumabe & Uso prévio de antraciclina \\
- Ramucirumabe & \\
\hline $\begin{array}{l}\text { Inibidores tirosina quinase } \\
\text { - Sunitinibe }\end{array}$ & \\
- Pazopanibe & Hipertensão arterial \\
- Axitinibe & \\
- Neratinibe & Doença cardíaca pré-existente \\
- Afatinibe & \\
- Sorafenibe & \\
- Desatinibe & \\
\hline
\end{tabular}

IC: insuficiência cardiaca.

concomitante com esses inibidores está associado a risco aumentado de embolia pulmonar $(4,4 x)$, queda na FEVE $(3,72 x)$ e HAS $(1,5 x)$. Não houve aumento da ocorrência de arritmias, infarto e prolongamento do QT. Maior risco de insuficiência cardíaca foi detectado em pacientes com idade inferior a 55 anos. ${ }^{58}$

\subsection{Taxanos}

O paclitaxel e o docetaxel são usados no tratamento de várias neoplasias sólidas. Cardiotoxicidade é fenômeno pouco frequente nesse grupo, com ocorrência de 12 por 100 (RR: 0,9 [0,53 -1,54]). ${ }^{59} \mathrm{O}$ docetaxel, em particular, parece estar associado a aumento da ocorrência de disfunção ventricular. Alguns relatos sugerem que os taxanos devem ser evitados em pacientes com disfunção ventricular prévia, com os mesmos critérios de não utilização de antraciclinas. Há relatos de que os taxanos causam bradicardia sinusal, bloqueios atrioventriculares, taquicardia ventricular e extrassístoles ventriculares. Porém, como os taxanos são usados em combinação com antraciclinas, é desafiador afirmar seu potencial de cardiotoxicidade. ${ }^{36,60}$

\subsection{Inibidores de Checkpoint Imunológicos}

Os ICls revolucionaram o tratamento do câncer. Esses imunoterápicos atuam modulando o sistema imunológico, inibindo a apoptose dos linfócitos T, gerando restauração da resposta celular antitumoral. Sua ação anti-apoptótica dá-se por inibição do CTLA-4 (ipilimumabe), do PD-1 (nivolumabe, pembrolizumabe) e do PDL-1 (atezolizumabe, durvalumabe, avelumabe) $^{61}$ (Figura 6).

A cardiotoxicidade dos $\mathrm{ICls}$ pode ser agrupada em duas categorias: efeitos adversos inflamatórios (miocardite, pericardite e vasculite) e toxicidade cardiovascular não inflamatória (síndrome Takotsubo-like, disfunção ventricular assintomática não inflamatória e arritmias). A maioria dos casos relatados é grave, com taxas de mortalidade de $50 \%$ na miocardite, $21 \%$ na doença pericárdica e $6 \%$ na vasculite. ${ }^{62}$ As principais causas de mortalidade da miocardite são arritmias e choque cardiogênico. ${ }^{62-64}$

Os eventos adversos ocorrem normalmente após a primeira ou segunda dose dos $\mathrm{ICls}$, mas há relatos esporádicos de eventos cardiovasculares até 32 semanas após o tratamento. A prevalência de envolvimento cardiovascular é maior em pacientes com terapia combinada, sexo feminino e idade acima de 75 anos. A prevalência de miocardite varia entre $0,06 \%$ e $0,3 \% .{ }^{62,63}$

Para pacientes que desenvolvem novos sintomas cardiovasculares durante ou logo após o tratamento com os ICls ou que apresentam arritmia, anormalidade do sistema de condução ou disfunção ventricular ao ecocardiograma, recomenda-se iniciar investigação cardiovascular com dosagem de biomarcadores (troponina, NT-proBNP e proteína $C$ reativa), ECG, painel viral, ecocardiograma com strain e RMC para confirmação diagnóstica e exclusão de miocardite viral (Ila, C).

Biópsia endomiocárdica deve ser considerada quando há suspeição diagnóstica mesmo com investigação inicial negativa (Ila, C).

\section{Radioterapia}

A incidência atual de cardiotoxicidade induzida por radiação é difícil de ser estimada devido a algumas razões, como longo intervalo entre a exposição e a manifestação clínica de cardiotoxicidade, uso de quimioterapia cardiotóxica concomitante e melhoria progressiva nas técnicas de radiação nos últimos anos, com redução da incidência de lesão estrutural cardíaca. Os estudos apontam risco relativo de eventos cardiovasculares fatais em $2,2 \%$ a $12,7 \%$ de sobreviventes de linfoma e em $1 \%$ a 2,2\% de pacientes com câncer de mama. ${ }^{65,66}$ Entre os sobreviventes expostos a radioterapia, o risco de disfunção ventricular aumenta 4,9 vezes. ${ }^{66} \mathrm{Na}$ neoplasia de mama, é mais frequente cardiotoxicidade relacionada a radioterapia em pacientes com lesão em hemitórax esquerdo ${ }^{67} \mathrm{e}$ naquelas em uso concomitante de antraciclinas. A lesão induzida pela radioterapia pode afetar o músculo cardíaco, as válvulas, o pericárdio, as coronárias e o sistema de condução, ${ }^{68}$ podendo ser diagnosticada 10 a 15 anos após a radioterapia.

\section{Prevenção e Tratamento da Cardiotoxicidade}

a) A prevenção da cardiotoxicidade deve ser realizada em todos os pacientes com câncer, com o reconhecimento dos fatores de risco cardiovasculares desde a consulta inicial, sendo recomendadas as seguintes medidas: cessação de tabagismo, cessação do alcoolismo, implementação de dieta regular visando à manutenção do peso adequado (índice de massa corpórea entre 18 e $24 \mathrm{~kg} / \mathrm{m}^{2}$ ), prática de exercícios físicos (atividade física aeróbica moderada por 30 minutos por dia por pelo menos 5 vezes na semana), controle da HAS, tratamento do diabetes e da dislipidemia (I, B).

b) Os fármacos de escolha para o tratamento da HAS são os inibidores da enzima conversora de angiotensina (IECA) ou os antagonistas do receptor da angiotensina (AT1). As estatinas são recomendadas no tratamento da dislipidemia, com o objetivo de manter níveis de LDL abaixo de 100 $\mathrm{mg} / \mathrm{dl}$. O tratamento do diabetes tem como fármaco de 


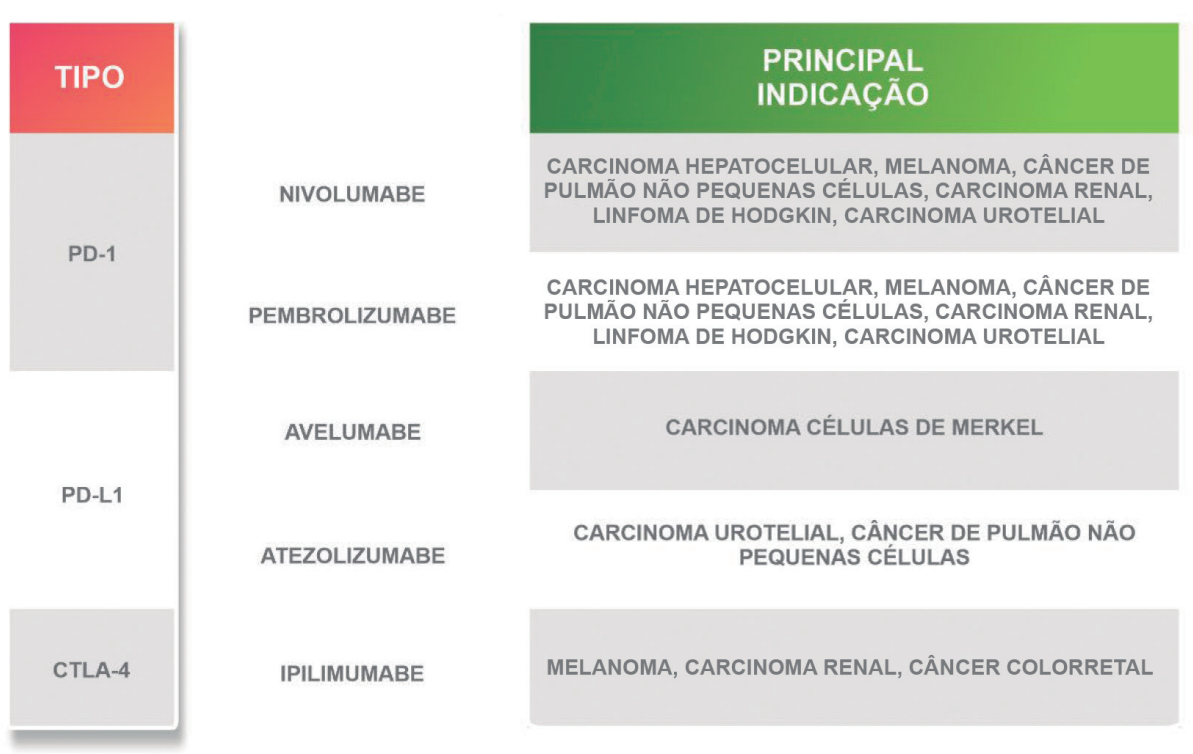

\section{CARDIOTOXICIDADE}

\section{ABORDAGEM}

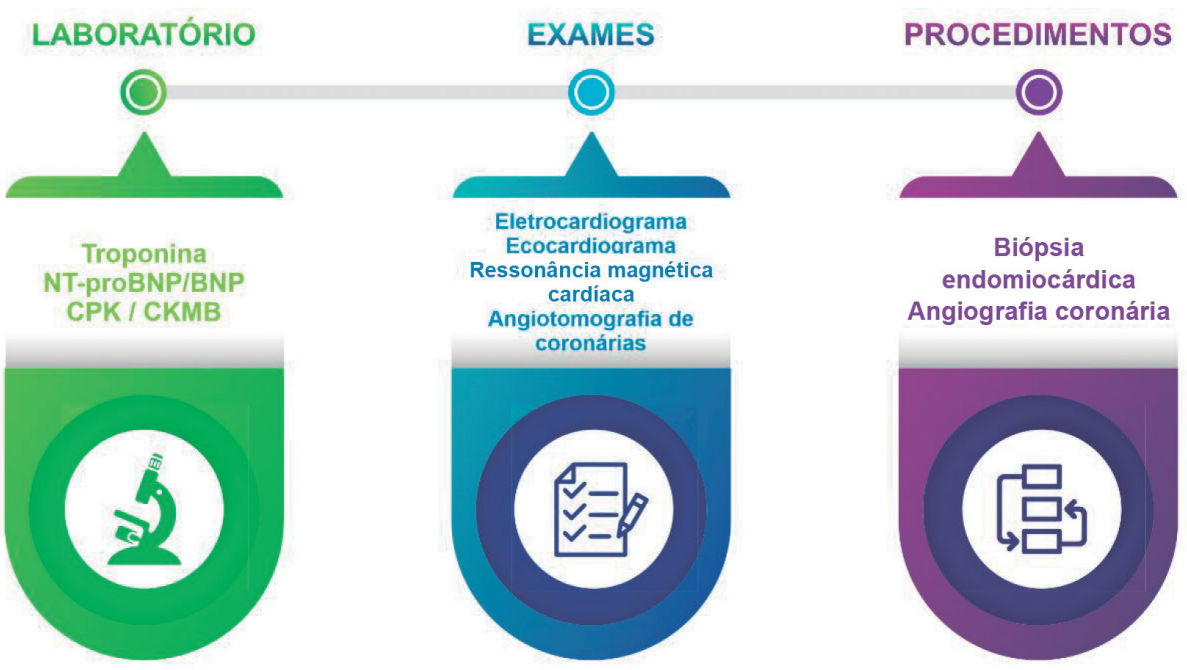

Figura 6 - Principais inibidores de checkpoint imunológicos relacionados a toxicidade cardíaca e sua abordagem.

escolha a metformina e, em casos de insuficiência cardíaca associada, devem-se utilizar os inibidores do SGLT2 (empaglifozina, dapaglifozina, canaglifozina) e, em casos de doença coronariana, dar preferência aos agonistas do GLP-1 (liraglutida, dulaglutida e semaglutida) (Ila, C).

c) Na avaliação da proposta terapêutica, devem ser reconhecidos os fatores de risco para cardiotoxicidade e implementadas as medidas específicas de acordo com o regime (Ila, C). d) Para pacientes com detecção de cardiotoxicidade subclínica (elevação de troponina ou redução no SLG absoluta $\geq 5 \%$ ou relativa $\geq 15 \%$ ):

- o uso de IECA ou de AT1 ou de betabloqueador pode ser considerado com o objetivo de prevenir disfunção ventricular e eventos cardiovasculares (Ila, B);

- repetir ecocardiografia com strain a cada 3 meses e dosagem de biomarcadores a cada ciclo, se assintomático, ou a qualquer momento, se surgirem sintomas (Ila, C); 


\section{Diretriz}

- quimioterapia não deve ser suspensa com base em alterações no strain e em biomarcadores (Ila, C);

- considere encaminhar o paciente para o cardiooncologista (Ila, C);

- considere excluir doença isquêmica do coração (Ila, C);

- considere iniciar dexrazoxano em pacientes que serão submetidos a doses altas de antraciclinas e com risco elevado de cardiotoxicidade (Ila, B).

e) Em pacientes com FEVE $\leq 50 \%$ e $\geq 40 \%$, terapia com IECA/AT1 e betabloqueador é recomendada antes do tratamento cardiotóxico (I, A).

f) Pacientes com FEVE $\leq 40 \%$ não devem receber terapia com antraciclina a menos que não haja opções eficazes de tratamento (Ila, A). g) Pacientes em uso de quimioterapia ou imunoterapia que desenvolvem insuficiência cardíaca e FEVE $<40 \%$, durante o tratamento, devem ter o tratamento antineoplásico suspenso temporariamente de acordo com discussão entre o cardiologista e o oncologista, e terapia para insuficiência cardíaca deve ser iniciada de acordo com as diretrizes e consensos (I, A).

h) Pacientes em uso de fármacos com potencial de cardiotoxicidade que apresentarem sinais ou sintomas de insuficiência cardíaca, devem ser encaminhados ao cardio-oncologista para avaliação clínica, realização de ecocardiograma e dosagem de biomarcadores (Ila, C).

i) As Figuras 7 e 8 apresentam os algoritmos de manejo da disfunção ventricular por antraciclinas e anti-HER2 que devem ser considerados (IIa, B).

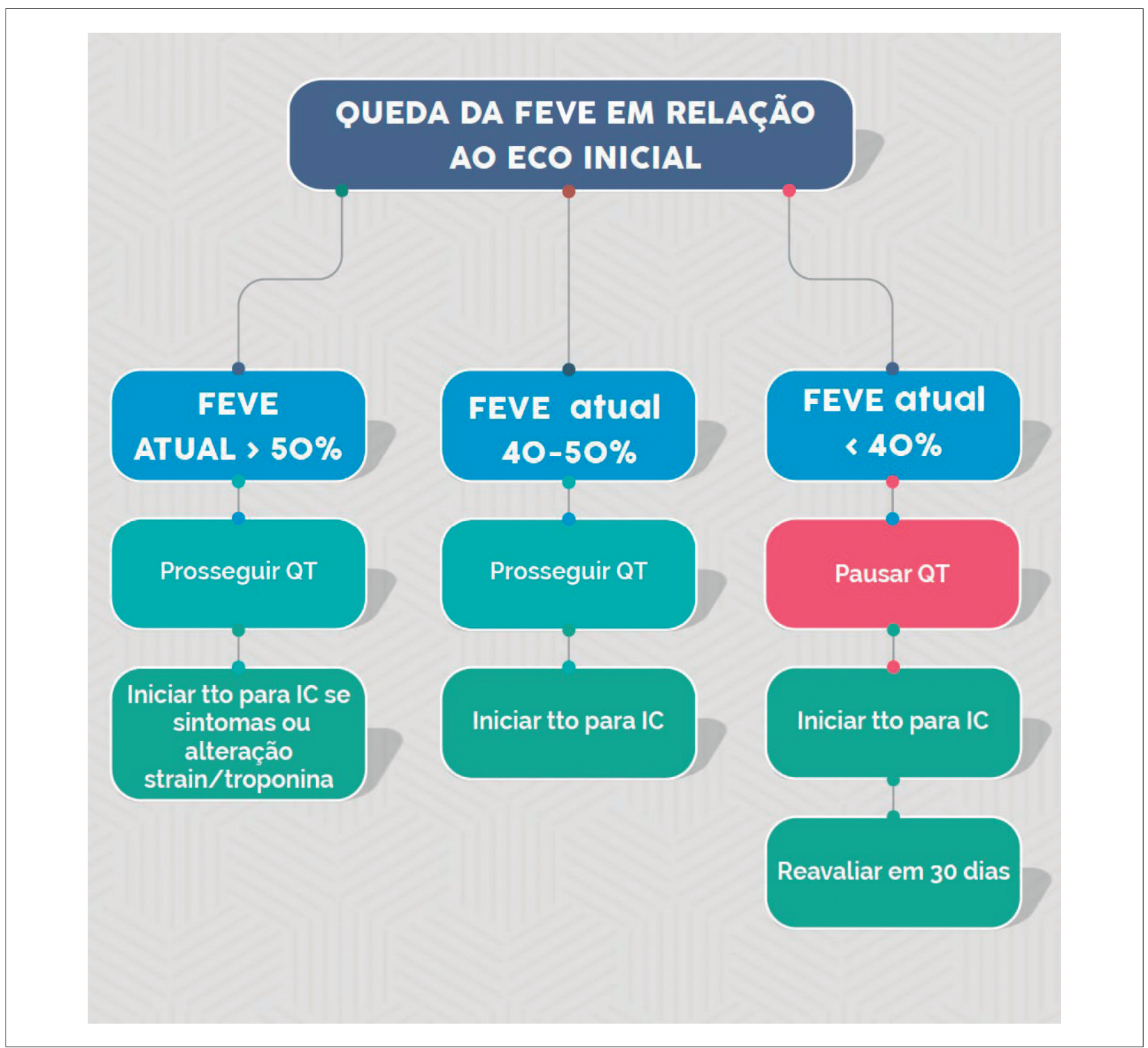

Figura 7 - Algoritmo de manejo da insuficiência cardíaca e disfunção ventricular por antraciclinas. ECO: ecocardiograma; FEVE: fração de ejeção do ventrículo esquerdo; QT: quimioterapia; IC: insuficiência cardíaca; tto: tratamento. 


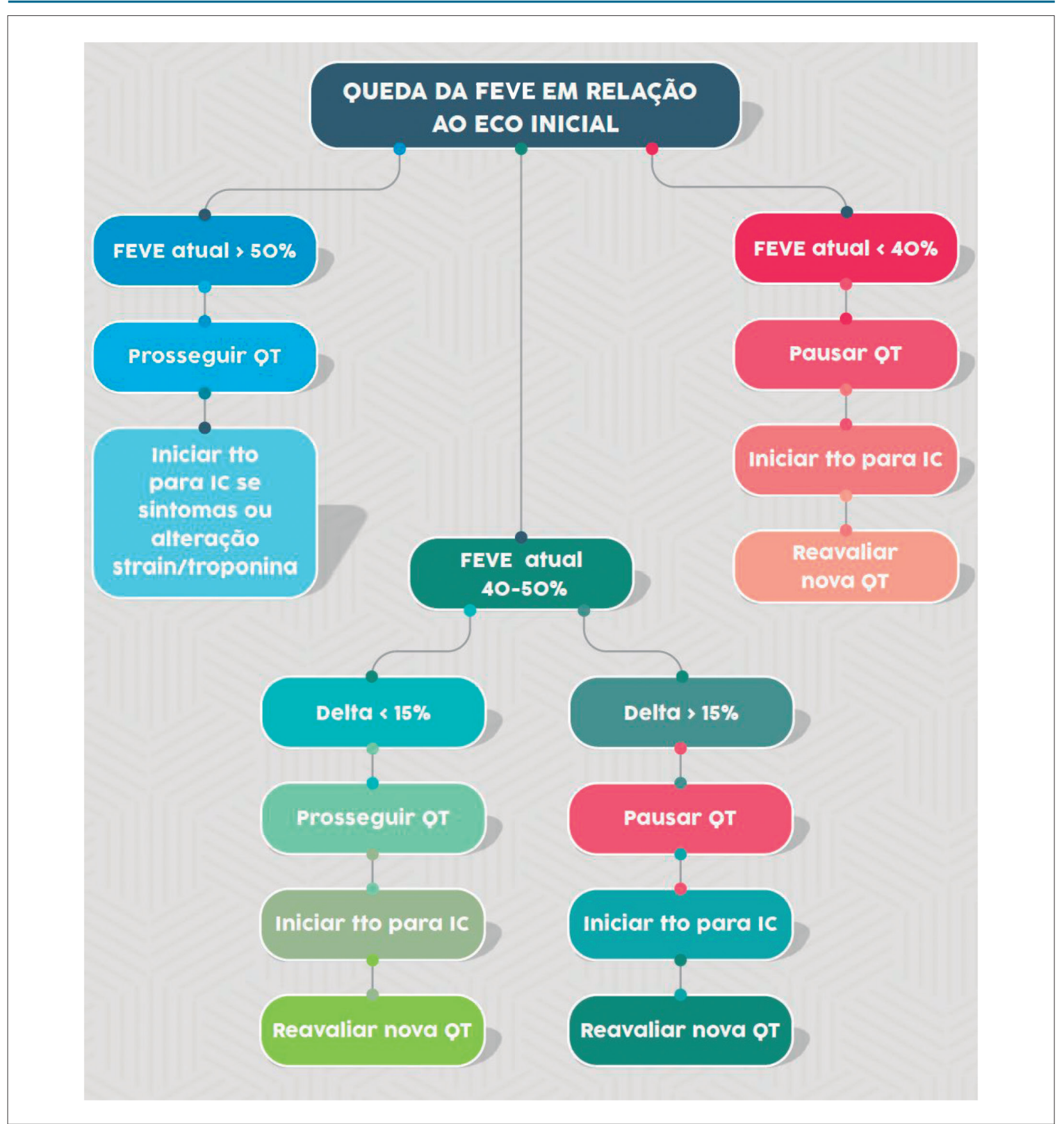

Figura 8 - Algoritmo de manejo da insuficiência cardiaca e da disfunção ventricular por terapia anti-HER2. ECO: ecocardiograma; FEVE: fração de ejeção do ventrículo esquerdo; IC: insuficiência cardíaca; QT: quimioterapia; tto: tratamento.

j) Em pacientes com cardiotoxicidade por trastuzumabe, após a estabilização dos sintomas e a recuperação da FEVE para acima de $40 \%$, a reintrodução do trastuzumabe deve ser considerada, desde que o paciente esteja sendo acompanhado pelo cardio-oncologista, com avaliação seriada por ecocardiografia e biomarcadores (Ila, B).

k) Em pacientes com cardiotoxicidade por trastuzumabe, não havendo melhora dos sintomas e persistindo FEVE abaixo de $40 \%$, a reintrodução do trastuzumabe só deve ser considerada se não houver alternativa terapêutica após ampla discussão com oncologista (lla, C).

I) Em pacientes em uso de sunitinibe ou outro fármaco anti-VEGF, avaliação e controle adequado da HAS são recomendados (Ila, C).

m) Em pacientes em uso de terapia com anticorpos monoclonais ou inibidores de tirosina quinase com ação anti-VEGF (bevacizumabe, sunitinibe, sorafenibe, axitinibe e pazopanibe), o maior risco de insuficiência cardíaca ocorre 
no início da terapia. Na presença de sinais e sintomas, devese investigar o paciente com ecocardiograma e dosagem de biomarcadores (Ila, B). Recomendam-se consultar o cardiooncologista, iniciar tratamento para insuficiência cardíaca e suspender o fármaco em discussão com oncologista (Ila, C). Após recuperação do quadro clínico e da FEVE, considera-se reiniciar a quimioterapia (Ila, C).

n) Em pacientes com insuficiência cardíaca ou com disfunção ventricular, tratamento medicamentoso deve ser instituído de acordo com as diretrizes (I, A).

o) A indicação de dispositivo de assistência circulatória e de transplante cardíaco segue as recomendações da Diretriz Brasileira de Insuficiência Cardíaca Aguda e Crônica, devendo-se discutir com o oncologista, antes da indicação, o status do paciente e o prognóstico oncológico, levando-se sempre em consideração as preferências do paciente.

p) A indicação de transplante cardíaco para pacientes com câncer segue as recomendações da Diretriz Brasileira de Insuficiência Cardíaca Aguda e Crônica (Tabela 8). Porém, devem ser considerados para transplante apenas os pacientes com insuficiência cardíaca aguda ou crônica que atendam aos critérios de remissão ou cura do câncer por um período maior que 3 anos (Ila, C).

q) Havendo suspeita ou confirmação de miocardite por ICls, a terapia com ICls deve ser interrompida e corticosteroide iniciado imediatamente (metilprednisolona, 1g intravenoso por dia, por 3 a 5 dias, seguida de prednisona, $1-2 \mathrm{mg} / \mathrm{kg} /$ dia). O corticosteroide deve ser continuado até a resolução dos sintomas e a normalização da troponina, da função sistólica e das anormalidades de condução (Ila, C). Em casos de pericardite, recomenda-se a utilização de corticosteroide oral (Ila, C). Na síndrome de Takotsubo, pode-se considerar a pulsoterapia (Ila, C) e, na cardiomiopatia dilatada, o tratamento é de suporte (Tabela 9).

r) Em pacientes com miocardite refratária ou em situações graves com choque cardiogênico, outras terapias imunossupressoras como globulina antitimócito, infliximabe (exceto em pacientes com insuficiência cardíaca), micofenolato mofetil, ciclofosfamida ou abatacepte devem ser considerados (Ila, C).

s) Para pacientes com taquiarritmia ou bradiarritmia por ICls, terapia apropriada medicamentosa e marca-passo devem ser considerados de acordo com as características clínicas (Ila, C). t) A terapia com ICls deve ser descontinuada nos casos de miocardite. A decisão de reiniciar a terapia deve ser individualizada, de acordo com o status do câncer, resposta ao tratamento, gravidade da cardiotoxicidade, analisando riscos e benefícios. Se o tratamento com ICls for reiniciado, recomendam-se monoterapia com uma droga anti-PD1 e vigilância cardiovascular (Ila,C).

u) Considerar o uso do dexrazoxano em pacientes com câncer de mama metastático com dose planejada elevada de antraciclina (doxorrubicina acima de $250 \mathrm{mg} / \mathrm{m}^{2}$ ) (I, A) e em pacientes com sarcoma e pacientes pediátricos com linfoma/ leucemia (Ila, A).

\section{Tromboembolismo Arterial e Venoso}

A doença tromboembólica é afecção comum no paciente com câncer, sendo considerada a segunda causa de mortalidade nessa população.

\subsection{Trombose Venosa}

O tromboembolismo venoso (TEV) inclui a trombose venosa profunda (TVP) e o tromboembolismo pulmonar (TEP). É uma grave complicação em pacientes com câncer, nos quais é a segunda causa de óbito. As neoplasias são associadas ao aumento do risco e da gravidade e à recorrência da trombose, além de resultar em taxas maiores de complicações relacionadas ao tratamento. Ademais, o paciente com neoplasia tem uma chance 2 a 9 vezes maior de recorrência de eventos tromboembólicos. ${ }^{70-72}$

O câncer induz um estado pró-trombótico devido à sua produção de micropartículas trombogênicas, à ativação plaquetária, às suas propriedades antifibrinolíticas e à produção de trombina. Além disso, a trombogênese é potencializada por fatores relacionados ao tipo de câncer, ao status da doença, ao uso de drogas concomitantes, ${ }^{73}$ como agentes eritroestimulantes, à presença de anemia e leucocitose, à obesidade e ao fenótipo laboratorial trombogênico, como presença de altos níveis de dímero $\mathrm{D}$ e de fragmento $1+2 \mathrm{da}$ protrombina. $^{74}$

Nos últimos 5 anos, alguns ensaios clínicos foram publicados especificamente na população oncológica, permitindo ampliar o arsenal terapêutico desses pacientes (Tabela 10). ${ }^{75,76}$

As recomendações para o manejo do TEV no paciente com câncer são:

Tabela 8 - Recomendações para transplante cardíaco. Comitê Coordenador da Diretriz de Insuficiência Cardíaca. Diretriz Brasileira de Insuficiência Cardíaca Crônica e Aguda ${ }^{69}$

\begin{tabular}{|c|c|c|}
\hline Recomendação & Classe & Nível de evidência \\
\hline $\begin{array}{l}\text { Em pacientes com insuficiência cardíaca aguda e/ou choque cardiogênico com baixo potencial de } \\
\text { recuperação, sugere-se que a avaliação da candidatura ao transplante seja iniciada precocemente } \\
\text { e que seja o mais completa possível, incluindo avaliação psicossocial, mesmo que com dificuldades } \\
\text { inerentes ao quadro agudo. }\end{array}$ & 1 & C \\
\hline $\begin{array}{l}\text { Em pacientes com choque cardiogênico refratário e sem recuperação adequada da função } \\
\text { miocárdica, a definição da candidatura para transplante deve considerar o grau de instabilidade } \\
\text { hemodinâmica, a presença de disfunções multiorgânicas, as comorbidades e a experiência do } \\
\text { centro. Escores prognósticos podem auxiliar na estimativa de risco de mortalidade pós-transplante a } \\
\text { curto e longo prazo. }\end{array}$ & Ila & C \\
\hline
\end{tabular}




\begin{tabular}{|c|c|c|c|c|}
\hline $\begin{array}{l}\text { Potenciais eventos } \\
\text { CV relacionados aos } \\
\text { inibidores de checkpoint }\end{array}$ & Métodos diagnósticos & $\begin{array}{l}\text { Potencial abordagem inicial para } \\
\text { tratamento }\end{array}$ & $\begin{array}{l}\text { Potencial terapia adicional se } \\
\text { estável e não respondendo à } \\
\text { abordagem inicial }\end{array}$ & $\begin{array}{c}\text { Potencial terapia adicional } \\
\text { se instável }\end{array}$ \\
\hline Miocardite & $\begin{array}{c}\text { Não invasivo: RMC, troponina, ECG } \\
\text { Invasivo: biópsia e patologia }\end{array}$ & $\begin{array}{l}\text { Metilprednisolona, 1g/dia por 3-5 } \\
\text { dias, seguida de 1,5mg/kg de } \\
\text { prednisona com monitorização } \\
\text { ambulatorial de troponina. } \\
\text { Terapia padrão para insuficiência } \\
\text { cardíaca com bloqueador neuro- } \\
\text { hormonal, se FEVE reduzida. }\end{array}$ & $\begin{array}{l}\text { Micofenolato, 500-750mg 2x/dia } \\
\text { Plasmaférese } \\
\text { Imunoglobulina intravenosa }\end{array}$ & $\begin{array}{c}\text { Globulina antitimócito } \\
\text { Abatacepte } \\
\text { Alentuzumabe } \\
\text { Suporte circulatório mecânico }\end{array}$ \\
\hline Pericardite & $\begin{array}{l}\text { Não invasivo: ecocardiografia } \\
\text { Invasivo: análise de líquidos }\end{array}$ & $\begin{array}{l}\text { Prednisona, } 1,5 \mathrm{mg} / \mathrm{kg} / \mathrm{dia} \text {, com } \\
\text { redução da dose ambulatorial por } \\
2 \text { meses. }\end{array}$ & $\begin{array}{l}\text { Metilprednisolona, 1g/dia por } \\
\text { 3-5 dias } \\
\text { Micofenolato, 500-750mg 2x/dia }\end{array}$ & $\begin{array}{l}\text { Drenagem pericárdica, } \\
\text { se presença de derrame } \\
\text { pericárdico volumoso com } \\
\text { sinais de instabilidade } \\
\text { hemodinâmica }\end{array}$ \\
\hline Síndrome de Takotsubo & $\begin{array}{c}\text { Não invasivo: } \\
\text { ecocardiografia, RMC } \\
\text { Invasivo: cineangiocoronariografia e } \\
\text { ventriculografia }\end{array}$ & $\begin{array}{l}\text { Terapia-padrão de insuficiência } \\
\text { cardiaca com bloqueador neuro- } \\
\text { hormonal, se FEVE reduzida. } \\
\text { Considerar metilprednisolona, } \\
\text { 1g/dia por 3-5 dias, seguida de } \\
\text { prednisona oral com redução de } \\
\text { dose por 4-6 semanas. }\end{array}$ & Micofenolato, $500-750 \mathrm{mg} 2 x / d i a$ & Suporte circulatório mecânico \\
\hline Cardiomiopatia dilatada & $\begin{array}{c}\text { Não invasivo: RMC, ecocardiografia, } \\
\text { troponina, peptídeo natriurético } \\
\text { Invasivo: } \\
\text { cineangiocoronariografia e } \\
\text { ventriculografia }\end{array}$ & $\begin{array}{l}\text { Terapia-padrão de insuficiência } \\
\text { cardíaca com bloqueador neuro- } \\
\text { hormonal, se FEVE reduzida. }\end{array}$ & $\begin{array}{l}\text { Terapia de ressincronização } \\
\text { cardíaca } \\
\text { Desfibrilador cardíaco } \\
\text { implantável }\end{array}$ & \\
\hline
\end{tabular}

Esta tabela detalha as toxicidades cardiovasculares associadas com os inibidores de checkpoint e potenciais estratégias de manejo. Muitas das estratégias listadas para outras toxicidades que não miocardite são extrapoladas da literatura de miocardite e baseadas em pequenas séries de casos ou relatos de casos. CV: cardiovascular; ECG: eletrocardiograma; FEVE: fração de ejeção do ventrículo esquerdo; RMC: ressonância magnética cardíaca. Tabela adaptada de Lenihan DJ et al. Proceedings. ${ }^{18}$

Tabela 10 - Estudos clínicos de TEV em pacientes com câncer

\begin{tabular}{|c|c|c|c|c|}
\hline Estudo & População & Intervenção & $\begin{array}{l}\text { Desfechos primários de } \\
\text { eficácia }\end{array}$ & Desfecho primário de segurança \\
\hline \multicolumn{5}{|l|}{ Prevenção primária } \\
\hline AVERT trial* & $\begin{array}{c}574 \text { pacientes ambulatoriais } \\
\text { com câncer e alto risco } \\
\text { para TEV }\end{array}$ & $\begin{array}{c}\text { Apixabana } 2,5 \mathrm{mg} 2 \mathrm{2x} / \mathrm{dia} \text { vs } \\
\text { placebo }\end{array}$ & $\begin{array}{l}\text { TEV documentado } 4,2 \% \text { vs } \\
\qquad 10,2 \% \text {. } \\
\text { HR: 0,41; IC } 95 \%: 0,26-0,65\end{array}$ & $\begin{array}{c}\text { Sangramento maior } \\
\text { 3,5\% vs. } 1,8 \% \\
\text { HR: } 2,0 ; \text { IC } 95 \%: 1,0-3,95 .\end{array}$ \\
\hline \multicolumn{5}{|l|}{ Tratamento } \\
\hline HOKUSAI VTE & $\begin{array}{c}1050 \text { pacientes com câncer } \\
\text { com TEV agudo sintomático } \\
\text { ou incidental }\end{array}$ & $\begin{array}{c}\text { HBPM por } 5 \text { dias + edoxabana } \\
60 \mathrm{mg} \text { vs dalteparina Tratamento: } \\
6 \text { meses }\end{array}$ & $\begin{array}{c}\text { Recorrência de TEV ou } \\
\text { sangramento maior } \\
12,8 \% \text { vs } 13 \%\end{array}$ & $\begin{array}{c}\text { Sangramento maior } \\
6,9 \% \text { vs. } 4 \% \\
\text { HR: } 1,77 ; \text { IC } 95 \%: 1,03-3,04\end{array}$ \\
\hline SELECT-D & $\begin{array}{l}406 \text { pacientes com câncer } \\
\text { e EP ou TEV sintomáticos }\end{array}$ & $\begin{array}{l}\text { Rivaroxabana vs dalteparina } \\
\text { Tratamento: } 6 \text { meses }\end{array}$ & $\begin{array}{c}\text { Recorrência de TEV: 4\% vs } 11 \% \\
\text { HR: 0,43; IC95\%: 0,19-0,99 }\end{array}$ & $\begin{array}{c}\text { Sangramento maior } 6 \% \text { vs. } 4 \% \\
\text { HR: } 1,83 \\
\text { IC } 95 \% 0,68-4,96\end{array}$ \\
\hline ADAM-VTE trial & $\begin{array}{l}300 \text { pacientes com TEV } \\
\text { associado ao câncer }\end{array}$ & $\begin{array}{c}\text { Apixabana } 10 \mathrm{mg} 2 \mathrm{2x} / \text { dia por } 7 \\
\text { dias seguido de } 5 \mathrm{mg} 2 \mathrm{2x} / \text { dia vs } \\
\text { dalteparina }\end{array}$ & $\begin{array}{c}\text { Recorrência de TEV } \\
\text { 0,7\% vs 6,3\%. } \\
\text { HR: 0,099; IC95\%: 0,013-0,78 }\end{array}$ & $\begin{array}{c}\text { Sangramento maior } 0 \% \text { vs } 1,4 \% \\
\text { HR: } 1,96 ; \\
\text { IC95\%: } 0,59-6,49\end{array}$ \\
\hline Caravaggio Study* & $\begin{array}{c}1055 \text { pacientes com } \\
\text { câncer com TEV ou EP } \\
\text { sintomáticos ou incidental }\end{array}$ & $\begin{array}{c}\text { Apixabana } 10 \mathrm{mg} \text { por } 10 \\
\text { dias seguida de } 5 \mathrm{mg} / \mathrm{dia} \text { vs } \\
\text { dalteparina }\end{array}$ & $\begin{array}{c}\text { Recorrência TEV } \\
5,6 \% \text { vs } 7,9 \% \\
\text { HR: } 0,63 ; \text { IC } 95 \%: 0,37-1,07\end{array}$ & $\begin{array}{c}\text { Sangramento maior } \\
3,8 \% \text { vs } 4 \% \\
\text { HR: 0,82; IC } \% 5 \%: 0,4-1,69\end{array}$ \\
\hline
\end{tabular}

*Ensaio clínico randomizado; $C A S S I N I$ = rivaroxabana em pacientes ambulatoriais de alto risco com câncer; $A V E R T$ = apixabana na prevenção de TEV em pacientes com câncer; HOKUSAI VTE = edoxabana versus dalteparina para tratamento de TEV sintomático; SELECT-D = anticoagulação em paciente com risco de recorrência de TEV; ADAM VTE = apixabana e dalteparina em TEV associado a neoplasia ativa; Caravaggio Study = apixabana para o tratamento de TEV associado ao câncer. EP: embolia pulmonar; HBPM: heparina de baixo peso molecular; HR: razão de chance; IC: intervalo de confiança; TEV: tromboembolismo venoso; TVP: trombose venosa profunda. Tabela adaptada de: Lenihan DJ et al. Proceedings. ${ }^{18}$ 
a) A equipe multidisciplinar que acompanha os pacientes oncológicos deve educá-los quanto ao risco de TEV, particularmente em situações de alto risco, como cirurgias de grande porte e durante o tratamento quimioterápico (Ila, C).

b) Pacientes hospitalizados devem receber profilaxia farmacológica, na ausência de contraindicações (Ila, B).

c) Profilaxia farmacológica não deve ser feita de rotina em pacientes admitidos para pequenos procedimentos ou para infusão de quimioterapia ou para transplante (Ila, C).

d) Para pacientes ambulatoriais de baixo risco, anticoagulação de rotina para prevenção de TEV não está recomendada (III, B).

e) Profilaxia farmacológica ambulatorial com apixabana, rivaroxabana ou enoxaparina deve ser oferecida a pacientes de alto risco para TEV, mensurado pelo escore de Khorana $(\geq$ 2) ou pelo CAT score configurando alto risco (mensuração de dímero D e avaliação do tipo de câncer) (Ila, A).

f) Na avaliação para profilaxia farmacológica ambulatorial, considere o risco de sangramento do paciente (maior nos tumores gastrointestinais) e suas preferências (Ila, C).

g) Pacientes com mieloma múltiplo em uso de talidomida ou lenalidomida ou dexametasona devem ser avaliados para a instituição de aspirina ou enoxaparina (Ila, C).

h) Pacientes que serão submetidos a cirurgia oncológica de grande porte devem receber profilaxia farmacológica de TEV (enoxaparina ou heparina de baixo peso molecular), que deve ser iniciada no pré-operatório, com exceção de pacientes com sangramento ativo ou alto risco de sangramento (I, A). Métodos mecânicos podem ser associados à profilaxia farmacológica, porém seu uso como monoterapia só deve ser feito em pacientes com contraindicação à heparina (Ila, B).

i) O regime combinado de profilaxia farmacológica e mecânica pode melhorar a eficácia, especialmente em pacientes de mais alto risco (Ila, B).

j) A tromboprofilaxia farmacológica para pacientes submetidos a cirurgia oncológica de grande porte deve se estender por 7 a 10 dias, devendo ser prolongada por 4 semanas de pós-operatório em casos de cirurgia abdominal aberta ou laparoscópica e em cirurgia pélvica se o paciente tem mais fatores de risco do tipo obesidade, imobilidade e história de TEV (Ila, B).

k) Em cirurgias menores ou de pequeno porte, a decisão do tempo de profilaxia deve ser personalizada (Ila, C).

I) O tratamento inicial do TEV no paciente oncológico pode ser realizado com heparina de baixo peso molecular (enoxaparina), heparina não fracionada, fondaparinux, apixabana ou rivaroxabana. Para pacientes iniciando tratamento com anticoagulação parenteral, a heparina de baixo peso molecular é preferida em relação à heparina não fracionada nos primeiros dias de tratamento, desde que o paciente não tenha disfunção renal (depuração de creatinina deve ser maior que $\left.40 \mathrm{ml} / \mathrm{min} / \mathrm{m}^{2}\right)(\mathrm{l}, \mathrm{A})$.

m) A anticoagulação a longo prazo pode ser realizada preferencialmente com heparina de baixo peso molecular, edoxabana, apixabana ou rivaroxabana por pelo menos 6 meses (I, A). n) A varfarina pode ser utilizada no paciente com câncer na indisponibilidade de outras medicações ou em situações específicas de contraindicação aos outros anticoagulantes, como na insuficiência renal crônica dialítica (Ila, B).

o) Os anticoagulantes de ação direta (DOACs), como rivaroxabana e apixabana, estão associados a maiores taxas de sangramento, especialmente em neoplasias do trato gastrointestinal e geniturinárias (Ila, B).

p) Devem-se analisar caso a caso as interações medicamentosas dos DOACs no paciente com câncer $(\mathrm{I}, \mathrm{A})$.

q) Anticoagulação por tempo superior a 6 meses deve ser oferecida a pacientes com câncer ativo, como os metastáticos, ou em quimioterapia, devendo ser analisados risco e benefício (Ila, C).

r) Com base na opinião de especialistas, na ausência de estudos randomizados, a inserção de filtro de veia cava não deve ser recomendada a pacientes com trombose crônica ou estabelecida (tempo maior que 4 semanas) nem àqueles com contraindicações temporárias à terapia anticoagulante (Ila, C).

s) A varfarina é a primeira opção de anticoagulação nos pacientes com insuficiência renal crônica dialítica (Ila, B).

t) $\mathrm{O}$ filtro de veia cava pode ser considerado em pacientes com TEV agudo (nas últimas 4 semanas), com contraindicação absoluta a anticoagulante e se o TEV for de alto risco (Ila, C)

u) A TVP e o TEP incidentais devem ser tratados da mesma maneira do TEV sintomático, por terem desfechos semelhantes (Ila, C).

v) O tratamento do TEP subsegmentar ou do trombo venoso visceral ou esplâncnico deve ser considerado caso a caso, analisando-se potenciais benefícios e riscos da anticoagulação (Ila, C).

w) Pacientes com câncer devem ter seu risco de TEV avaliado ambulatorialmente com o escore de Khorana e o CAT score, devendo-se analisar os riscos e os benefícios dessa estratégia individualmente, por estar associada à redução de eventos tromboembólicos mas não à redução de mortalidade (Ila, B).

x) Em casos de sangramento clinicamente significativo associado à varfarina, o tratamento de escolha é a vitamina $K$ intravenosa (10 mg) e o complexo protrombínico intravenoso (500 U/kg) (Ila, B).

y) Em casos de sangramento associado a rivaroxabana, edoxabana e apixabana, não há antídoto específico disponível. Portanto, recomenda-se a utilização de antifibrinolíticos (ácido tranexâmico, $1 \mathrm{~g}$ a $2 \mathrm{~g}$ intravenoso) e complexo protrombínico (500 U/kg intravenoso). Em casos de refratariedade, recomendase a utilização de plasma $(15 \mathrm{ml} / \mathrm{kg}$ ), crioprecipitado $(1 \mathrm{U} / \mathrm{kg})$ e plaquetas (1-2 unidades) por aférese (Ila, C).

Há variação substancial do risco de TEV em pacientes com câncer e diferentes situações clínicas. Os pacientes com câncer devem ter seu risco de TEV analisado na avaliação basal e periodicamente a partir de então, em particular no início da terapia antineoplásica e no momento da hospitalização. Fatores de risco individuais, incluindo biomarcadores ou sítio do câncer, não identificam com alta acurácia pacientes com câncer em risco de TEV. Ambulatorialmente, a avaliação deve ser feita por meio do escore de Khorana e do CAT score (Ila,C) (Tabelas 11 e 12, respectivamente). 


\begin{tabular}{|c|c|}
\hline Característica do paciente & Pontos \\
\hline \multicolumn{2}{|l|}{ Sítio do câncer } \\
\hline Risco muito alto (estômago e pâncreas) & 2 \\
\hline Alto risco (pulmão, linfoma, ginecológico, bexiga, testicular, renal) & 1 \\
\hline Contagem de plaquetas pré-quimioterapia $\geq 350.000 / \mu \mathrm{l}$ & 1 \\
\hline Nível de hemoglobina $<10 \mathrm{~g} / \mathrm{dL}$ e/ou uso de fatores de crescimento de glóbulos vermelhos & 1 \\
\hline Contagem de leucócitos pré-quimioterapia $>11.000 / \mu \mathrm{l}$ & 1 \\
\hline Índice de massa corpórea $\geq 35 \mathrm{~kg} / \mathrm{m}^{2}$ & 1 \\
\hline \multicolumn{2}{|l|}{ Calcular a pontuação total, adicionando pontos para cada critério do modelo } \\
\hline \multicolumn{2}{|l|}{ Interpretação } \\
\hline \multicolumn{2}{|l|}{ Escore de alto risco $\geq 3$ pontos } \\
\hline Escore de risco intermediário $1-2$ pontos & \\
\hline
\end{tabular}

Tabela 12 - Nomograma (CAT score) para predizer o risco de TEV em 6 meses $^{78}$

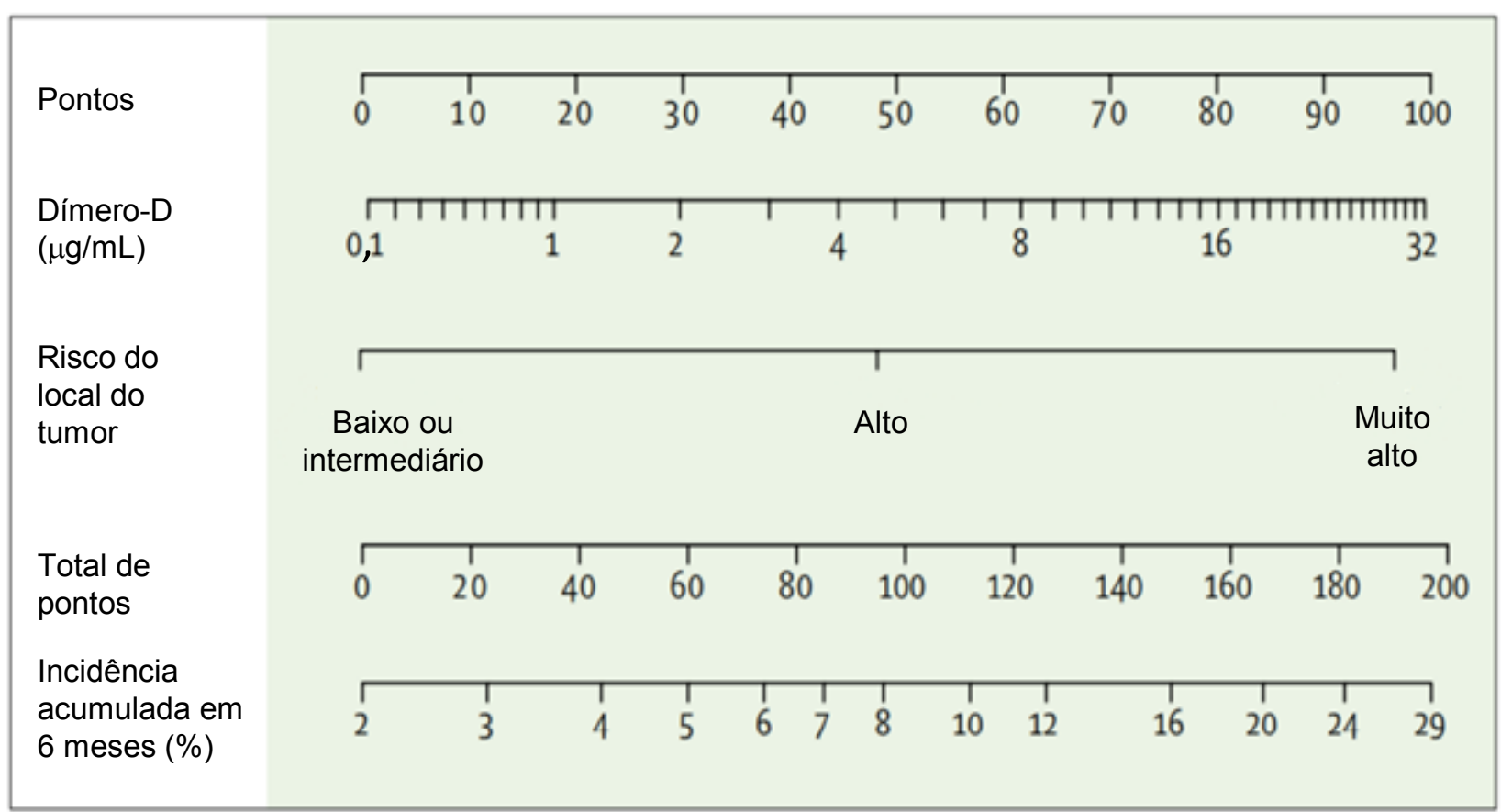

\subsection{Trombose Arterial}

Em estudo epidemiológico com 279.719 participantes e comparando pacientes com neoplasia e controles sem neoplasia, a incidência de eventos arteriais foi de 4,7\% nos primeiros e 2,2\% nos controles em um período de 6 meses. ${ }^{79}$ Geralmente, esses eventos ocorrem em indivíduos com neoplasias metastáticas de pâncreas, mama, colorretal e pulmão em uso de antraciclinas, taxanos e platina. $\mathrm{O}$ estado pró-trombótico pode favorecer eventos embólicos secundários à fibrilação atrial. Alguns fármacos antineoplásicos, especialmente inibidores VEGF, podem induzir complicações tromboembólicas. Em pacientes sob terapia hormonal, maiores taxas de eventos trombóticos arteriais são observadas mais frequentemente com os inibidores de aromatase do que com o tamoxifeno. Em muitos casos, quinases e suas vias desempenham papel crítico na homeostase vascular e metabólica das células. A inibição dessas quinases pode causar sequelas cardiovasculares, dependendo do tipo de quinase. As toxicidades vasculares mais preocupantes que podem ocorrer com os novos agentes incluem eventos isquêmicos arteriais, como infarto agudo do miocárdio, acidente vascular cerebral e isquemia de membro, assim como eventos tromboembólicos venosos. ${ }^{79}$ 
Relatos recentes mostram que a terapia com inibidor de VEGF resulta em eventos vasculares adversos, como dissecção de aorta, acidente vascular cerebral e trombose arterial e venosa. O bevacizumabe é associado a maior taxa de TEV dentre os inibidores VEGF, aproximadamente $12 \%$ comparado a $2 \%$ com os outros fármacos. ${ }^{49,80}$

\section{Síndrome Metabólica Associada à Terapia de Privação Androgênica}

O tratamento de neoplasias de próstata localmente avançada baseia-se no controle hormonal de testosterona. Esse bloqueio pode ser obtido cirurgicamente (orquiectomia) ou pela terapia medicamentosa de privação androgênica. Os agonistas de $\mathrm{GnRH}$ (hormônio liberador de gonadotrofina: leuprolide, goserelina e triptorelina) e os antagonistas de $\mathrm{GnRH}$ (degarelix) causam bloqueio central com redução dos níveis de hormônio luteinizante, hormônio folículo estimulante e testosterona. Os inibidores de receptor androgênico adrenal (abiraterona) e os inibidores diretos androgênicos (enzalutamida) também agem reduzindo a testosterona. São medicações utilizadas com intenção curativa em pacientes de alto risco com doença não metastática e como terapia padrão na doença metastática. Entender o impacto dessas medicações no risco cardiovascular é importante, pois muitos dos fatores de risco que levam ao câncer de próstata também podem resultar em doença cardiovascular, como idade avançada, tabagismo, dieta e obesidade. Estudos apontam detecção mais prevalente desses fatores de risco na população de pacientes com câncer de próstata.

A terapia antiandrogênica reconhecida leva a alterações metabólicas caracterizadas por hiperinsulinemia, hipercolesterolemia e alterações na composição corporal, com aumento da gordura predominantemente visceral e redução de massa magra. A síndrome metabólica resultante da terapia antiandrogênica está associada a aumento de complicações cardiovasculares. Recomenda-se a modificação dos fatores de risco com terapia hipolipemiante, tratamento anti-hipertensivo, controle estrito da glicemia e utilização de antiagregantes plaquetários (Ila, B).

\section{Arritmia Cardíaca}

Diversos fatores presentes nos pacientes com câncer, como infecção, distúrbios hidroeletrolíticos, desidratação, procedimentos cirúrgicos e terapias oncológicas e adjuvantes, predispõem à ocorrência de arritmias cardíacas. ${ }^{81}$ Essas arritmias são complicações relativamente frequentes em pacientes com câncer e estima-se que ocorram em 16-36\% desses pacientes. ${ }^{82,83}$

Os tipos de arritmias cardíacas no paciente oncológico incluem amplo espectro: taquicardia sinusal, bradiarritmias, taquiarritmias e distúrbios de condução. Dentre as arritmias supraventriculares, a mais comum é a fibrilação atrial. Taquicardia ventricular e fibrilação ventricular são raras, mas podem ocorrer especialmente na presença do alargamento do QT e em pacientes com hipocalemia ou hipomagnesemia. ${ }^{84,85}$ A Tabela 13 apresenta os principais fármacos e a incidência de arritmias cardíacas.

\subsection{Prolongamento QT}

O diagnóstico do prolongamento do intervalo QT é eletrocardiográfico, devendo-se calcular o QTc pela fórmula de Bazett QT / $(\text { RR })^{1 / 2}$ ou Fridericia QT / $(\text { RR })^{1 / 3}$. Consideramse normais valores de QTC $\leq 440 \mathrm{~ms}$ nos homens e entre 450 e 460 ms nas mulheres. Tanto fatores congênitos como adquiridos podem ser responsáveis por prolongamento do QT. Dentre as condições mais citadas estão: sexo feminino, bradicardia, anormalidades eletrolíticas, efeitos de drogas, isquemia miocárdica, insuficiência cardíaca, miocardites, hipotermia e canalopatias. ${ }^{86}$

Tabela 13 - Principais fármacos relacionados a arritmias cardíacas e suas incidências

\begin{tabular}{lc}
\hline Fármaco & Incidência \\
\hline Antraciclinas & $\begin{array}{c}\text { Alterações eletrocardiográficas: } 38,6 \% \\
\text { FA: } 2-10 \%\end{array}$ \\
\hline Agentes antimicrotúbulos (Paclitaxel) & $\begin{array}{c}\text { Bradicardia sinusal: } 29 \% \\
\text { BAV } \text { 1० }^{\circ} \text { grau: } 25 \%\end{array}$ \\
\hline $\begin{array}{l}\text { Antimetabólitos } \\
\text { (5-Fluorouracil e Capecitabina) }\end{array}$ & $\begin{array}{c}\text { Alterações eletrocardiográficas: } 68 \% \\
\text { Arritmias (FA, TSV, TV): } 5 \%\end{array}$ \\
\hline Platina (Cisplatina) & TSV: $12-32 \%$ \\
\hline Talidomida & Bradicardia: $27 \%$ \\
\hline Trióxido arsênio & Prolongamento QT e arritmias ventriculares: até $50 \%$ \\
\hline Inibidor Tirosina Quinase & Alargamento QT e arritmias: $3,5 \%$ \\
\hline Crizotinibe & Alargamento QT e arritmias: $0,6-3 \%$ \\
\hline Dasatinibe & Alargamento QT e arritmias: $1-4 \%$ \\
\hline Sunitinibe & Alargamento QT e arritmias: $12-15 \%$ \\
\hline Vandetinibe & \\
\hline
\end{tabular}

BAV: bloqueio atrioventricular; FA: fibrilação atrial; TSV: taquicardia supraventricular; TV: taquicardia ventricular. 
O prolongamento do QT é uma preocupação em pacientes com câncer, pois tanto o tratamento oncológico como os distúrbios hidroeletrolíticos e as medicações concomitantes podem contribuir para esse prolongamento e para a predisposição à ocorrência de arritmias complexas. ${ }^{83} \mathrm{~A}$ monitorização do QT e a correção de fatores que contribuam para o prolongamento do QT devem ser consideradas em pacientes em uso de medicações que aumentem o intervalo QT. A cardiotoxicidade é definida quando há prolongamento de QTc $>500 \mathrm{~ms}$ e/ou variação do QT > 60ms do basal (Tabela 14). ${ }^{87,88}$

O intervalo QT e os fatores de risco associados com prolongamento do QT devem ser avaliados antes e depois do tratamento com as drogas sabidamente relacionadas a arritmias cardíacas, como inibidores de tirosina quinase (crizotinibe, dasatinibe, sunitinibe) e trióxido de arsênio. A avaliação do ECG e dos eletrólitos deve ser feita durante o tratamento nos momentos basal, 7-15 dias após o início da terapêutica, após mudanças em doses nos primeiros 3 meses e a depender da frequência da terapia. Antes do adiamento da quimioterapia, deve-se considerar a suspensão de outros medicamentos relacionados ao prolongamento do QT, como antieméticos, antidepressivos, antiarrítmicos, antifúngicos, antipsicóticos. A correção de distúrbio hidroeletrolítico também deve ser realizada. Pacientes em uso de trióxido de arsênio devem ser monitorados com ECG semanalmente. ${ }^{22}$

O prolongamento do intervalo QT aumenta a incidência de arritmias ventriculares e torsades de points. ${ }^{88}$ As taquicardias ventriculares, em geral, estão associadas a miocardiopatias estruturais [doença arterial coronariana (DAC), miocardiopatia dilatada, cardiopatias do ventrículo direito, anormalidades congênitas, miocardiopatia hipertrófica e canalopatias]. ${ }^{89} \mathrm{O}$ objetivo do tratamento das arritmias ventriculares é diminuir morbidade e eventos de morte súbita, sendo fundamental avaliar os fatores desencadeantes. Indica-se terapêutica farmacológica para casos refratários e/ou sintomáticos. ${ }^{90}$

\subsection{Fibrilação Atrial}

A fibrilação atrial é a arritmia cardíaca mais frequente no paciente oncológico. Sua ocorrência está relacionada ao estado pró-inflamatório desses pacientes e também à resposta inflamatória à cirurgia oncológica e aos efeitos cardiotóxicos da terapia antineoplásica. ${ }^{91} \mathrm{~A}$ compreensão dos mecanismos que desencadeiam fibrilação atrial e promovem sua manutenção é importante para que haja prevenção.

Diversos mecanismos podem induzir fibrilação atrial, tais como alteração miocárdica por distúrbio hidroeletrolítico, dano lipossomal e mitocondrial, inflamação, doença pericárdica e aumento do estresse oxidativo induzindo apoptose celular. ${ }^{92}$

Existe grande dificuldade em se estabelecer a relação causal dos eventos arrítmicos com cada quimioterápico. Primeiramente, em razão do pequeno número de estudos publicados e da administração simultânea de muitas drogas, que tornam difícil relacionar droga e efeito. Os quimioterápicos mais associados a arritmias são as antraciclinas (doxorrubicina, epirrubicina), os agentes antimicrotúbulos (paclitaxel e docetaxel), os antimetabólitos (5-fluorouracil, capecitabina e gencitabina), os agentes alquilantes (cisplatina e ciclofosfamida), os inibidores da tirosina quinase (ibrutinibe, ponatinibe, sorafenibe e sunitinibe) e os anticorpos monoclonais (trastuzumabe e cetuximabe), além dos imunoterápicos.

O câncer é associado a um estado pró-trombótico, podendo aumentar o risco de eventos embólicos no paciente com fibrilação atrial, que também apresenta maior ocorrência de complicações hemorrágicas decorrentes do tratamento e, portanto, maior morbimortalidade. Não há recomendações baseadas em consensos e diretrizes sobre o uso dos antitrombóticos em pacientes com fibrilação atrial. ${ }^{85,93}$

A escolha da terapia antritrombótica no paciente com câncer deve ser individualizada, analisando-se os fatores farmacocinéticos e farmacodinâmicos, as interações medicamentosas, o risco de trombose e o risco de sangramento (Ila, B).

Deve-se evitar a varfarina no paciente oncológico com fibrilação atrial, pois essa droga é associada a menor

Tabela 14 - Recomendações para pacientes em uso de fármacos com potencial de prolongamento de QT.

\begin{tabular}{l}
\hline Evitar uso de drogas relacionadas ao prolongamento de QTc em pacientes com QTc pré-tratamento > 470ms \\
\hline Descontinuar drogas relacionadas ao prolongamento de QTc se QTc > 500ms ou > 550ms se QRS alargado basal (>120ms secundário a marca-passo ou bloqueio de ramo) \\
\hline Redução de dose ou descontinuação de drogas se QTc aumentar > 60ms do valor pré-tratamento \\
\hline Manter concentração de eletrólitos (potássio, magnésio e cálcio séricos) dentro dos valores normais \\
\hline Evitar interações medicamentosas \\
\hline Em pacientes com lesão renal aguda ou doença renal crônica, ajustar para a função renal as drogas com eliminação renal que prolonguem QTc \\
\hline Evitar infusão intravenosa rápida de drogas que prolonguem QTc \\
\hline Evitar administração em conjunto de mais de 1 droga que prolongue QTc \\
\hline Evitar drogas que prolonguem QTc em pacientes com história de torsade de points induzida por drogas ou pacientes ressuscitados de morte cardíaca súbita \\
\hline Evitar uso de drogas que prolonguem QTc em pacientes com doenças congênitas \\
\hline Realizar ECG com frequência dependendo da terapia instituída, dose administrada e concentração das drogas \\
\hline ECG: eletrocardiograma: QTc: intervalo QT corrigido. Fonte: Adaptado de Porta-Sanchez et al 88
\end{tabular}

ECG: eletrocardiograma; QTC: intervalo QT corrigido. Fonte: Adaptado de Porta-Sanchez et al.88 
eficácia e a maior risco de sangramento por interações medicamentosas, pela presença de maior ocorrência de disfunção hepática, alterações dietéticas, caquexia e desnutrição (Ila, B).

Os DOACs (dabigatrana, rivaroxabana, apixabana e edoxabana) são superiores à varfarina em termos de eficácia e sangramento na população geral com fibrilação atrial, porém a evidência para sua utilização no paciente com câncer vem de análises de subestudos e de dados observacionais (Ila, B).

Apesar de não haver validação dos escores clássicos na população com câncer, recomenda-se iniciar anticoagulação nesses pacientes utilizando-se os mesmos critérios adotados na população sem câncer: escores $\mathrm{CHADS}_{2}$ e $\mathrm{CHA}_{2} \mathrm{DS}_{2}$-VASc acima de 2 indicam anticoagulação (Ila, C) (Tabela 15).

A terapia antitrombótica no paciente com câncer deve ser personalizada, analisando-se perfil do paciente, tipo de câncer, risco de trombose e de sangramento, esse último por exemplo, por meio do escore de HAS-BLED (Ila, C) (Tabela 16).

Não há estudos prospectivos e randomizados sobre DOACs em pacientes com câncer e fibrilação atrial. Análise de subestudos dos ensaios clínicos randomizados demonstra segurança e eficácia daquelas drogas nos pacientes com câncer. Essa evidência associada ao resultado de estudos em TEV e câncer, que confirmam a superioridade dos DOACs quando comparados a heparina de baixo peso molecular, sugere que os DOACs são opção viável como terapia antitrombótica nos pacientes com câncer e fibrilação atrial (Ila, C).

Uso rotineiro de DOACs em pacientes com fibrilação atrial e tumores do trato gastrointestinal e geniturinário pode ser considerado, devendo ser analisado risco potencial de sangramento (IIb,B).

Recomenda-se o envolvimento do cardiologista desde o início no manejo do paciente com câncer e fibrilação atrial, devido às maiores taxas de uso de anticoagulação e menor incidência de complicações isquêmicas e hemorrágicas (Ila, C).

\section{Doença Arterial Coronariana}

A DAC e o câncer apresentam diversos fatores de risco em comum e frequentemente coexistem no mesmo paciente (Figura 9). A presença de fatores de risco, como idade avançada, tabagismo, diabetes, HAS, sedentarismo e dislipidemia, é elevada nos pacientes com câncer. ${ }^{94}$ Outros fatores comuns nesses pacientes e que contribuem para o desenvolvimento de DAC são disfunção endotelial, estresse oxidativo, predisposição genética e inflamação crônica. ${ }^{95}$

O tratamento oncológico também contribui para a elevada prevalência de DAC nos pacientes oncológicos. ${ }^{49}$ Pacientes com câncer de pulmão submetidos a tratamento quimioterápico apresentam aumento de 5,3 vezes (IC 95\%: 2,002-14,152) no risco de lesão coronariana importante, o que sugere que esse tratamento possa estar associado com complexidade anatômica. ${ }^{96}$ Os mecanismos principais de acometimento de DAC relacionada a terapia oncológica são: vasoespasmo, trombose e aterosclerose acelerada. ${ }^{49}$

Nos pacientes em uso de cisplatina de modo isolado ou em associação com vincristina ou bleomicina, observouse trombose coronária em angiografia coronária sem aterosclerose prévia. Essas drogas podem induzir disfunção/ lesão endotelial, que parece ser o mecanismo básico da alteração vasoativa causada por esses fármacos. ${ }^{97-99}$ A cisplatina leva à morte de células endoteliais pela produção de micropartículas pró-coagulantes. ${ }^{100}$

Outra classe de quimioterápico tipicamente relacionada a DAC nos pacientes com câncer são os antimetabólitos, especialmente o 5-fluorouracil e a capecitabina. A incidência de angina ou quadros agudos varia de $3,9 \%$ a $12,5 \% .^{101}$ O mecanismo pelo qual esses fármacos causam toxicidade não está completamente estabelecido e várias hipóteses foram geradas para explicar esses quadros, tais como vasoespasmo agudo, toxicidade direta aos miócitos, disfunção endotelial e estado de hipercoagulabilidade causando trombose..$^{101,102}$ O vasoespasmo agudo é frequentemente observado e estudos experimentais sugerem que a vasoconstricção causada pelo 5-fluorouracil esteja relacionada a proteína quinase C e endotelina-1. ${ }^{103,104}$ De modo semelhante ao

Tabela 15 - Escore de risco de tromboembolismo associado a fibrilação atrial

\begin{tabular}{lcc}
\hline $\mathrm{CHA}_{2} \mathrm{DS}_{2}$-VASc & & \\
\hline $\mathrm{C}$ & Descrição & Pontos \\
\hline $\mathrm{H}$ & Insuficiência cardíaca & 1 \\
\hline $\mathrm{A}_{2}$ & Hipertensão arterial & 1 \\
\hline $\mathrm{D}$ & Idade $(\geq 75$ anos) & 2 \\
\hline $\mathrm{S}_{2}$ & Diabetes mellitus & 1 \\
\hline $\mathrm{V}$ & AlT ou AVC prévio & 2 \\
\hline $\mathrm{A}$ & Doença vascular (IAM prévio, doença arterial periférica ou placa aórtica) & 1 \\
\hline $\mathrm{Sc}$ & Idade (65-74 anos) & 1 \\
\hline
\end{tabular}

AlT: ataque isquêmico transitório; AVC: acidente vascular cerebral; IAM: infarto agudo do miocárdio. 


\begin{tabular}{|c|c|}
\hline$\square$ & Hipertensão arterial (1 ponto) \\
\hline$\square$ & Função hepática anormal (1 ponto) \\
\hline$\square$ & Função renal anormal (1 ponto) \\
\hline$\square$ & Acidente vascular cerebral (1 ponto) \\
\hline$\square$ & Tendência ou predisposição a sangramento (1 ponto) \\
\hline$\square$ & INR lábil em pacientes que tomam varfarina (1 ponto) \\
\hline$\square$ & Idosos: acima de 60 anos (1 ponto) \\
\hline$\square$ & Medicamentos: agente(s) antiplaquetários concomitantes ou AINES (1 ponto) \\
\hline$\square$ & Abuso de álcool (1 ponto) \\
\hline \multicolumn{2}{|c|}{ AINES: anti-inflamatórios não esteroidais; INR: razão normalizada internacional. } \\
\hline \multicolumn{2}{|c|}{0 ponto: 1,02 sangramento por 100 pacientes/ano } \\
\hline \multicolumn{2}{|c|}{1 ponto: 1,13 sangramento por 100 pacientes/ano } \\
\hline \multicolumn{2}{|c|}{2 pontos: 1,88 sangramento por 100 pacientes/ano } \\
\hline \multicolumn{2}{|c|}{3 pontos: 3,74 sangramentos por 100 pacientes/ano } \\
\hline \multicolumn{2}{|c|}{4 pontos: 8,70 sangramentos por 100 pacientes/ano } \\
\hline \multicolumn{2}{|c|}{ 5-9 pontos: dados insuficientes (alto risco) } \\
\hline
\end{tabular}

5-fluorouracil, os taxanos são outra classe de fármacos que induzem quadros de angina secundários a espasmos coronarianos. A incidência de dor torácica relatada em pacientes em uso de paclitaxel é de aproximadamente $0,2-4 \%{ }^{105,106}$

Aterosclerose acelerada tem sido observada em pacientes recebendo tratamento com os inibidores de tirosina quinase de segunda e terceira gerações. Esses fármacos apresentam risco aumentado de oclusão coronária quando comparados a imatinibe $(\mathrm{OR}=$ 3,45 [IC 95\%: 2,30-5,18). ${ }^{107}$ Dos inibidores de tirosina quinase, o ponatinibe parece ser o mais relacionado a toxicidade vascular. Tromboses arterial e venosa foram descritas em $27 \%$ dos pacientes recebendo ponatinibe, independentemente da presença de fatores de risco cardiovasculares. ${ }^{107}$ Os pacientes tratados com bevacizumabe apresentam elevado risco de isquemia coronariana quando comparados a grupo controle (RR: 2,47; IC 95\%: 1,4-4,36). ${ }^{108}$ Os pacientes em uso de ICls apresentam uma composição de células inflamatórias alterada na placa aterosclerótica (aumento de células TCD3 + em relação a macrófagos CD68+), que pode predispor a progressão de placa e/ou eventos coronários Clínicos. ${ }^{109}$

O tratamento radioterápico é classicamente relacionado ao desenvolvimento de DAC, em geral reportado de modo tardio após exposição à radiação. A incidência é variável na literatura, com tendência à redução nas últimas décadas em virtude de técnicas mais modernas que diminuem a radiação direta ao coração. A patogênese da DAC é multifatorial, resultando em lesão miocárdica direta, alteração do tônus vascular, ativação inflamatória e estresse oxidativo. ${ }^{110,111}$
Em virtude da complexidade do paciente com câncer e DAC, sua mortalidade é maior do que a de pacientes sem câncer a longo prazo. ${ }^{112,113} \mathrm{Na}$ abordagem desses pacientes, é importante conhecer o prognóstico oncológico, as perspectivas terapêuticas e a programação de cirurgias oncológicas. O controle de fatores de risco deve ser reforçado nos pacientes com DAC evidenciada. O uso de stent farmacológico deve ser preferido nesses pacientes quando indicada intervenção terapêutica. ${ }^{114} \mathrm{~A}$ terapia com antiplaquetários deve ser mantida conforme diretrizes habituais de abordagem de DAC e síndrome coronariana aguda, a menos que existam contraindicações, como sangramento tumoral. ${ }^{115-117}$

Recomendações:

a) $\mathrm{O}$ controle de fatores de risco (HAS, diabetes, dislipidemias) e da perda ponderal, a cessação de tabagismo e a orientação dietética devem ser feitos em todos os pacientes que serão submetidos a fármacos com predisposição a DAC (I, A).

b) O stent farmacológico deve ser preferido nesses pacientes (Ila, B).

c) A dupla antiagregação pode ser mantida em pacientes com níveis de plaquetas $>30$ mil, na ausência de contraindicação (Ila, B).

d) A pesquisa de DAC está indicada em pacientes após 5 anos da exposição mediastinal a dose de 30 gy ou mais (Ila, B).

e) Nos pacientes que apresentaram síndrome coronariana aguda com 5-fluorouracil, recomenda-se a avaliação do cardio-oncologista e deve-se considerar a estratificação de DAC (Ila, B). 


\section{Diretriz}

\section{DOENÇA ARTERIAL CORONARIANA CARDIO-ONCOLOGIA}

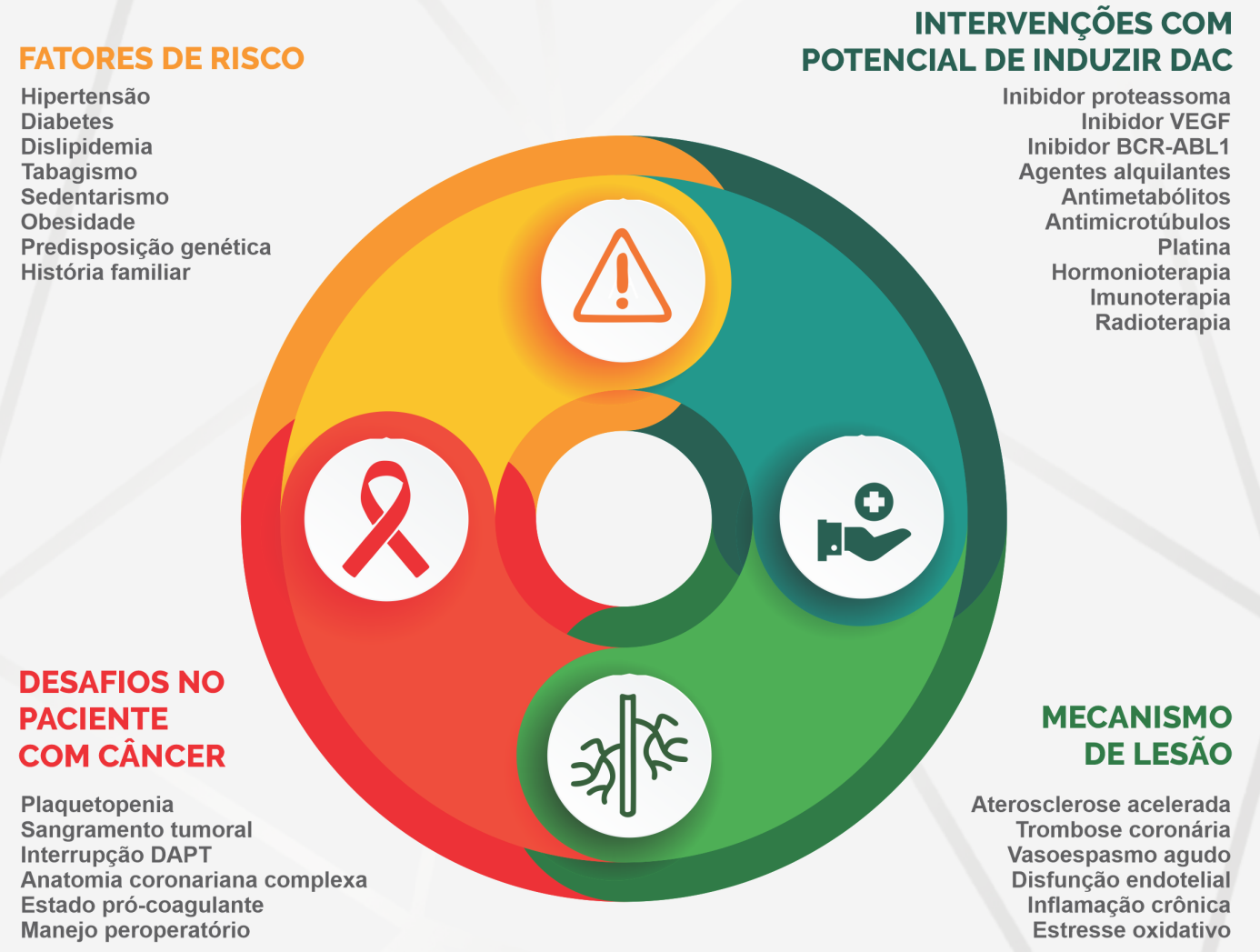

Figura 9 - Doença arterial coronariana na cardio-oncologia. DAC: doença arterial coronariana; DAPT: dupla antiagregação plaquetária; VEGF: fator de crescimento endotelial vascular. 
f) Pode-se considerar a re-exposição em pacientes que apresentaram eventos leves, que estejam assintomáticos e cujo benefício do 5 -fluorouracil tenha impacto prognóstico. $\mathrm{O}$ uso de nitratos e vasodilatadores pode ser considerado nesse cenário (IIb, B).

\section{Hipertensão Arterial}

A prevalência de HAS é maior nos pacientes com câncer e sobreviventes quando comparados à população geral. ${ }^{118}$ A HAS é o principal fator de risco modificável de eventos cardiovasculares nesses pacientes. ${ }^{119}$ A HAS, a doença renal crônica, a doença cardiovascular e o câncer têm fatores de risco em comum, como tabagismo, obesidade e diabetes. Muitos tipos de câncer e seus tratamentos causam ou agravam a HAS preexistente por efeitos vasculares, endoteliais e renais. ${ }^{22}$

Recomenda-se a aferição periódica da pressão arterial no paciente com câncer (Ila, C).

A seleção de agentes anti-hipertensivos deve levar em consideração fatores de risco individuais, efeitos do tratamento antineoplásico e interações medicamentosas. Estima-se que 35\% dos pacientes com câncer desenvolverão HAS ao longo do tratamento. Pacientes com história de câncer têm uma prevalência maior de HAS que a população geral. ${ }^{94}$ Pacientes com câncer renal, gástrico e ovariano têm níveis tensionais mais elevados que aqueles com outros sítios tumorais. Exposição a quimioterapia é um fator de risco independente para HAS. ${ }^{120}$

\subsection{HAS e Tratamento Quimioterápico}

A terapia com inibidores de tirosina quinase anti-VEGF e inibidores de tirosina quinase multi-alvo acentua e induz HAS. ${ }^{121}$ Os mecanismos são redução da produção de óxido nítrico e de angiogênese, levando a aumento da resistência vascular sistêmica. A terapia anti-VEGF leva à retenção fluida por comprometer a natriurese, além de induzir vasoconstricção mediada por endotelina-1 e microangiopatia trombótica, semelhante à fisiopatologia da eclampsia. ${ }^{121}$ Em recente meta-análise publicada, o uso dos inibidores de tirosina quinase anti-VEGF aumentou o risco de cardiotoxicidade, como HAS, sangramento e disfunção ventricular. A HAS foi a cardiotoxicidade vascular mais comum. ${ }^{122}$

Os agentes alquilantes parecem induzir HAS por nefrotoxicidade, porém não há muita evidência de seu real efeito na pressão arterial. A ciclofosfamida tem sido associada a complicações vasculares múltiplas, como doença veno-oclusiva no pulmão e fígado, doença tromboembólica e isquemia miocárdica. A evidência pré-clínica demonstra injúria endotelial e anormalidades do sistema renina-angiotensina-aldosterona nos animais tratados com ciclofosfamida. ${ }^{21,22}$

Tanto a ifosfamida quanto a cisplatina aparentemente induzem HAS por causar nefrotoxicidade. ${ }^{123}$ Os agentes antimicrotúbulos afetam a mitose, agindo na tubulina para impedir a polimerização do microtúbulo. Estudos experimentais mostram que a vimblastina atua no endotélio e na apoptose, porém seu efeito na HAS é desconhecido. ${ }^{124,125}$ A gencitabina e os inibidores de proteassoma podem desencadear HAS associada a microangiopatia trombótica. As medicações adjuvantes utilizadas nos pacientes com câncer associadas a HAS são: corticosteroides, eritropoietina, inibidores de calcineurina e anti-inflamatórios.

\subsection{HAS Induzida pelo Câncer}

A HAS pode ser uma manifestação paraneoplásica do carcinoma hepatocelular, câncer renal, doença carcinoide, entre outras. Ocorre por produção de renina, angiotensinogênio, angiotensina I ou catecolaminas. Entre indivíduos com carcinoma de células renais, a prevalência de HAS excede $75 \%$ e ocorre pela perda de néfrons relacionada a nefrectomia e particularmente pelo tratamento com inibidores VEGF. Além disso, o carcinoma renal pode secretar peptídeos vasoativos, principalmente a endotelina-1. A presença de HAS no câncer renal pode significar doença mais agressiva, com impacto negativo no prognóstico. ${ }^{126,127} \mathrm{O}$ feocromocitoma e o paraganglioma são tumores neuroendócrinos das células cromafins, com incidência anual de 0,8 por 100 mil pessoas. A HAS relacionada a esses tumores é causada por secreção de catecolaminas (norepinefrina, epinefrina e dopamina) e pode estar associada a sintomas como cefaleia, palpitações e sudorese. ${ }^{128}$

O paciente com câncer e HAS têm maior incidência de insuficiências cardíaca e renal. A HAS é fator de risco independente de DAC, insuficiência cardíaca e arritmia, sendo o principal fator de risco modificável para evitar insuficiência cardíaca. ${ }^{47,129}$

A pressão arterial deve ser aferida de maneira adequada e periódica no paciente com câncer (I, A).

Pacientes em uso de inibidores de tirosina quinase anti-VEGF, inibidores de tirosina quinase multi-alvo, agentes alquilantes ou esteroides em altas doses devem ser submetidos a monitorização mais frequente da pressão arterial (Ila, C).

A meta da pressão arterial no paciente com câncer segue as recomendações do paciente sem câncer: < 130 × 80 $\mathrm{mmHg}$ (Ila, B).

O tratamento medicamentoso deve ser personalizado, porém a demonstração de proteinúria ou de disfunção ventricular determina a indicação de IECA ou AT1 (Ila, B).

No caso de não haver proteinúria ou disfunção ventricular, bloqueador de canal de cálcio do tipo diidropiridina (amlodipina) pode ser iniciado (Ila, C).

Diuréticos devem ser utilizados com critério bem definido e vigilância pelo risco de hipovolemia e distúrbios hidroeletrolíticos (Ila, C).

Bloqueador de canal de cálcio não diidropiridínico (verapamil e diltiazem) em pacientes com câncer (III, B). Esses medicamentos, por serem metabolizados no CYP3A4, podem alterar os níveis séricos dos quimioterápicos.

Sugere-se buscar causas secundárias de HAS, como hipovolemia e dor (Ila, C). 


\section{Referências}

1. Abdel-Qadir H, Thavendiranathan P, Austin PC, Lee DS, Amir E, Tu JV, et al. Development and validation of a multivariable prediction model for major adverse cardiovascular events after early stage breast cancer: a population-based cohort study. Eur Heart J. 2019;40(48):3913-20.

2. Brant LCC, Nascimento BR, Passos VMA, Duncan BB, Bensenor IJM, Malta DC, et al. Variations and particularities in cardiovascular disease mortality in Brazil and Brazilian states in 1990 and 2015: estimates from the Global Burden of Disease. Rev Bras Epidemiol. 2017;20Suppl 01(Suppl 01):116-28.

3. Collaborators GBDB. Burden of disease in Brazil, 1990-2016: a systematic subnational analysis for the Global Burden of Disease Study. 2016. Lancet 2018;392(10149):760-75.

4. Ala CK, Klein AL, Moslehi JJ. Cancer Treatment-Associated Pericardial Disease: Epidemiology, Clinical Presentation, Diagnosis, and Management. Curr Cardiol Rep. 2019;21(12):156.

5. Alfano CM, Cheville AL, Mustian K. Developing High-Quality Cancer Rehabilitation Programs: A Timely Need. Am Soc Clin Oncol Educ Book. 2016;35:241-9.

6. Global Burden of Disease Cancer C, Fitzmaurice C, Abate D, Abbasi N, Abbastabar H, Abd-Allah F, et al. Global, Regional, and National Cancer Incidence, Mortality, Years of Life Lost, Years Lived With Disability, and Disability-Adjusted Life-Years for 29 Cancer Groups, 1990 to 2017: A Systematic Analysis for the Global Burden of Disease Study. JAMA Oncol. 2019; 5(12):1749-68

7. Al-Kindi SG, Oliveira GH. Prevalence of Preexisting Cardiovascular Disease in Patients With Different Types of Cancer: The Unmet Need for Onco-Cardiology. Mayo Clin Proc. 2016;91(1):81-3.

8. Tan C, Tasaka H, Yu KP, Murphy ML, Karnofsky DA. Daunomycin, an antitumor antibiotic, in the treatment of neoplastic disease. Clinica evaluation with special reference to childhood leukemia. Cancer. 1967;20(3):333-53.

9. Ainger LE, Bushore J, Johnson WW, Ito J. Daunomycin: a cardiotoxic agent J Natl Med Assoc. 1971;63(4):261-7.

10. Lipshultz SE, Lipsitz SR, Mone SM, Goorin AM, Sallan SE, Sanders SP, et al. Female sex and higher drug dose as risk factors for late cardiotoxic effects of doxorubicin therapy for childhood cancer. N Engl J Med. 1995;332(26):1738-43.

11. Cardinale D, Sandri MT, Colombo A, Colombo N, Boeri M, Lamantia $\mathrm{G}$, et al. Prognostic value of troponin I in cardiac risk stratification of cancer patients undergoing high-dose chemotherapy. Circulation. 2004;109(22):2749-54

12. Allen S, Brown V, Prabhu P, Scott M, Rockall T, Preston S, et al. A randomised controlled trial to assess whether prehabilitation improves fitness in patients undergoing neoadjuvant treatment prior to oesophagogastric cancer surgery: study protocol. BMJ Open. 2018 Dec 22;8(12):e023190

13. Amigoni M, Giannattasio C, Fraschini D, Galbiati M, Capra AC, Madotto $\mathrm{F}$, et al. Low anthracyclines doses-induced cardiotoxicity in acute lymphoblastic leukemia long-term female survivors. Pediatr Blood Cancer. 2010;55(7):1343-7.

14. Anker MS, Hadzibegovic S, Lena A, Belenkov Y, Bergler-Klein J, de Boer RA, et al. Recent advances in cardio-oncology: a report from the 'Heart Failure Association 2019 and World Congress on Acute Heart Failure 2019'. ESC Heart Fail. 2019;6(6):1140-8.

15. Anquetil C, Salem JE, Lebrun-Vignes B, Johnson DB, Mammen AL, Stenzel W, et al. Immune Checkpoint Inhibitor-Associated Myositis. Circulation. 2018;138(7):743-5.

16. Armenian SH, Lacchetti C, Barac A, Carver J, Constine LS, Denduluri N, et al. Prevention and Monitoring of Cardiac Dysfunction in Survivors of Adult Cancers: American Society of Clinical Oncology Clinical Practice Guideline. J Clin Oncol. 2017;35(8):893-911.
17. Hajjar LA. 5th Global Cardio-Oncology Summit. Frontiers Media SA; 2019.

18. Lenihan DJ, FradleyMG, DentS, Brezden-Masley C, Carver J, Kalil Filho K, etal. Proceedings From the Global Cardio-Oncology Summit: The Top 10 Priorities to Actualize for CardioOncology. JACC: CardioOncology. 2019;1(2):256-72.

19. Curigliano G, Cardinale D, Suter T, Plataniotis G, de Azambuja E, Sandri MT, et al. Cardiovascular toxicity induced by chemotherapy, targeted agents and radiotherapy: ESMO Clinical Practice Guidelines. Ann Oncol. 2012;23 Suppl 7:vii155-66.

20. Chow EJ, Baker KS, Lee SJ, Flowers ME, Cushing-Haugen KL, Inamoto Y, et al. Influence of conventional cardiovascular risk factors and lifestyle characteristics on cardiovascular disease after hematopoietic cell transplantation. J Clin Oncol. 2014;32(3):191-8

21. Curigliano G, Lenihan D, Fradley M, Ganatra S, Barac A, Blaes A, et al. Management of cardiac disease in cancer patients throughout oncological treatment: ESMO consensus recommendations. Ann Oncol. 2020;31(2):171-90.

22. Zamorano JL, Lancellotti P, Rodriguez Munoz D, Aboyans V, Asteggiano R, Galderisi M, et al. 2016 ESC Position Paper on cancer treatments and cardiovascular toxicity developed under the auspices of the ESC Committee for Practice Guidelines: The Task Force for cancer treatments and cardiovascular toxicity of the European Society of Cardiology (ESC). Eur Heart J. 2016;37(36):2768-801

23. Lenihan DJ, Hartlage G, DeCara J, Blaes A, Finet JE, Lyon AR, et al. CardioOncology Training: A Proposal From the International Cardioncology Society and Canadian Cardiac Oncology Network for a New Multidisciplinary Specialty. J Card Fail 2016;22(6):465-71.

24. McGowan JV, Chung R, Maulik A, Piotrowska I, Walker JM, Yellon DM Anthracycline Chemotherapy and Cardiotoxicity. Cardiovasc Drugs Ther. 2017;31(1):63-75.

25. Lyon AR, Dent S, Stanway S, Earl H, Brezden-Masley C, Cohen-Solal A, et al Baseline cardiovascular risk assessment in cancer patients scheduled to receive cardiotoxic cancer therapies: a position statement and new risk assessment tools from the Cardio-Oncology Study Group of the Heart Failure Association of the European Society of Cardiology in collaboration with the International Cardio-Oncology Society. Eur J Heart Fail. 2020.;28 maio. Doi;10.1002/ ejhf.1920 on line

26. Shankar SM, Marina N, Hudson MM, Hodgson DC, Adams MJ, Landier W et al. Monitoring for cardiovascular disease in survivors of childhood cancer: report from the Cardiovascular Disease Task Force of the Children's Oncology Group. Pediatrics. 2008;121(2):e387-96. Epub 2008 Jan 10.

27. Henriksen PA. Anthracycline cardiotoxicity: an update on mechanisms, monitoring and prevention. Heart. 2018;104(12):971-7.

28. Narezkina A, Nasim K. Anthracycline Cardiotoxicity. Circ Heart Fail. 2019;12(3):e005910.

29. Zhang S, Liu X, Bawa-Khalfe T, Lu LS, Lyu YL, Liu LF, et al. Identification of the molecular basis of doxorubicin-induced cardiotoxicity. Nat Med. 2012;18(11):1639-42.

30. He Q, Wang F, Ryan TD, Chalasani M, Redington AN. Repeated Remote Ischemic Conditioning Reduces Doxorubicin-Induced Cardiotoxicity. JACC: CardioOncology. 2020;2(1):41-52.

31. Coelho-Filho OR, Shah RV, Mitchell R, Neilan TG, Moreno H, Jr., Simonson $\mathrm{B}$, et al. Quantification of cardiomyocyte hypertrophy by cardiac magnetic resonance: implications for early cardiac remodeling. Circulation. 2013;128(11):1225-33.

32. Ewer MS, Ewer SM. Cardiotoxicity of anticancer treatments. Nat Rev Cardiol 2015;12(11):620.

33. Boyd A, Stoodley P, Richards D, Hui R, Harnett P, Vo K, et al. Anthracyclines induce early changes in left ventricular systolic and diastolic function: A single centre study. PLoS One. 2017 Apr 13;12(4):e0175544. 
34. Chang VY, Wang JJ. Pharmacogenetics of Chemotherapy-Induced Cardiotoxicity. Curr Oncol Rep. 2018;20(7):52.

35. Sachidanandam K, Gayle AA, Robins HI, Kolesar JM. Unexpected doxorubicin-mediated cardiotoxicity in sisters: possible role of polymorphisms in histamine n-methyl transferase. J Oncol Pharm Pract. 2013;19:269-72.

36. Slamon D, Eiermann W, Robert N, Pienkowski T, Martin M, Press M, et al. Adjuvant trastuzumab in HER2-positive breast cancer. N Engl J Med. 2011;365(14):1273-83.

37. Perez EA, Romond EH, Suman VJ, Jeong JH, Sledge G, Geyer CE, Jr., et al. Trastuzumab plus adjuvant chemotherapy for human epidermal growth factor receptor 2-positive breast cancer: planned joint analysis of overall survival from NSABP B-31 and NCCTG N9831. I Clin Oncol. 2014;32(33):3744-52.

38. Wang SY, Long JB, Hurria A, Owusu C, Steingart RM, Gross CP, et al Cardiovascular events, early discontinuation of trastuzumab, and their impact on survival. Breast Cancer Res Treat. 2014;146(2):411-9.

39. Jerusalem G, Lancellotti P, Kim SB. HER2 + breast cancer treatment and cardiotoxicity: monitoring and management. Breast Cancer Res Treat. 2019;177(2):237-50

40. Seferina SC, de Boer M, Derksen MW, van den Berkmortel F, van Kampen RJ, van de Wouw AJ, et al. Cardiotoxicity and Cardiac Monitoring During Adjuvant Trastuzumab in Daily Dutch Practice: A Study of the Southeast Netherlands Breast Cancer Consortium. Oncologist. 2016;21(2):555-62.

41. Tarantini L, Cioffi G, Gori S, Tuccia F, Boccardi L, Bovelli D, etal. Trastuzumab adjuvant chemotherapy and cardiotoxicity in real-world women with breast cancer. J Card Fail. 2012;18(2):113-9.

42. Leong DP, Cosman T, Alhussein MM, Tyagi NK, Karampatos S, Barron CC, et al. Safety of Continuing Trastuzumab Despite Mild Cardiotoxicity: A Phase I Trial. JACC: CardioOncology. 2019;1(1):1-10.

43. Procter M, Suter TM, de Azambuja E, Dafni U, van Dooren V, Muehlbauer S, et al. Longer-term assessment of trastuzumab-related cardiac adverse events in the Herceptin Adjuvant (HERA) trial. J Clin Oncol. 2010;28(21):3422-8.

44. Lidbrink E, Chmielowska E, Otremba B, Bouhlel A, Lauer S, Liste Hermoso $M$, et al. A real-world study of cardiac events in > 3700 patients with HER2positive early breast cancer treated with trastuzumab: final analysis of the OHERA study. Breast Cancer Res Treat. 2019;174(1):187-96.

45. Choueiri TK, Mayer EL, Je Y, Rosenberg JE, Nguyen PL, Azzi GR, et al Congestive heart failure risk in patients with breast cancer treated with bevacizumab. J Clin Oncol. 2011;29(6):632-8.

46. Richards CI, Je Y, Schutz FA, Heng DY, Dallabrida SM, Moslehi IJ, et al. Incidence and risk of congestive heart failure in patients with renal and nonrenal cell carcinoma treated with sunitinib. J Clin Oncol. 2011;29(25):3450-6.

47. Qi WX, Shen Z, Tang LN, Yao Y. Congestive heart failure risk in cancer patients treated with vascular endothelial growth factor tyrosine kinase inhibitors: a systematic review and meta-analysis of 36 clinical trials. $\mathrm{Br} J$ Clin Pharmacol. 2014;78(4):748-62.

48. Waliany S, Sainani KL, Park LS, Zhang CA, Srinivas S, Witteles RM. Increase in Blood Pressure Associated With Tyrosine Kinase Inhibitors Targeting Vascular Endothelial Growth Factor. JACC: CardioOncology. 2019;1(1):24-36.

49. Herrmann I, Yang EH, Iliescu CA, Cilingiroglu M, Charitakis K, Hakeem A, et al. Vascular Toxicities of Cancer Therapies: The Old and the New--An Evolving Avenue. Circulation. 2016;133(13):1272-89.

50. Willis MS, Patterson C. Proteotoxicity and cardiac dysfunction--Alzheimer's disease of the heart? N Engl J Med. 2013;368(5):455-64

51. Russell SD, Lyon A, Lenihan DJ, Moreau P, Joshua D, Chng W-J. Serial echocardiographic assessment of patients (pts) with relapsed multiple myeloma (RMM) receiving carfilzomib and dexamethasone (Kd) vs bortezomib and dexamethasone $(\mathrm{Vd})$ : a substudy of the phase 3 Endeavor Trial (NCT01568866). [abstract]. Blood; 2015;126:4250.
52. Lendvai N, Devlin S, Patel M, Knapp KM, Ekman D, Grundberg I, et al. Biomarkers of cardiotoxicity among multiple myeloma patients subsequently treated with proteasome inhibitor therapy.[abstract]. Blood. $2015 ; 126: 4257$.

53. Maverakis E, Cornelius LA, Bowen GM, Phan T, Patel FB, Fitzmaurice S, et al. Metastatic melanoma - a review of current and future treatment options. Acta Derm Venereol. 2015;95(5):516-24.

54. Luke JJ, Flaherty KT, Ribas A, Long GV. Targeted agents and immunotherapies: optimizing outcomes in melanoma. Nat Rev Clin Oncol. 2017;14(8):463-82.

55. Johnson DB, Sosman JA. Therapeutic Advances and Treatment Options in Metastatic Melanoma. JAMA Oncol. 2015;1(3):380-6.

56. Dummer R, Ascierto PA, Gogas HJ, Arance A, Mandala M, Liszkay G, et al. Encorafenib plus binimetinib versus vemurafenib or encorafenib in patients with BRAF-mutant melanoma (COLUMBUS): a multicentre, open-label, randomised phase 3 trial. Lancet Oncol. 2018;19(5):603-15

57. Ascierto PA, McArthur GA, Dreno B, Atkinson V, Liszkay G, Di Giacomo AM et al. Cobimetinib combined with vemurafenib in advanced BRAF(V600)mutant melanoma (COBRIM): updated efficacy results from a randomised, double-blind, phase 3 trial. Lancet Oncol. 2016;17(9):1248-60.

58. Mincu RI, Mahabadi AA, Michel L, Mrotzek SM, Schadendorf D, Rassaf T, et al. Cardiovascular Adverse Events Associated With BRAF and MEK Inhibitors: A Systematic Review and Meta-analysis. JAMA Netw Open. 2019 Aug 2;2(8):e198890

59. Ferguson T, Wilcken N, Vagg R, Ghersi D, Nowak AK. Taxanesfor adjuvanttreatment of early breast cancer. Cochrane Database of Systematic Reviews. 2007;4:1-50.

60. Swain SM, Baselga J, Kim SB, Ro J, Semiglazov V, Campone M, et al Pertuzumab, trastuzumab, and docetaxel in HER2-positive metastatic breast cancer. N Engl J Med. 2015;372(8):724-34.

61. Haanen JB, Robert C. Immune Checkpoint Inhibitors. Prog Tumor Res 2015;42:55-66

62. Bonaca MP, Olenchock BA, Salem JE, Wiviott SD, Ederhy S, Cohen A, et al. Myocarditis in the Setting of Cancer Therapeutics: Proposed Case Definitions for Emerging Clinical Syndromes in Cardio-Oncology. Circulation. 2019;140(2):80-91.

63. Varricchi G, Galdiero MR, Marone G, Criscuolo G, Triassi M, Bonaduce D, et al. Cardiotoxicity of immune checkpoint inhibitors. ESMO Open. 2017 Oct 26;2(4):e000247.

64. Wang DY, Salem JE, Cohen JV, Chandra S, Menzer C, Ye F, et al. Fatal Toxic Effects Associated With Immune Checkpoint Inhibitors: A Systematic Review and Meta-analysis. JAMA Oncol. 2018;4(12):1721-8.

65. Jaworski C, Mariani JA, Wheeler G, Kaye DM. Cardiac complications of thoracic irradiation. J Am Coll Cardiol. 2013;61(23):2319-28.

66. Aleman BM, van den Belt-Dusebout AW, De Bruin ML, van 't Veer MB, Baaijens $\mathrm{MH}$, de Boer JP, et al. Late cardiotoxicity after treatment for Hodgkin lymphoma. Blood. 2007;109(5):1878-86.

67. Correa CR, Litt HI, Hwang WT, Ferrari VA, Solin LJ, Harris EE. Coronary artery findings after left-sided compared with right-sided radiation treatment for early-stage breast cancer. J Clin Oncol. 2007;25(21):3031-7.

68. Desai MY, Jellis CL, Kotecha R, Johnston DR, Griffin BP. RadiationAssociated Cardiac Disease: A Practical Approach to Diagnosis and Management. JACC Cardiovasc Imaging. 2018;11(8):1132-49.

69. Comite Coordenador da Diretriz de Insuficiencia C, Rohde LEP, Montera MW, Bocchi EA, Clausell NO, Albuquerque DC, et al. Arq Bras Cardiol. 2018:111(3):436-539.

70. Lyman GH, Khorana AA, Falanga A, Clarke-Pearson D, Flowers C Jahanzeb M, et al. American Society of Clinical Oncology guideline: recommendations for venous thromboembolism prophylaxis and treatment in patients with cancer. J Clin Oncol. 2007:25(34):5490-505. 
71. Walker AJ, Card TR, West J, Crooks C, Grainge MJ. Incidence of venous thromboembolism in patients with cancer - a cohort study using linked United Kingdom databases. Eur J Cancer. 2013;49(6):1404-13.

72. Chee CE, Ashrani AA, Marks RS, Petterson TM, Bailey KR, Melton LJ, 3rd, et al. Predictors of venous thromboembolism recurrence and bleeding among active cancer patients: a population-based cohort study. Blood. 2014;123(25):3972-8.

73. Ay C, Pabinger I, Cohen AT. Cancer-associated venous thromboembolism: Burden, mechanisms, and management. Thromb Haemost. 2017;117(2):219-30.

74. Thaler J, Ay C, Pabinger I. Clinical significance of circulating microparticles for venous thromboembolism in cancer patients. Hamostaseologie. 2012;32(2):127-31

75. Li A, Garcia DA, Lyman GH, Carrier M. Direct oral anticoagulant (DOAC) versus low-molecular-weight heparin $(\mathrm{LMWH})$ for treatment of cancer associated thrombosis (CAT): A systematic review and meta-analysis. Thromb Res. 2019;173:158-63.

76. Pritchard ER, Murillo JR, Jr., Putney D, Hobaugh EC. Single-center retrospective evaluation of safety and efficacy of direct oral anticoagulants versus low-molecular-weight heparin and vitamin $\mathrm{K}$ antagonist in patients with cancer. J Oncol Pharm Pract. 2019;25(1):52-9.

77. Khorana AA, Kuderer NM, Culakova E, Lyman GH, Francis CW. Development and validation of a predictive model for chemotherapyassociated thrombosis. Blood. 2008;111(10):4902-7.

78. Ay C, Dunkler D, Marosi C, Chiriac AL, Vormittag R, Simanek R, et al. Prediction of venous thromboembolism in cancer patients. Blood. 2010;116(24):5377-82.

79. Navi BB, Reiner AS, Kamel H, ladecola C, Okin PM, Elkind MSV, et al. Risk of Arterial Thromboembolism in Patients With Cancer. J Am Coll Cardiol. 2017;70(8):926-38

80. Meyer T, Robles-Carrillo L, Robson T, Langer F, Desai H, Davila M, et al. Bevacizumab immune complexes activate platelets and induce thrombosis in FCGR2A transgenic mice. J Thromb Haemost. 2009;7(1):171-81.

81. Guglin M, Aljayeh M, Saiyad S, Ali R, Curtis AB. Introducing a new entity: chemotherapy-induced arrhythmia. Europace. 2009;11(12):1579-86.

82. Yeh ET, Bickford CL. Cardiovascular complications of cancer therapy: incidence, pathogenesis, diagnosis, and management. J Am Coll Cardiol. 2009;53(24):2231-47.

83. Tamargo J, Caballero R, Delpon E. Cancer chemotherapy and cardiac arrhythmias: a review. Drug Saf. 2015;38(2):129-52.

84. Kishi S, Yoshida A, Yamauchi T, Tsutani H, Lee JD, Nakamura T, etal. Torsade de pointes associated with hypokalemia after anthracycline treatment in a patient with acute lymphocytic leukemia. Int J Hematol. 2000;71(2):172-9.

85. Farmakis D, Parissis J, Filippatos G. Insights into onco-cardiology: atrial fibrillation in cancer. J Am Coll Cardiol. 2014;63(10):945-53.

86. Vorchheimer DA. What is QT interval prolongation? J Fam Pract. 2005;Suppl(6):S4-7.

87. Priori SG, Blomstrom-Lundqvist C, Mazzanti A, Blom N, Borggrefe M, Camm J, et al. 2015 ESC Guidelines for the management of patients with ventricular arrhythmias and the prevention of sudden cardiac death: The Task Force for the Management of Patients with Ventricular Arrhythmias and the Prevention of Sudden Cardiac Death of the European Society of Cardiology (ESC). Endorsed by: Association for European Paediatric and Congenital Cardiology (AEPC). Eur Heart J. 2015;36(41):2793-867.

88. Porta-Sanchez A, Gilbert C, Spears D, Amir E, Chan J, Nanthakumar K, et al. Incidence, Diagnosis, and Management of QT Prolongation Induced by Cancer Therapies: A Systematic Review. J Am Heart Assoc. 2017 Dec 7;6(12):e007724.

89. Delacretaz E. Clinical practice. Supraventricular tachycardia. N Engl J Med. 2006;354(10):1039-51
90. Sociedade Brasileira de Cardiologia. [Guidelines for the evaluation and treatment of patients with heart arrhythmia]. Arq Bras Cardiol. 2002;79(Suppl 5):7-50.

91. Cheng WL, Kao YH, Chen SA, Chen YJ. Pathophysiology of cancer therapyprovoked atrial fibrillation. Int J Cardiol. 2016;219:186-94.

92. Lopez-Fernandez T, Martin-Garcia A, Roldan Rabadan I, Mitroi C, Mazon Ramos P, Diez-Villanueva P, etal. Atrial Fibrillation in Active Cancer Patients: Expert Position Paper and Recommendations. Rev Esp Cardiol (Engl Ed). 2019;72(9):749-59.

93. Melloni C, Shrader P, Carver J, Piccini JP, Thomas L, Fonarow GC, et al. Management and outcomes of patients with atrial fibrillation and a history of cancer: the ORBIT-AF registry. Eur Heart J Qual Care Clin Outcomes. 2017;3(3):192-7.

94. Costa I, Bittar CS, Fonseca SMR, CMPD ES, Dos Santos Rehder MHH, Rizk SI, et al. Brazilian cardio-oncology: the 10-year experience of the Instituto do Cancer do Estado de Sao Paulo. BMC Cardiovasc Disord. 2020;20(1):206.

95. Handy CE, Quispe R, Pinto X, Blaha MJ, Blumenthal RS, Michos ED, et al. Synergistic Opportunities in the Interplay Between Cancer Screening and Cardiovascular Disease Risk Assessment: Together We Are Stronger. Circulation. 2018;138(7):727-34.

96. Yang Q, Chen Y, Gao H, Zhang J, Zhang J, Zhang M, et al. ChemotherapyRelated Anatomical Coronary-Artery Disease in Lung Cancer Patients Evaluated by Coronary-Angiography SYNTAX Score. Arq Bras Cardiol. 2020;114(6):1004-12.

97. Ito D, Shiraishi J, Nakamura T, Maruyama N, Iwamura Y, Hashimoto S, et al. Primary percutaneous coronary intervention and intravascular ultrasound imaging for coronary thrombosis after cisplatin-based chemotherapy. Heart Vessels. 2012;27(6):634-8.

98. Jafri M, Protheroe A. Cisplatin-associated thrombosis. Anticancer Drugs. 2008;19(9):927-9.

99. Karabay KO, Yildiz O, Aytekin V. Multiple coronary thrombi with cisplatin. J Invasive Cardiol. 2014;26(2):E18-20.

100. Periard D, Boulanger CM, Eyer S, Amabile N, Pugin P, Gerschheimer $C$, et al. Are circulating endothelial-derived and platelet-derived microparticles a pathogenic factor in the cisplatin-induced stroke? Stroke. 2007;38(5):1636-8.

101. Yuan C, Parekh H, Allegra C, George TJ, Starr JS. 5-FU induced cardiotoxicity: case series and review of the literature. Cardiooncology. 2019 Sep 06;5:13.

102. Chong $\mathrm{H}$, Ghosh AK. Coronary Artery Vasospasm Induced by 5 -fluorouracil: Proposed Mechanisms, Existing Management Options and Future Directions. Interv Cardiol. 2019;14(2):89-94.

103. Mosseri M, Fingert HJ, Varticovski L, Chokshi S, Isner JM. In vitro evidence that myocardial ischemia resulting from 5 -fluorouracil chemotherapy is due to protein kinase $\mathrm{C}$-mediated vasoconstriction of vascular smooth muscle. Cancer Res. 1993;53(13):3028-33.

104. Thyss A, Gaspard MH, Marsault R, Milano G, Frelin C, Schneider M. Very high endothelin plasma levels in patients with 5-FU cardiotoxicity. Ann Oncol. 1992;3(1):88.

105. Schrader C, Keussen C, Bewig B, von Freier A, Lins M. Symptoms and signs of an acute myocardial ischemia caused by chemotherapy with Paclitaxel (Taxol) in a patient with metastatic ovarian carcinoma. Eur J Med Res. 2005;10(11):498-501.

106. Shah K, Gupta S, Ghosh J, Bajpai J, Maheshwari A. Acute non-ST elevation myocardial infarction following paclitaxel administration for ovarian carcinoma: a case report and review of literature. J Cancer Res Ther. 2012;8(3):442-4.

107. Douxfils J, Haguet H, Mullier F, Chatelain C, Graux C, Dogne JM. Association Between BCR-ABL Tyrosine Kinase Inhibitors for Chronic Myeloid Leukemia and Cardiovascular Events, Major Molecular Response, and Overall Survival: A Systematic Review and Meta-analysis. JAMA Oncol. 2016;2(5):625-32. 
108. Totzeck M, Mincu RI, Rassaf T. Cardiovascular Adverse Events in Patients With Cancer Treated With Bevacizumab: A Meta-Analysis of More Than 20 000 Patients. J Am Heart Assoc. 2017 Aug 10;6(8):e006278.

109. Newman JL, Stone JR. Immune checkpoint inhibition alters the inflammatory cell composition of human coronary artery atherosclerosis. Cardiovasc Pathol. 2019 Nov-Dec;43:107148.

110. Ping Z, Peng Y, Lang H, Xinyong C, Zhiyi Z, Xiaocheng W, et al. Oxidative Stress in Radiation-Induced Cardiotoxicity. Oxid Med Cell Longev. 2020;2020:3579143.

111. Wang H, Wei J, Zheng Q, Meng L, Xin Y, Yin X, et al. Radiation-induced heart disease: a review of classification, mechanism and prevention. Int J Biol Sci. 2019;15(10):2128-38

112. Landes $\mathrm{U}$, Kornowski R, Bental T, Assali A, Vaknin-Assa H, Lev E, et al. Long-term outcomes after percutaneous coronary interventions in cancer survivors. Coron Artery Dis. 2017;28(1):5-10

113. Nakatsuma K, Shiomi H, Morimoto T, Watanabe H, Nakagawa Y, Furukawa $\mathrm{Y}$, et al. Influence of a history of cancer on long-term cardiovascular outcomes after coronary stent implantation (an Observation from Coronary Revascularization Demonstrating Outcome Study-Kyoto Registry Cohort-2). Eur HeartJ Qual Care Clin Outcomes. 2018;4(3):200-7.

114. Ganatra S, Sharma A, Levy MS. Re-Evaluating the Safety of Drug-Eluting Stents in Cancer Patients. JACC Cardiovasc Interv. 2017;10(22):2334-7.

115. Valgimigli M, Bueno H, Byrne RA, Collet JP, Costa F, Jeppsson A, et al. 2017 ESC focused update on dual antiplatelet therapy in coronary artery disease developed in collaboration with EACTS: The Task Force for dual antiplatelet therapy in coronary artery disease of the European Society of Cardiology (ESC) and of the European Association for Cardio-Thoracic Surgery (EACTS). Eur Heart J. 2018;39(3):213-60

116. Urban P, Mehran R, Colleran R, Angiolillo DJ, Byrne RA, Capodanno D, etal. Defining High Bleeding Risk in Patients Undergoing Percutaneous Coronary Intervention. Circulation. 2019;140(3):240-61.

117. Iliescu C, Grines CL, Herrmann J, Yang EH, Cilingiroglu M, Charitakis K, et al. SCAl expert consensus statement: Evaluation, management, and special considerations of cardio-oncology patients in the cardiac catheterization laboratory (Endorsed by the Cardiological Society of India, and Sociedad Latino Americana de Cardiologia Intervencionista). Catheter Cardiovasc Interv. 2016;87(5):895-9.

118. Cameron AC, Touyz RM, Lang NN. Vascular Complications of Cancer Chemotherapy. Can J Cardiol. 2016;32(7):852-62.
119. Piccirillo JF, Tierney RM, Costas I, Grove L, Spitznagel EL. Prognostic importance of Comorbidity in a hospital-based cancer registry. Jama-J Am Med Assoc. 2004;291(20):2441-7.

120. Boursiquot BC, Zabor EC, Glezerman IG, Jaimes EA. Hypertension and VEGF (Vascular Endothelial Growth Factor) Receptor Tyrosine Kinase Inhibition: Effects on Renal Function. Hypertension 2017.Jul 24.HYPERTENSIONAHA.117.092275 online ahrad of print.

121. Budolfsen C, Faber J, Grimm D, Kruger M, Bauer J, Wehland M et al. Tyrosine Kinase Inhibitor-Induced Hypertension: Role o Hypertension as a Biomarker in Cancer Treatment. Curr Vasc Pharmacol. 2019;17(6):618-34.

122. Li J, Gu J. Cardiovascular Toxicities with Vascular Endothelial Growth Factor Receptor Tyrosine Kinase Inhibitors in Cancer Patients: A Meta-Analysis of 77 Randomized Controlled Trials. Clin Drug Investig. 2018;38(12):1109-23.

123. Miller RP, Tadagavadi RK, Ramesh G, Reeves WB. Mechanisms of Cisplatin nephrotoxicity. Toxins (Basel). 2010;2(11):2490-518.

124. Stoter G, Koopman A, Vendrik CP, Struyvenberg A, Sleyfer DT, Willemse $\mathrm{PH}$, et al. Ten-year survival and late sequelae in testicular cancer patients treated with cisplatin, vinblastine, and bleomycin. J Clin Oncol. 1989;7(8):1099-104.

125. Soultati A, Mountzios G, Avgerinou C, Papaxoinis G, Pectasides D, Dimopoulos MA, et al. Endothelial vascular toxicity from chemotherapeutic agents: preclinical evidence and clinical implications. Cancer Treat Rev. 2012;38(15):473-83.

126. Bendtsen MAF, Grimm D, Bauer J, Wehland M, Wise P, Magnusson $\mathrm{NE}$, et al. Hypertension Caused by Lenvatinib and Everolimus in the Treatment of Metastatic Renal Cell Carcinoma. Int J Mol Sci. 2017;18(8):1736.

127. Liu Y, Zhou L, Chen Y, Liao B, Ye D, Wang K, et al. Hypertension as a prognostic factor in metastatic renal cell carcinoma treated with tyrosine kinase inhibitors: a systematic review and meta-analysis. BMC Urol. 2019;19(1):49.

128. Farrugia FA, Martikos G, Tzanetis $\mathrm{P}$, Charalampopoulos A, Misiakos E, Zavras N, et al. Pheochromocytoma, diagnosis and treatment: Review of the literature. Endocr Regal. 2017;51(3):168-81.

129. Tini G, Sarocchi M, Tocci G, Arboscello E, Ghigliotti G, Novo G, et al. Arterial hypertension in cancer: The elephant in the room. Int J Cardiol $2019 ; 281: 133-9$ 